University of Tennessee Health Science Center

UTHSC Digital Commons

\title{
Age-Associated Hepatic Drug Transporter Expression and Its Implications for Pediatric Pharmacotherapyflexibility affect DNA topoisomerase I function
}

Lisa Tang

University of Tennessee Health Science Center

Follow this and additional works at: https://dc.uthsc.edu/dissertations

Part of the Medicinal and Pharmaceutical Chemistry Commons

\section{Recommended Citation}

Tang, Lisa , "Age-Associated Hepatic Drug Transporter Expression and Its Implications for Pediatric Pharmacotherapyflexibility affect DNA topoisomerase I function" (2007). Theses and Dissertations (ETD). Paper 260. http://dx.doi.org/10.21007/etd.cghs.2007.0312. 


\title{
Age-Associated Hepatic Drug Transporter Expression and Its Implications for Pediatric Pharmacotherapyflexibility affect DNA topoisomerase I function
}

\begin{abstract}
Members of the ATP-binding cassette $(A B C)$ family of drug transporter proteins translocate various endogenous and exogenous substrates across intra- and extracellular membranes. Two specific $A B C$ transporters, the multidrug resistance 1/P-glycoprotein (MDR1/P-gp) and the multidrug resistance protein 2 (MRP2), serve as major hepatic transporters that mediate the biliary excretion of various organic anions and cations along with glutathione-, glucuronate-, or sulfate-conjugates of several drug substrates. However, very little is known about the expression of these transporters in the early infant and childhood ages of human development. We, therefore, characterized the ontogeny of these transporters by measuring their gene and protein expression. Furthermore, we also characterized the ontogeny of four nuclear receptors through measurement of their gene expression. Nuclear receptors belong to a highly conserved gene superfamily of transcriptional factors that regulate the expression of their target genes, many of which include members of the ABC transporters. We identified four main nuclear receptors that have been associated with the modulation of gene expression of MDR1/P-gp and MRP2 to include pregnane $X$ receptor (PXR), constitutive androstane receptor (CAR), farnesoid $X$ receptor (FXR), and hepatic nuclear factor 4a (HNF4alpha). Our study revealed lower gene expression of MDR1/P-gp and MRP2 in the early infant period of development. We also identified a lower protein expression of MRP2 in the early infant period. For the nuclear receptors, we found significantly lower expression levels for PXR and FXR in the early periods of development. Positive correlations were established between the nuclear receptors PXR and FXR to the ABC transporters MDR1/P-gp and MRP2. HNF4a, which has been described as a master regulator of other nuclear receptors, was determined to be positively correlated with PXR and CAR.
\end{abstract}

Due to the various challenges associated with conducting scientific research in newborns, infants and children and obtaining tissue samples in this population, we wished to establish the ontogeny of the human equivalent of the $A B C$ transporters and nuclear receptors in a rat model. As such, we determined the ontogeny of Mdr1a/1b, Mrp2, Pxr, Car, Fxr, and Hnf4alpha from rat liver samples in seven different postnatal ages in order to compliment our human results with more selected spacing of age and sample numbers in our rat samples. Similar to our human pediatric liver findings, rat liver Mdr1a/1b and Mrp2 gene expression appeared limited in the first week of life and increased thereafter. The same findings were true for the rat P-gp and Mrp2 protein samples. The rat nuclear receptors Pxr, Car, and Fxr all exhibited a positive correlation with both Mdr1a/1b and Mrp2 gene expression. Furthermore, Hnf4a was also positively correlated with all three nuclear receptors.

In a subsequent experiment, we aimed to explore the functional consequences in changes in drug transporter expression on the pharmacokinetics of their drug substrates. Ceftriaxone, a third generation cephalosporin antibiotic frequently used in pediatric pharmacotherapy, was selected as our model compound. The pharmacokinetics of a single intravenous dose of ceftriaxone was compared between wild-type (WT) Wistar rats as compared to a mutant strain of Mrp2-deficient (TR-) rats. We chose the use of TR- rats as a surrogate animal to represent the immaturity of Mrp2 early on in development as was evident from our rat and human liver samples model. Using the TR- rat model, we reported significantly longer elimination half-life $\left(\mathrm{t}_{1 / 2}\right)(\mathrm{p}<0.05)$, undetectable amounts of drug in the feces $(\mathrm{p}<0.05)$, and an increase in the urinary excretion of unchanged drug $(p<0.001)$ in the TR- as compared to the WT rats.

In summary, these results demonstrate that the hepatic ABC transporters MDR1/P-gp and MRP2 are differentially expressed during childhood maturation and suggest that the observed reduced expression of MRP2 in human liver in early infancy may result in clinically significant differences in the disposition of medications used in pediatric pharmacotherapy. 


\section{Document Type \\ Dissertation \\ Degree Name \\ Doctor of Philosophy (PhD) \\ Program \\ Pharmaceutical Sciences}

\section{Research Advisor}

Bernd Meibohm, Ph.D.

\section{Keywords}

ontogeny, liver drug transporter, nuclear receptor, multidrug resistance protein, ceftriaxone

\section{Subject Categories}

Medicinal and Pharmaceutical Chemistry | Medicine and Health Sciences | Pharmacy and Pharmaceutical Sciences 


\title{
AGE-ASSOCIATED HEPATIC DRUG TRANSPORTER EXPRESSION AND ITS IMPLICATIONS FOR PEDIATRIC PHARMACOTHERAPY
}

\author{
A Dissertation \\ Presented for \\ The Graduate Studies Council \\ The University of Tennessee \\ Health Science Center
}

\author{
In Partial Fulfillment \\ Of the Requirements for the Degree \\ Doctor of Philosophy \\ From The University of Tennessee
}

By

Lisa Eng Tang

December 2007 
Copyright $(02007$ by Lisa Tang All rights reserved 


\section{DEDICATION}

To my husband and son, who remind me daily of the joys of life, and to my parents for their everlasting love and support. 


\section{ACKNOWLEDGEMENTS}

First and foremost, I would like to express my deepest and most sincere appreciation to my advisor, Dr. Bernd Meibohm, who has been my biggest advocate throughout this incredible journey. I would also like to thank the other members of my committee, Dr. Michael Christensen, Dr. Stephanie Phelps, Dr. Erin G. Schuetz, and Dr. Charles Ryan Yates for their invaluable suggestions, guidance, and assistance. I would like to especially acknowledge Dr. Erin G. Schuetz and Dr. Ronald N. Hines for generously providing me with the human liver samples without which a major portion of this research would not have been possible. I must also thank Dr. Wenhui Zhang for establishing the groundwork for much of my research. Much thanks to the Department of Comparative Medicine especially Ms. Sharon Lokey for her assistance in the rat pharmacokinetics experiments.

A tremendous thank you to all my fellow graduate students particularly those currently in my lab including Nageshwar Budha, Dr. Nathaneal Dirks, Dr. Margaret Thomson, Pavan Vaddady, and Yi Zhang for their thoughtful advice and discussions. Also thanks to the students who have graduated before me including Dr. Manish Gupta, Dr. Penfei Song, and Dr. Shen Li for their support throughout my Ph.D. endeavor.

Support of this work was provided through the American Foundation for Pharmaceutical Education and the Seldon D. Feurt Memorial Fund through the University of Tennessee College of Pharmacy. 


\begin{abstract}
Members of the ATP-binding cassette (ABC) family of drug transporter proteins translocate various endogenous and exogenous substrates across intra- and extracellular membranes. Two specific ABC transporters, the multidrug resistance 1/P-glycoprotein (MDR1/P-gp) and the multidrug resistance protein 2 (MRP2), serve as major hepatic transporters that mediate the biliary excretion of various organic anions and cations along with glutathione-, glucuronate-, or sulfate-conjugates of several drug substrates. However, very little is known about the expression of these transporters in the early infant and childhood ages of human development. We, therefore, characterized the ontogeny of these transporters by measuring their gene and protein expression. Furthermore, we also characterized the ontogeny of four nuclear receptors through measurement of their gene expression. Nuclear receptors belong to a highly conserved gene superfamily of transcriptional factors that regulate the expression of their target genes, many of which include members of the ABC transporters. We identified four main nuclear receptors that have been associated with the modulation of gene expression of MDR1/P-gp and MRP2 to include pregnane X receptor (PXR), constitutive androstane receptor (CAR), farnesoid X receptor (FXR), and hepatic nuclear factor $4 \alpha(\mathrm{HNF} 4 \alpha)$. Our study revealed lower gene expression of MDR1/P-gp and MRP2 in the early infant period of development. We also identified a lower protein expression of MRP2 in the early infant period. For the nuclear receptors, we found significantly lower expression levels for PXR and FXR in the early periods of development. Positive correlations were established between the nuclear receptors PXR and FXR to the ABC transporters MDR1/P-gp and MRP2. HNF4 $\alpha$, which has been described as a master regulator of other nuclear receptors, was determined to be positively correlated with PXR and CAR.

Due to the various challenges associated with conducting scientific research in newborns, infants and children and obtaining tissue samples in this population, we wished to establish the ontogeny of the human equivalent of the $\mathrm{ABC}$ transporters and nuclear receptors in a rat model. As such, we determined the ontogeny of Mdr1a/1b, Mrp2, Pxr, Car, Fxr, and Hnf4 $\alpha$ from rat liver samples in seven different postnatal ages in order to compliment our human results with more selected spacing of age and sample numbers in our rat samples. Similar to our human pediatric liver findings, rat liver Mdr1a/1b and Mrp2 gene expression appeared limited in the first week of life and increased thereafter. The same findings were true for the rat P-gp and Mrp2 protein samples. The rat nuclear receptors Pxr, Car, and Fxr all exhibited a positive correlation with both Mdr1a/1b and Mrp2 gene expression. Furthermore, Hnf4 $\alpha$ was also positively correlated with all three nuclear receptors.
\end{abstract}

In a subsequent experiment, we aimed to explore the functional consequences in changes in drug transporter expression on the pharmacokinetics of their drug substrates. Ceftriaxone, a third generation cephalosporin antibiotic frequently used in pediatric pharmacotherapy, was selected as our model compound. The pharmacokinetics of a single intravenous dose of ceftriaxone was compared between wild-type (WT) Wistar rats as compared to a mutant strain of Mrp2-deficient (TR-) rats. We chose the use of TR- 
rats as a surrogate animal to represent the immaturity of Mrp2 early on in development as was evident from our rat and human liver samples model. Using the TR- rat model, we reported significantly longer elimination half-life $\left(\mathrm{t}_{1 / 2}\right)(\mathrm{p}<0.05)$, undetectable amounts of drug in the feces $(\mathrm{p}<0.05)$, and an increase in the urinary excretion of unchanged drug $(\mathrm{p}<0.001)$ in the TR-as compared to the WT rats.

In summary, these results demonstrate that the hepatic $\mathrm{ABC}$ transporters MDR1/P-gp and MRP2 are differentially expressed during childhood maturation and suggest that the observed reduced expression of MRP2 in human liver in early infancy may result in clinically significant differences in the disposition of medications used in pediatric pharmacotherapy. 


\section{TABLE OF CONTENTS}

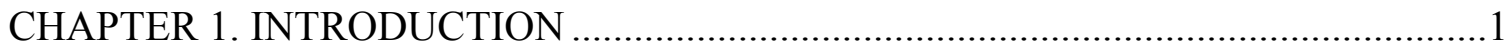

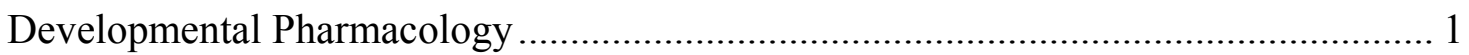

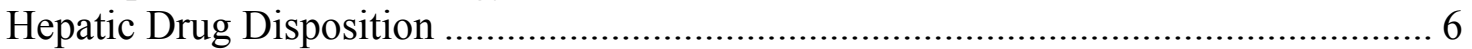

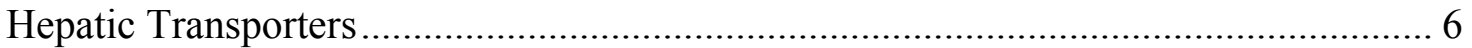

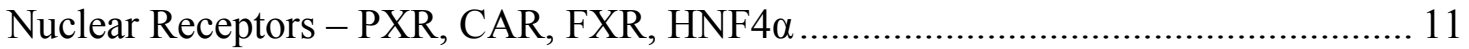

Central Hypothesis and Specific Aims ……………............................................... 12

\section{CHAPTER 2. AGE-ASSOCIATED EXPRESSION OF HEPATIC ABC DRUG} TRANSPORTERS AND NUCLEAR RECEPTORS IN HUMAN

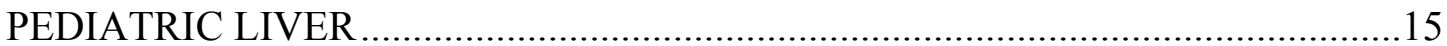

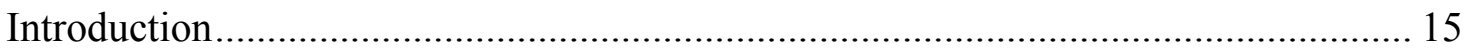

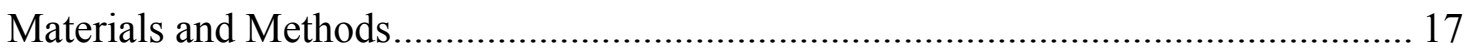

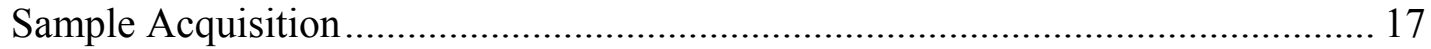

Total RNA Isolation and cDNA Synthesis .......................................................... 19

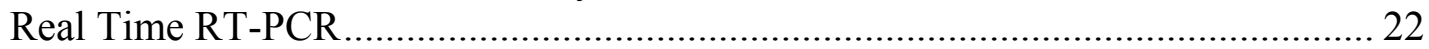

Tissue Membrane Protein Isolation ..................................................................... 25

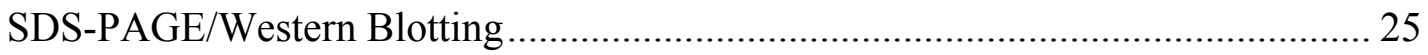

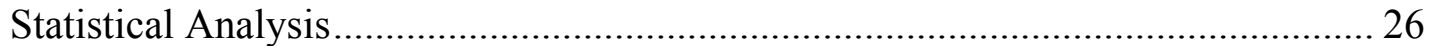

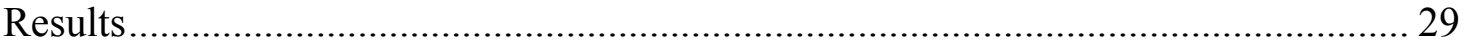

mRNA Expression of MDR1/P-gp and MRP2 in Human Pediatric Liver

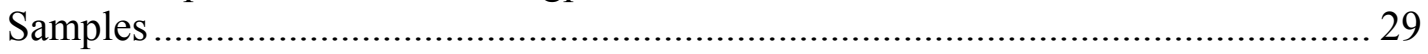

mRNA Expression of Orphan Nuclear Receptors (NRs) in Human Pediatric

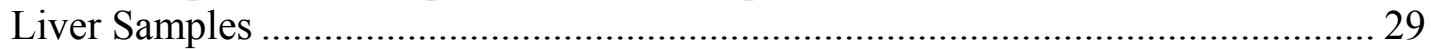

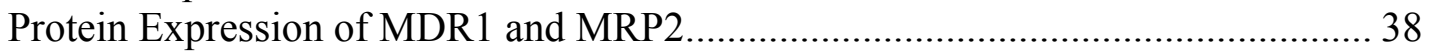

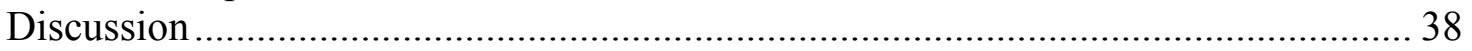

\section{CHAPTER 3. AGE-ASSOCIATED EXPRESSION OF HEPATIC ABC DRUG} TRANSPORTERS AND NUCLEAR RECEPTORS IN RAT LIVER ........................48

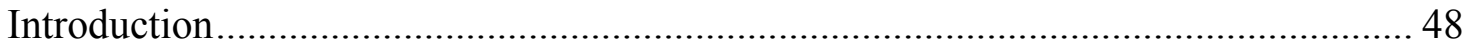

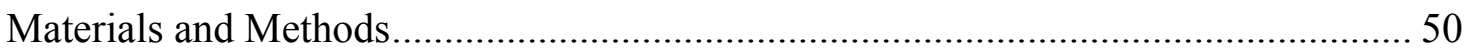

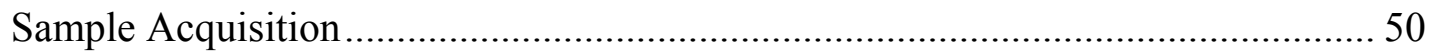

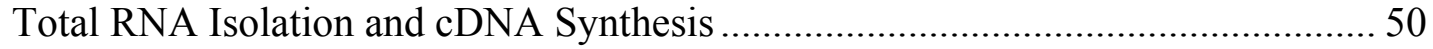

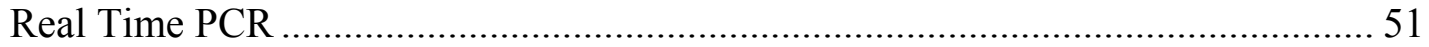

Tissue Membrane Protein Isolation .................................................................... 54

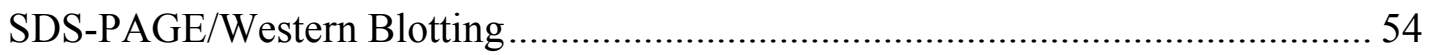

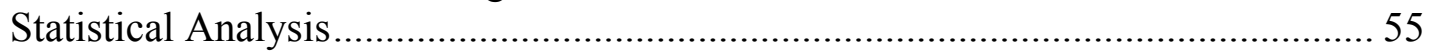

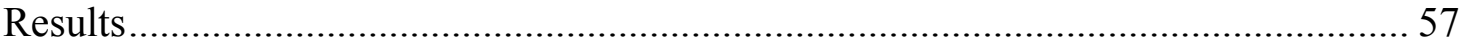

mRNA Expression of Mdr1a, Mdr1b, and Mrp2 in Rat Liver Samples................... 57

mRNA Expression of Orphan Nuclear Receptors (NRs) in Rat Liver Samples....... 57

Protein Expression of Mdr1/P-gp and Mrp2 in Rat Liver Samples.......................... 62

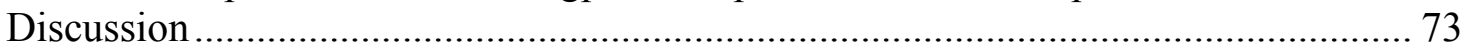




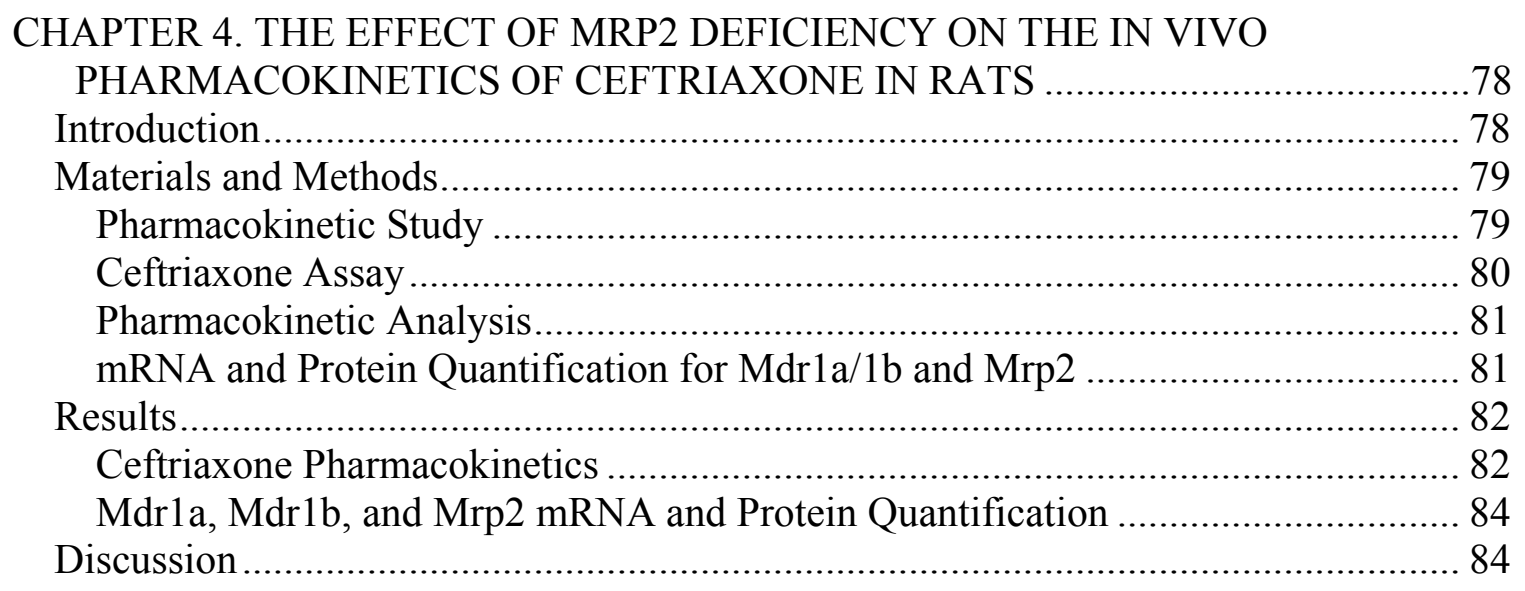

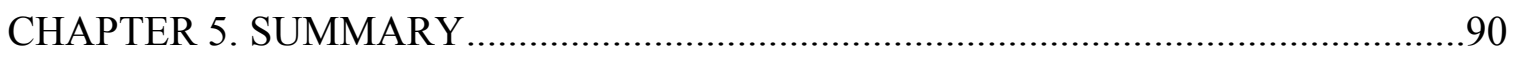

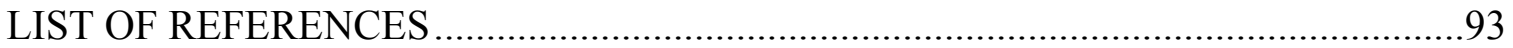

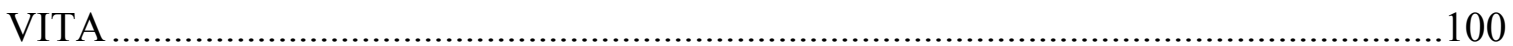




\section{LIST OF TABLES}

Table 1-1. Example of Drugs Currently Listed on the Pediatric Priority List. ............2

Table 2-1. Donor Demographics for Human Pediatric Liver Samples Provided by St. Jude Children's Research Hospital (SJCRH)................................18

Table 2-2. Donor Demographics for Human Pediatric Liver Samples Provided by Medical College of Wisconsin (MCW) ............................................20

Table 2-3. Combined Patient Demographics for Human Pediatric Liver Samples for Protein Analysis

Table 2-4. Primer Sequence for Target Gene-Specific 5'-(FAM)-Labeled TaqMan $^{\circledR}$ Assay-on-Demand ${ }^{\text {TM }}$ Human Probes.

Table 3-1. Primer Sequence for Target Gene-Specific 5'-(FAM)-Labeled TaqMan $^{\circledR}$ Assay-on-Demand ${ }^{\mathrm{TM}}$ Rat Probes...........................................52

Table 4-1. Mean \pm SD Pharmacokinetic Parameters in WT versus TR- Rats. .85 


\section{LIST OF FIGURES}

Figure 1-1. Ontogeny of CYP450 Family of Drug Metabolizing Enzymes..................4

Figure 1-2. Select Drug Transporters in Human Hepatocytes......................................

Figure 1-3. Predicted Secondary Structures of P-gp (A) and MRP2 (B). ...................9

Figure 1-4. Graphic Representation of P-gp........................................................10

Figure 1-5. Basic Structure of Nuclear Receptors....................................................13

Figure 2-1. Calibration Curve for MDR1, MRP2, PXR, CAR, FXR, and

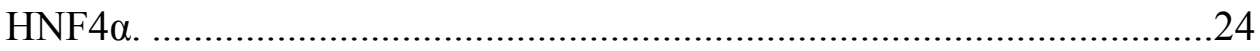

Figure 2-2. Representative Real Time PCR Amplification Plot for Target

Human Genes.......................................................................................27

Figure 2-3. Normalized Target Gene Expression......................................................30

Figure 2-4. mRNA Expression of MDR1/P-gp in Human Pediatric Liver

Samples. .................................................................................... 31

Figure 2-5. mRNA Expression of MRP2 in Human Pediatric Liver Samples.............32

Figure 2-6. mRNA Expression of PXR in Human Pediatric Liver Samples................33

Figure 2-7. mRNA Expression of CAR in Human Pediatric Liver Samples. ...............34

Figure 2-8. mRNA Expression of FXR in Human Pediatric Liver Samples................35

Figure 2-9. mRNA Expression of HNF4 $\alpha$ in Human Pediatric Liver Samples. ..........36

Figure 2-10. HNF4 $\alpha$ Correlations in Human Pediatric Liver Samples. ..........................37

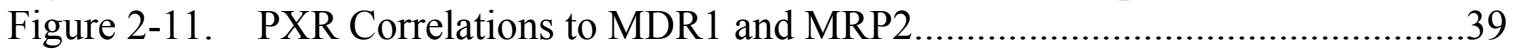

Figure 2-12. CAR correlations to MDR1 and MRP2 ...............................................40

Figure 2-13. FXR Correlations to MDR1 and MRP2 .............................................41

Figure 2-14. Representative Western Immunoblots of MDR1/P-gp and MRP2 in

Human Pediatric Liver Samples. .............................................................42

Figure 2-15. MDR1/P-gp Protein Expression in Human Pediatric Liver

Samples..............................................................................4 43

Figure 2-16. MRP2 Protein Expression in Human Pediatric Liver Samples. ...............44

Figure 3-1. Calibration Curve for Mdr1a, Mdr1b, Mrp2, Pxr, Car, Fxr, and

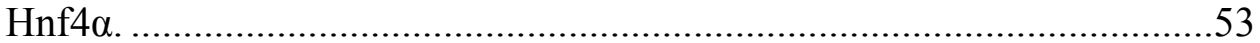

Figure 3-2. Sample Real Time PCR Amplification Plot for Target Rat Genes............56

Figure 3-3. Ontogeny of Mdr1a, Mdr1b, and Mrp2 Expression in Rat Liver

Samples.........................................................................................58

Figure 3-4. Ontogeny of Normalized Mdr1a mRNA Expression in Rat Liver

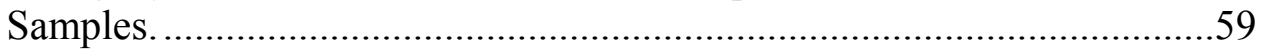

Figure 3-5. Ontogeny of Normalized Mdr1b mRNA Expression in Rat Liver Samples. ......................................................................................60

Figure 3-6. Ontogeny of Normalized Mrp2 mRNA Expression in Rat Liver Samples.

Figure 3-7. Ontogeny of Nuclear Receptors Pxr, Car, Fxr, and Hnf4 $\alpha$ in Rat Liver Samples.

Figure 3-8. Ontogeny of Normalized Pxr mRNA Expression in Rat Liver Samples. .64

Figure 3-9. Ontogeny of Normalized Car mRNA Expression in Rat Liver Samples. 
Figure 3-10. Ontogeny of Normalized Fxr mRNA Expression in Rat Liver

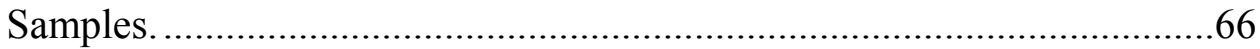

Figure 3-11. Ontogeny of Normalized Hnf4 $\alpha$ mRNA Expression in Rat Liver

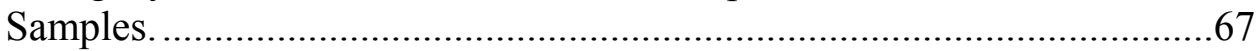

Figure 3-12. Hnf4 $\alpha$ Correlation Analysis in Rat Liver Samples. ................................68

Figure 3-13. Pxr Correlations to Mdr1a, Mdr1b, and Mrp2 .....................................69

Figure 3-14. Car Correlations to Mdr1a, Mdr1b, and Mrp2 .......................................70

Figure 3-15. Fxr Correlations to Mdr1a, Mdr1b, and Mrp2 .......................................... 71

Figure 3-16. Ontogeny of Mdr1a and Mrp2 Protein Expression in Rat Liver

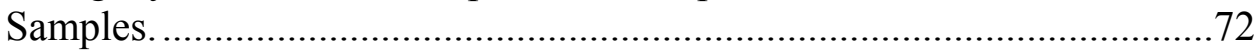

Figure 3-17. Ontogeny of Normalized Mdr1/P-gp Protein Expression in Rat Liver Samples. ...............................................................................74

Figure 3-18. Ontogeny of Normalized Mrp2 Protein Expression in Rat Liver Samples. . .75

Figure 4-1. Plasma Ceftriaxone Concentration versus Time Profile in WT versus TR-Rats. .83

Figure 4-2 WT versus TR- Rat Liver Mdr1a, Mdr1b, and Mrp2 mRNA Expression..............................................................................86

Figure 4-3. Immunoblot of WT and TR- Rat Liver P-gp and Mrp2 Protein ...............86

Figure 4-4. WT versus TR- Mdr1/P-gp and Mrp2 Protein Expression.......................87 


\section{LIST OF ABBREVIATIONS}

A

$\mathrm{ABC}$

ACUC

ADME

AF1

AF2

ATP

AUC

BHT

BPCA

BSA

BSA

BSEP

CAR/Car

cDNA

CL

$\mathrm{CL}_{\mathrm{H}}$

$\mathrm{CL}_{\mathrm{R}}$

$\mathrm{CL}_{\mathrm{T}}$

cMOAT

CNS

$\mathrm{C}_{\mathrm{t}}$

Cyc

CYP450

CYP7A1

DBD

DEPC

dH20

DME

DNA

dNTP

dT

DTT

EDTA

EHBR

FD\&C

FDA

FDAMA

FNIH

FXR/Fxr
Absorbance

ATP binding cassette

Animal Care and Use Committee

Absorption, Distribution, Metabolism, Elimination

Activation function 1

Activation function 2

Adenosine triphosphate

Area under the curve

Ethylenediamine tetraacetic acid Best Pharmaceuticals for Children Act

Body surface area

Bovine serum albumin

Bile salt export pump

Constitutive androstane receptor Complementary deoxyribonucleic acid

Cytoplasmic loop

Hepatic clearance

Renal clearance

Total clearance

Canalicular multi-specific organic anion transporter

Central nervous system

Cycle threshold Cyclophilin A

Cytochrome P-450

Cholesterol 7- $\alpha$ hydroxylase

DNA-binding domain

Diethylpyrocarbonate

Deionized water

Drug metabolizing enzyme

Deoxyribonucleic acid

Deoxyribonucleotide triphosphate

Deoxyribose thymidine

Dithiothreitol

Potassium phosphate

Eisai hyperbilirubinemic

Food, Drug, and Cosmetics Act

Food and Drug Administration

Food and Drug Administration Modernization Act Foundation for the National Institute of Health FNIH

Farnesoid X receptor 
GAPDH

GFR

GSH

GST

$\mathrm{H}_{1}$

HDTA

HPLC

HRE

IBABP

$\mathrm{k}$

$\mathrm{K}_{2} \mathrm{HPO}_{4}$

$\mathrm{KCL}$

KHPO4

LBD

MCW

MDR1

Mdr1a

Mdrlb

$\mathrm{MgCl} 2$

mRNA

MRP2/Mrp2

MSD

NAT

NBD

NR

NTCP

OAT

OCT

PBST

PD

PEPT2

P-gp

PK

PMI

PVDF

PXR/Pxr

RNA

RT-PCR

SD

SD

SDS-PAGE

SJCRH

SLC
Glyceraldehyde 3-phosphate dehydrogenase Glomerular filtration rate Glutathione

Glutathione-S-transferases Histamine 1 Hexadecyltrimethylammonium bromide High pressure liquid chromatography Hormone response elements Ileal bile acid binding protein. Elimination rate constant Potassium monophosphate Potassium chloride Butylated hydroxytoluene Ligand binding domain Medical College of Wisconsin Multidrug resistance protein 1 Multidrug resistance 1 isoform a Multidrug resistance 1 isoform $b$

Magnesium chloride Messenger RNA Multidrug resistance protein 2 Membrane spanning domains

$\mathrm{N}$-acetyltransferases Nucleotide-binding domain Nuclear receptor Sodium taurocholate contransporting peptide Organic anion transporter Organic cation transporter Phosphate buffered solution with Tween Pharmacodynamic Peptide co-transporter 2 P-glycoprotein Pharmacokinetic Post-mortem interval Polyvinylidene fluoride Pregnane $\mathrm{X}$ receptor Ribonucleic acid Reverse transcriptase-polymerase chain reaction Sprague-Dawley Standard deviation Sodium dodecylsulfate polyacrylamide gel electrophoresis St. Jude Children's Research Hospital Solute carrier family 
SULT

$t_{1 / 2}$

TAMRA

TR-

UDPGA

UGT

WT

XRE
Sulfotransferases

Half-life

6-carboxytetramethylrohodamine

Transport deficient

Uridine diphosphate glucuronic acid Glucuronosyltransferases

Wild-type

Xenobiotic response elements 


\section{CHAPTER 1. INTRODUCTION}

\section{Developmental Pharmacology}

Developmental pharmacology represents an area of pediatric research that translates our current knowledge of normal physiologic growth and development into age appropriate clinical pharmacotherapy. This relatively new field within pharmacologic research grew out of necessity in the late $20^{\text {th }}$ century with an emergence of reports describing a lack of drug efficacy and/or drug related toxicity in the neonatal and pediatric population. Standard classical approaches of using dosing guidelines based on adult doses scaled for weight or body surface area (BSA) may lead to toxicity in the pediatric population. This is well documented in the case of "gray baby syndrome" where infants given adult doses of chloramphenicol scaled by body weight died of chloramphenicol toxicity due to the inability of their liver enzymes to detoxify the drug. Sadly, the newborns who received chloramphenicol exhibited a myriad of physical signs and symptoms including an ashen appearance (thus termed "gray baby syndrome"), vomiting, respiratory distress, refusal to feed, periods of cyanosis, abdominal distention, cadiovascular collapse, and eventually death [1]. Other examples of drugs exhibiting an increase or decreased efficacy, or worse, ineffective drug therapy and/or severe toxicity in the pediatric population include zidovudine, acetaminophen, caffeine, digoxin, aminoglycosides, carbamazapine, valproic acid, and phenytoin [2, 3].

The Food and Drug Administration Modernization Act of 1997 (FDAMA) emphasizes the critical need for clinical studies and improved guidelines of drug use in pediatrics. In particular, FDAMA allows the regulatory agency to not only mandate labeling changes for a list of approved drugs for which additional pediatric information may produce health benefits but also, when appropriate, to request manufacturers to design and conduct pediatric clinical trials on new drug applications. This mandate has led to the creation of a Pediatric Priority List, consisting of drugs with off-labeled usage in pediatrics. The list has been updated annually to include new drug entities and remove drugs updated with new pediatric labeling. An example of the drugs on the Pediatric Priority List is shown in Table 1-1. A more recent law passed by Congress in 2002, termed the Best Pharmaceuticals for Children Act (BPCA), encourages drug manufacturers or sponsors to conduct pediatric studies for either on-patent or off-patent drugs. In return, the manufacturer may obtain six months of additional market exclusivity for their patented drug. Should the manufacturer decline the request from the Food and Drug Administration regarding further pediatric studies, especially in the case for off-patent drugs, the act then enables the Foundation for the National Institute of Health (FNIH) to fund such studies.

In order to achieve safe and effective use of drugs in pediatrics, there must be an understanding of the impact of the normal growth and development process (ontogeny) on the pharmacokinetic (PK) and pharmacodynamic (PD) properties of medications. The fundamental pharmacokinetic processes include absorption, distribution, metabolism, and 
Table 1-1. Example of Drugs Currently Listed on the Pediatric Priority List.

Product Name Indication

Albuterol
Alprazolam
Ampicillin/sulbactam
Benazepril
Bumetanide
Cephalexin
Diclofenac
Dopamine
Efavirenz
Furosemide
Lithium
Methylphenidate
Metoclopramide
Omeprazole
Oxycodone
Paroxetine
Pravastatin
Rosiglitazone
Valproate
Venlafaxine

Asthma

Anxiety

Antibiotic

Hypertension

Diuresis

Antibiotic

Anti-inflammatory

Increase cardiac output

HIV infection

Diuresis

Bi-polar disorder

Attention-deficient hyperactivity disorder

Prokinetic

Gastro-esophageal reflux

Pain

Depression. Obsessive-compulsive disorder

Hypercholesterolemia

Type II diabetes

Mania. Migraine prevention. Seizures.

Depression. Generalized anxiety disorder. 
elimination (ADME) while pharmacodynamics can be described by the relationship of the concentration at the effect site and the observed beneficial or toxic effects.

Absorptive processes that can change with maturation include factors such as gastric $\mathrm{pH}$, gastric emptying and motility, intestinal length, epidermal thickness, and even skeletal-muscle blood flow. Distribution of drugs into a physiologic space relies heavily on the body composition of an individual. Since distribution of small drug molecules in the body is mainly driven by diffusion, their physicochemical properties including molecular weight, ionization, and permeability are crucial determinants of their volume of distribution. For example, infants in general have relatively larger extracellular $(40 \%$ total body weight) and total-body water spaces $(80 \%)$ along with higher water to lipid ratio in their adipose stores as compared to adults ( $20 \%$ extracellular $/ 50 \%$ total-body water). Thus, the apparent volumes of distribution for hydrophilic drugs in newborns will be larger then those of adults. Another factor that can alter the volume of distribution is protein binding. Newborns have frequently reduced plasma protein binding as compared to adults. This results in a higher fraction of unbound drug in the plasma of newborns. Reduced protein binding in newborns may be due to an overall decrease in total plasma protein concentration, higher plasma free fatty acids concentration and unconjugated bilirubin resulting in competitive displacement of acidic drugs from albumin binding sites, and potential competitive binding from residual compounds passed from the mother prior to birth [4].

Drug metabolizing enzymes (DMEs) are subdivided into two groups - Phase I and Phase II. Phase I enzymes are primarily responsible for the biotransformation of a wide array of endogenous and exogenous compounds. Phase II enzymes generally inactivate or detoxify xenobiotics through conjugation with small molecules such as glutathione, uridine diphosphate glucuronic acid (UDPGA), or sulfates. More recently, elimination of xenobiotics and their metabolites by uptake and export transporters has been referred to as Phase III of the elimination process. Pediatric drug metabolism differs greatly from adults due to a differential maturation in drug-metabolizing enzymes prior to and after birth. The ontogeny of Phase I enzymes, comprised of those in the cytochrome P450 (CYP450) family, has been well characterized for several members including CYP3A, CYP2C, CYP2D, CYP2E, and CYP1A (Figure 1-1). The CYP3A enzymes account for approximately $30 \%$ of total hepatic CYP450 content [5] and contributes to the oxidative metabolism of approximately $50 \%$ of marketed drugs [6]. CYP3A7 has been established as the predominant enzyme of the CYP3A family in newborns. An ontogenic switch from CYP3A7 to CYP3A4 occurs shortly after birth whereby $3 \mathrm{~A} 7$ rapidly declines in the first weeks of life and 3A4 increases throughout the postnatal period [7, 8]. Though CYP2D6 protein can be detected in the neonate liver, its activity (as assessed by dextromethorphan metabolism) remains low ( $<1 \%$ of adults) and only increases to approximately $20 \%$ of adult enzymatic activity after 28 days of life $[9,10]$. The CYP2C subfamily accounts for approximately $20 \%$ of the total adult CYP 450 content and metabolism of current drugs on the market $[5,11]$. The two predominant isoforms of the CYP2C family include CYP2C9 and CYP2C19. At birth, CYP2C9 expression is comparable to that of adults but $\mathrm{CYP} 2 \mathrm{C} 19$ expression requires an additional five months of postnatal development before reaching maximal values [12]. Expression and function 


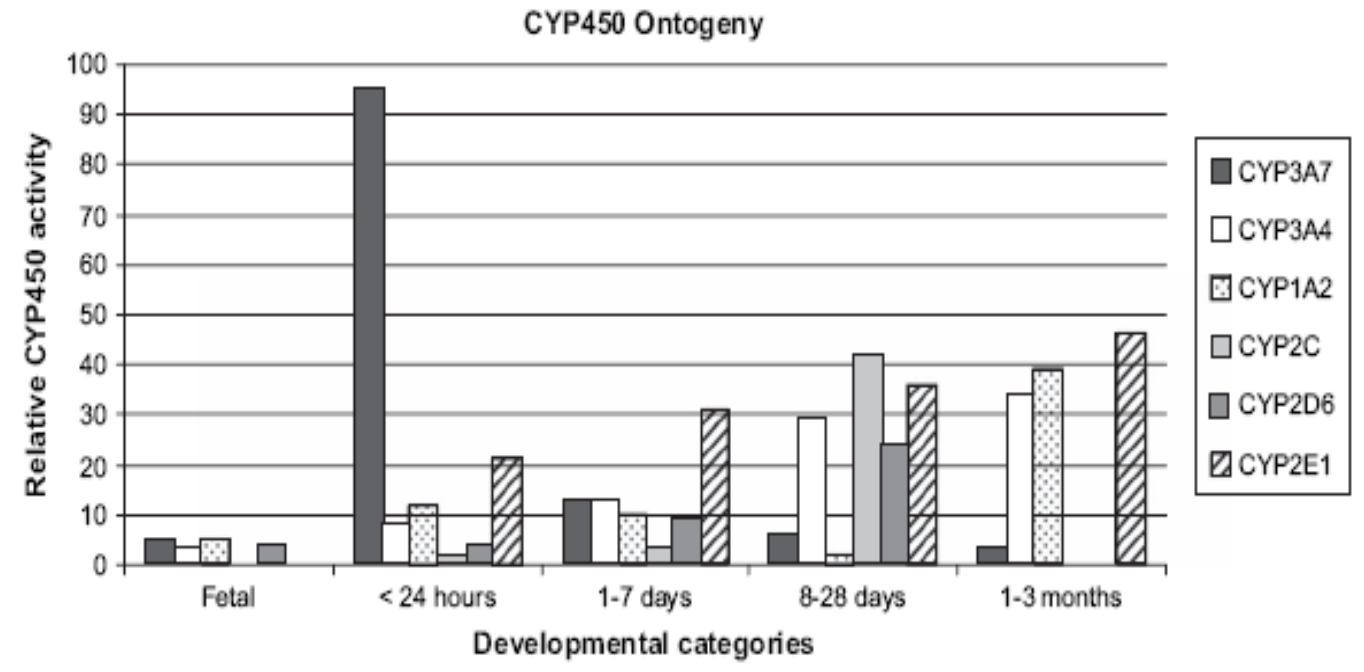

Figure 1-1. Ontogeny of CYP450 Family of Drug Metabolizing Enzymes.

Source: Reprinted from Seminars in Fetal and Neonatal Medicine, Volume 10, Blake M. J. et al., 'Ontogeny of drug metabolizing enzymes in the neonate', 123-38, 2005, with permission from Elsevier. 
of both CYP2E1 and CYP1A1 increase with postnatal age. Furthermore, the large variability observed for CYP2E1 and CYP1A1 expression appears to be dependent upon xenobiotic induction or inhibition along exposure to various environmental factors [13]. Knowledge regarding the development of Phase II metabolizing enzymes including glucuronosyltransferases (UGT), sulfotransferases (SULT), glutathione-S-transferases (GST), and N-acetyltransferases (NAT) is incomplete. However, preliminary reports suggest that while many of the Phase II enzymes are expressed early in development others exhibit tissue-specific ontogenic expression [14]. Many of the Phase III transporters belong to the ATP-binding cassette family (ABC) as well as the solute carrier family (SLC). These transporters can facilitate the cellular uptake or extrusion of various endogenous and exogenous compounds. Expression of these transporters appears organ and tissue specific, however, very little is known regarding the ontogeny of these transporters. A more detailed discussion of these various drug transporters will be provided in the subsequently sections.

Renal elimination of xenobiotics depends on glomerular filtration rate, active secretion and reabsorption through renal tubular transporters, as well as passive reabsorption. At birth, glomerular filtration rate (GFR) increases dramatically with postnatal age and approaches adult values as early as 6 months of age for a full term infant $[15,16]$. Renal secretion and reabsorption depend on various transporters including those belonging to the ATP-binding cassette (ABC) family, organic anion/cation transporters (OATs/OCTs), and the peptide co-transporter PEPT2, a member of the SLC15 family [17]. Unfortunately, little information exists regarding the maturation of these transporters in the renal tubule. Ongoing research has already improved the identification and characterization of these renal transporters, but ultimately, studies into their developmental processes will help clarify our understanding of pediatric renal drug elimination.

Similar to renal transporters, ontogeny of pharmacodynamic (PD) processes has received little attention in the literature. The phamacodynamic response is a result of the interaction between the drug molecule and receptors and its downstream molecular consequences including changes in ion channels, second messenger systems, and signaling pathways results in a complex process. Much of the Food and Drug Administration (FDA) guidance for conducting pediatric studies [18] is based upon an underlying assumption that drug action, concentration-response rate, and clinical outcomes in pediatric pharmacotherapy are comparable to adults. However, as in the case of tacrolimus, the imprecision resulting from the use of a priori PK parameters from adults in a pediatric model demonstrates the limitations of these basic assumptions [19]. Pharmacodynamic parameters including receptor concentration, affinity, and intrinsic activity may very well demonstrate age-associated differences in their effect. Doseresponse discrepancies due to age-associated effects have been documented for warfarin [20], cyclosporine [21], sotalol [22] and midazolam [23].

While advances in developmental pharmacology during the past decade have certainly improved our understanding of pediatric physiology, there remains a gap in incorporating these age-associated changes into clinical pharmacotherapy. Furthermore, 
the maturation of key PK parameters including several Phase II drug metabolizing enzymes, Phase III transporters, and various PD parameters such as cellular receptors and signaling pathways still warrant further investigation.

\section{Hepatic Drug Disposition}

For most small molecule drugs, overall drug elimination occurs through two main components; namely, clearance via the renal route $\left(\mathrm{CL}_{\mathrm{R}}\right)$ and clearance via hepatic metabolism and transport $\left(\mathrm{CL}_{\mathrm{H}}\right)$. As described previously, efficient and effective biotransformation and inactivation/detoxification of xenobiotics starts with Phase I and Phase II drug metabolizing enzymes. Furthermore, elimination of xenobiotics and their metabolites through liver transporters into the bile is part of Phase III of the elimination process. Because of the overlap in their substrate specificity, tissue distribution, and gene regulation between several drug metabolizing enzymes and transporters, Phase I/II and Phase III processes appear to work synergistically to decrease the oral bioavailability and increase the renal and biliary excretion of xenobiotics [24-26].

It is well established that genetic polymorphisms and environmental factors can influence an individual's expression and function of DMEs [27]. However, recent studies suggest that developmental changes in DMEs can also contribute to the variability observed for drug metabolism. Detailed reviews in recent years on the development of Phase I and Phase II enzymes provide detailed insight into the differences observed between pediatric versus adult pharmacokinetics [3, 13-15, 28]. However, knowledge regarding drug transporter ontogeny is currently very limited.

\section{Hepatic Transporters}

As mentioned previously, Phase III transporters are comprised of those belonging in the ATP-binding cassette family (ABC) as well as the solute carrier family (SLC). Hepatic transporters are an essential component in the overall hepatic clearance and hepatobiliary elimination. A multitude of hepatic transporters align both the apical (canalicular) and basolateral (sinusoidal) membranes of the hepatocyte (Figure 1-2). Transporters expressed in the basolateral membrane mediate the uptake of various organic anions and cations from the blood into the liver [29, 30]. Transporters in the canalicular membrane belong to the ABC family and mediate the transport of various organic anions and cations along with glutathione-, glucuronate-, or sulfate-conjugates of several drug substrates into the bile. The focus of the current dissertation will focus on these apical transporters, specifically MDR1/P-gp (ABCB1) and MRP2 (ABCB2), as these are the main transporters which mediate the hepatobiliary elimination of a number of drug substrates (for simplicity, only the common transporter name will be used). However, the role of the uptake transporters in hepatic clearance should not be undermined and will be considered in future investigations. 


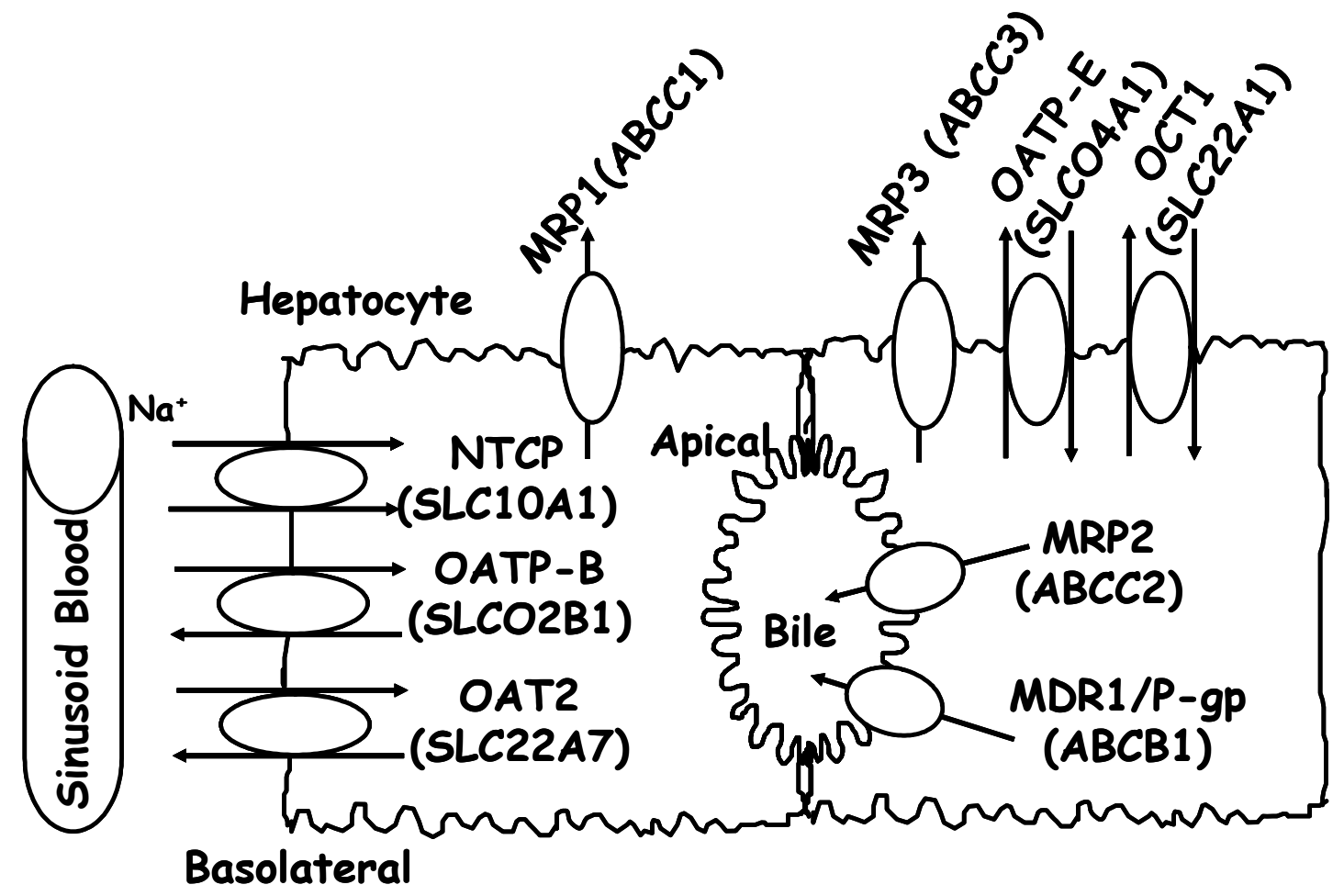

Figure 1-2. Select Drug Transporters in Human Hepatocytes.

MDR1/P-gp (ABCB1), multidrug resistance 1; MRP1 (ABCC1), multidrug resistance protein 1; MRP2 (ABCC2), multidrug resistance protein 2; MRP3 (ABCC3), multidrug resistance protein 3; OATP-E (SLCO4A1), organic anion transport polypeptide E; OCT1 (SLC22A1), organic cation transporter 1; NTCP (SLC10A1), sodium taurocholate cotransporting polypeptide; OATP-B (SLCO2B1), organic anion transport polypeptide B; OAT2 (SCL22A7), organic anion transporter 2; $\mathrm{Na}^{+}$, sodium. 
The ATP-binding cassette (ABC) superfamily of transporters consists of seven subfamilies of highly conserved proteins that mediate the unidirectional transport of various endogenous as well as exogenous compounds. MDR1/P-gp was originally identified in 1976 as a $170 \mathrm{kDa}$ cell surface glycoprotein displaying drug resistance properties in cancer cells [31]. Several years later, this multidrug transporter was found to actively extrude a large number of diverse compounds including natural products, hydrophobic amphipathic compounds, as well as cytotoxic drugs used in anticancer therapy [32]. In humans, P-gp is encoded by the MDR1 gene. However, in rodents, P-gp is the product of two gene isoforms - Mdrla and Mdr1b. The sequence homology along with domain organization of all $\mathrm{ABC}$ transporters is well conserved. $\mathrm{ABC}$ transporters characteristically have 12 transmembrane regions organized into two membrane spanning domains (MSDs). Each MSD is associated with a nucleotide-binding domain (NBD) located on the cytoplasmic side of the membrane (Figure 1-3 and Figure 1-4) [33, 34]. The $\alpha$-helices of the MSDs form pore-like structures through which different substrates on the intracellular side can be extruded across the lipid bilayer. Conformational changes within MSDs due to substrate binding are believed to induce an open or closed state of these transporters $[35,36]$. Adenosine triphosphate (ATP) associated with the binding domains provides the energy required for active transport of substrates against the concentration gradient. P-gp is highly expressed in several organs including the brush border membrane of enterocytes, the canalicular surface of hepatocytes, the apical surface of proximal tubules in the kidney, and the endothelial cells of the blood brain barrier [37, 38]. Localization of P-gp is particularly conducive for its role in extruding xenobiotics or toxins thereby protecting against cellular toxicity.

MRP2, initially named the canalicular multi-specific organic anion transporter (cMOAT), was discovered as the defective transporter in the human Dubin-Johnson syndrome as well as the naturally occurring mutant strains of the Eisai hyperbilirubinemic (EHBR) and transport deficient (TR-) rats. MRP2 is encoded by the ABCC2 gene and has a molecular weight of approximately $190 \mathrm{kDa}$. Unlike P-gp, the structure of MRP2 contains an extra membrane spanning domain at the $\mathrm{NH}_{2}$-termus which terminates in the extracytosolic region (Figure 1-3B) [39, 40]. MRP2 is highly expressed in the gut, liver, and kidney and shares many of the same substrates as P-gp [41]. MRP2 plays an important role in the hepatobiliary transport of a range of conjugated and unconjugated anionic compounds as well as bile acids and bilirubin. Due to its function in the transport of a gamut of glucuronidated drug substrates, it is no surprise that MRP2 co-localizes with various Phase II metabolizing enzymes. Furthermore, MRP2 mediated transport of xenobiotics often depends on co-transport with reduced glutathione (GSH) [42].

Similar to Phase I and Phase II enzymes, hepatic transporters are subject to genetic polymorphisms drug-induced inhibition, and drug- and disease-induced alterations of expression levels. These interactions and alterations may profoundly influence the fate of drugs. An example of a transporter based drug-drug interaction involves fexofenadine and erythromycin. Fexofenadine, a histamine $1\left(\mathrm{H}_{1}\right)$-selective antagonist, does not undergo significant biotransformation in humans with $95 \%$ of the dose excreted in either urine or bile [43]. Co-administration of fexofenadine with erythromycin increases the 
A

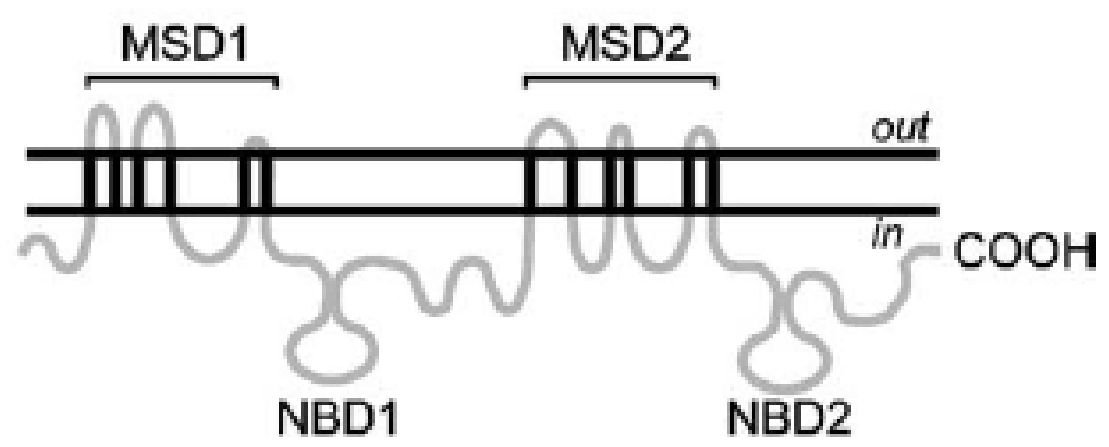

B

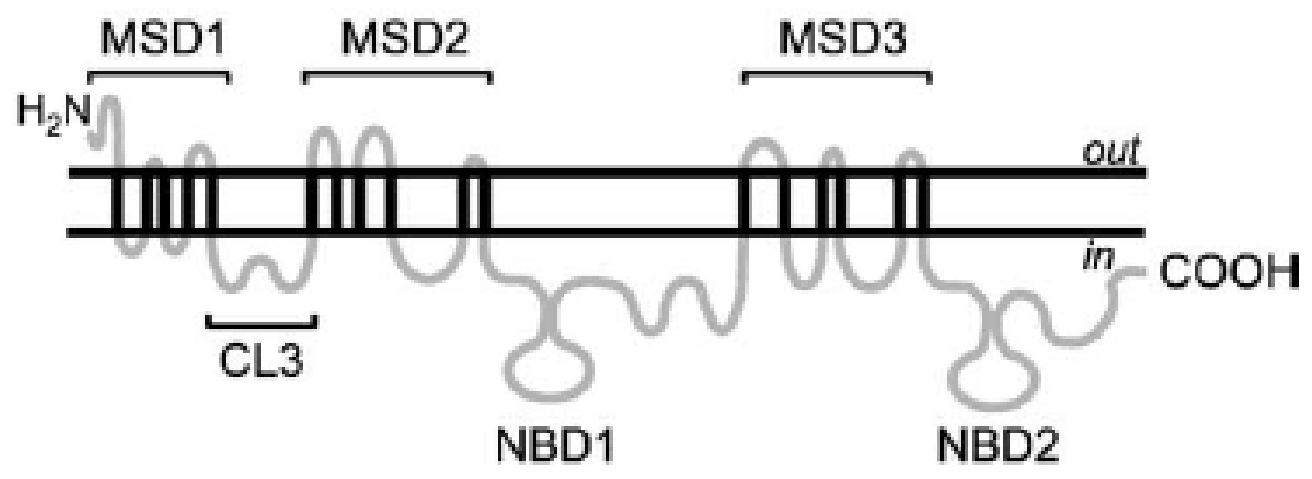

Figure 1-3. Predicted Secondary Structures of P-gp (A) and MRP2 (B).

MSD, membrane spanning domain; NBD, nucleotide binding domain; CL, cytoplasmic loop. Source: Reprinted from Toxicology and Applied Pharmacology, Volume 204, Leslie E.M. et al., 'Multidrug resistance proteins: role of P-glycoprotein, MRP1, MRP2, and BCRP (ABCG2) in tissue defense', 216-237, 2005, with permission from Elsevier. 


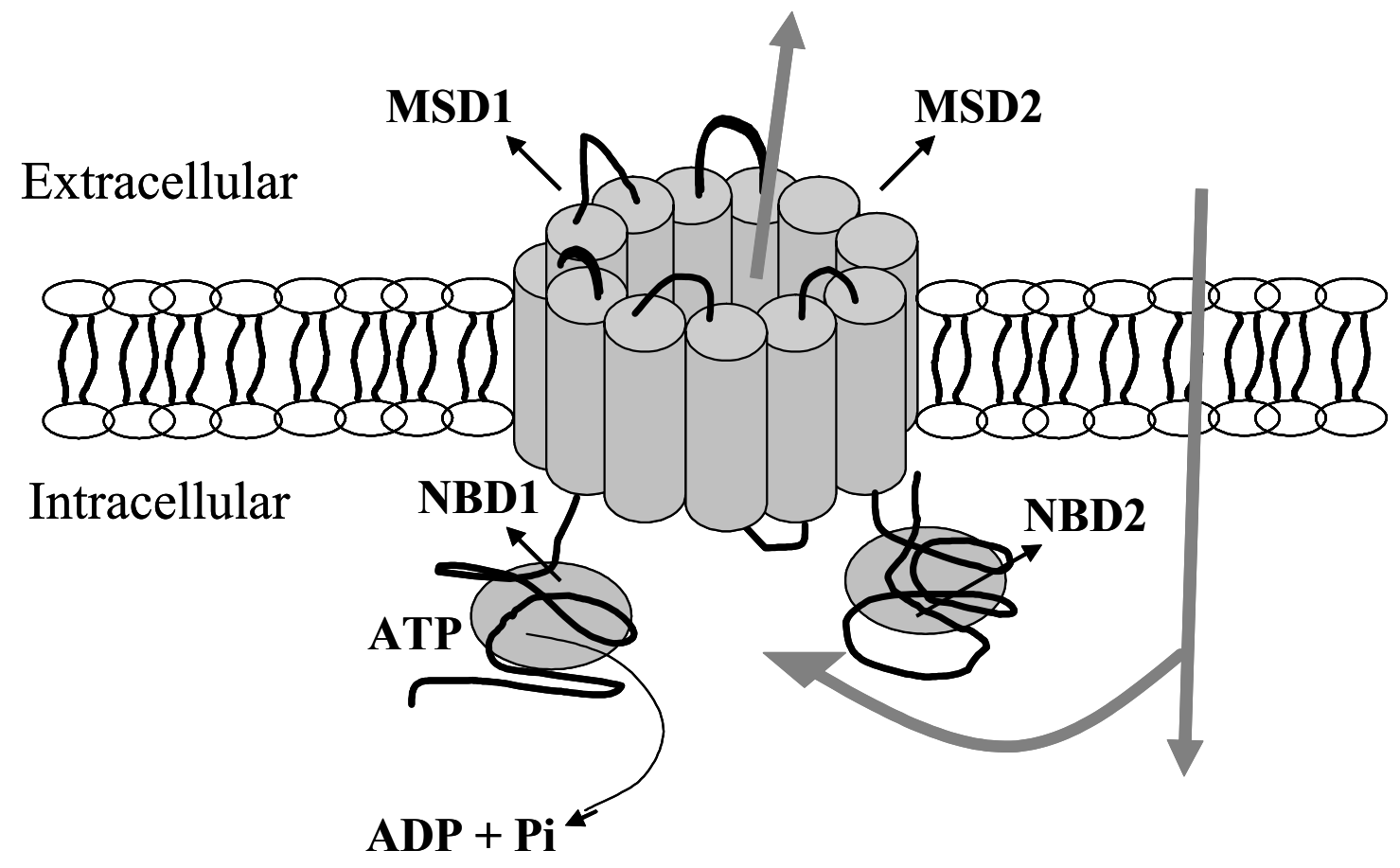

Figure 1-4. Graphic Representation of P-gp.

Represented is a single P-gp transporter with two membrane spanning domains (MSDs) each associated with six transmembrane regions. Associated with each MSD is a nucleotide binding domain (NBD). Grey arrows trace the path of substrates. 
steady state plasma levels of fexofenadine by $109 \%$ [44]. A study using isolated perfused rat liver with fexofenadine and erythromycin concludes that erythromycin inhibits the biliary excretion of fexofenadine thus contributing to its increase in plasma concentration [45]. Another documented transporter based drug-drug interaction occurs between digoxin and quinidine. Quinidine inhibits biliary excretion of digoxin as mediated through P-gp by as much as $42 \%$ [46].

As more transporter associated drug interactions emerge in the literature, knowledge about the changes which occur during transporter development become increasingly important. While the ontogeny of hepatic Phase I and Phase II clearance mechanisms have been well documented [16], little is known regarding the development of drug transporters and its potential impact on the pharmacokinetic and pharmacodynamic profile of medications. One of the most dramatic examples of P-gp associated drug toxicity involves the use of loperamide, a potent opioid agent often used as an antidiarrheal agent. Central nervous system (CNS) toxicity by loperamide results in respiratory depression; however, at the recommended doses, loperamide entry into the CNS is prevented by P-gp at the blood brain barrier. Despite its apparent safety, case reports of loperamide induced respiratory depression in infants have been described in the literature $[47,48]$ and loperamide is contraindicated for children under two year of age. The question whether this is directly due to a lower expression of P-gp in children younger than two years remains to be answered. Another example of a potential transporter related drug toxicity involves ceftriaxone and MRP2. Ceftriaxone is a third generation cephalosporin antibiotics often used in the pediatric population to treat lower respiratory infections or acute otitis media. Approximately $33 \%$ of the drug is eliminated unchanged in the bile through MRP2 $[49,50]$. There are several clinical reports of ceftriaxone related biliary sludge or pseudolithiasis in the pediatric population $[51,52]$. This is secondary to the high concentration of ceftriaxone in the liver which forms an insoluble salt with calcium in the bile [53]. In fact, in cases where high doses of ceftriaxone are given, the risk of ceftriaxone induced cholestasis drastically increases [54]. Little is known regarding the development of MRP2 in the human liver. Immature or lower expression of MRP2 in the liver in the early years of life may lead to an accumulation of ceftriaxone in the hepatocyte and thus, increase the risk of cholestasis. However, further studies are needed in order to elucidate the development of MRP2 in human pediatric livers and confirm the mechanisms underlying these adverse events caused by administration of ceftriaxone in children.

\section{Nuclear Receptors - PXR, CAR, FXR, HNF4a}

Like the ABC transporters, nuclear receptors (NRs) also comprise a highly conserved superfamily of genes. Instead of encoding for drug transporters though, NRs transcribe into various transcriptional factors which regulate the expression of their target genes. Functionally, constitutive and inducible NRs can modulate the expression of several phase I and II drug metabolizing enzymes as well as drug transporters when activated by endogenous and exogenous compounds including hormones and drug molecules $[55,56]$. The well conserved structure of NRs includes a variable modulator 
domain known as an activation function 1 (AF1) at the N-terminus followed by the DNAbinding domain (DBD) containing two well conserved zinc fingers specific to NRs.

DBD links the receptor to the promoter regions of its target genes termed either hormone response elements (HREs) or xenobiotic response elements (XREs). Located on the Cterminus are the ligand binding domain (LBD) as well the activation function 2 (AF2). As the name suggests, the LBD serves as the binding site for specific ligands. Upon ligand binding, LBD undergoes a conformational change resulting in a transcriptionally active state prepared for recruitment of coactivators by activation function 2 (AF2) (Figure 1-5). Based on their classification, NRs can either bind to their target sequences as a homodimer, heterodimer, or a monomer [56].

Nuclear receptors that target expression of genes which encode for P-gp and MRP2 include the pregnane $\mathrm{X}$ receptor (PXR/NR1I2), the constitutive androstane receptor (CAR/NR1I3), the farnesoid X receptor (FXR/NR1H4), and the hepatic nuclear factor $4 \alpha(\mathrm{HNF} 4 \alpha)$ [57]. PXR and CAR have been implicated in the coordinate induction of phase I and II drug metabolizing enzymes and drug transporters [58]. FXR is a bile acid receptor responsible for the regulation of bile acid synthesis and enterohepatic recirculation [59]. HNF4 $\alpha$, a constitutively expressed NR, is crucial for liver development and differentiation and also appears to be a key regulator for various drug disposition gene expression [57].

\section{Central Hypothesis and Specific Aims}

Hepatic drug clearance involves a concerted process involving drug metabolizing enzymes and drug transporters. While much effort has been placed in understanding the ontogeny of drug metabolizing enzymes (Phase I and Phase II), there remains a void in our knowledge into the developmental process of drug transporters. Hepatic export transporters of particular relevance for the elimination of clinically used drugs into the bile include MDR1/P-gp and MRP2. We hypothesized that in pediatric livers, MDR1/Pgp and MRP2 mRNA and protein expression would be significantly lower early in development (infancy) as compared to older ages (childhood and adulthood). We hypothesized that these expression differences would have functional consequences that affect the in vivo pharmacokinetics of drugs which are substrates for these transporters. Because nuclear receptors including PXR, CAR, FXR, and HNF4 $\alpha$ regulate the expression of MDR1 and MRP2, we hypothesized these nuclear receptor would be correlated with MDR1/P-gp and MRP2 expression and would also exhibit significantly lower mRNA expression in the early period of development.

In specific aim 1 (Chapter 2), we characterized the ontogeny of hepatic drug transporters (MDR1/P-gp and MRP2) and nuclear receptors (PXR, CAR, FXR, and $\mathrm{HNF} 4 \alpha$ in human pediatric liver samples. We hypothesized that there would be lower hepatic drug transporter and nuclear receptor expression in the early infant period of development as compared to the older childhood ages. 


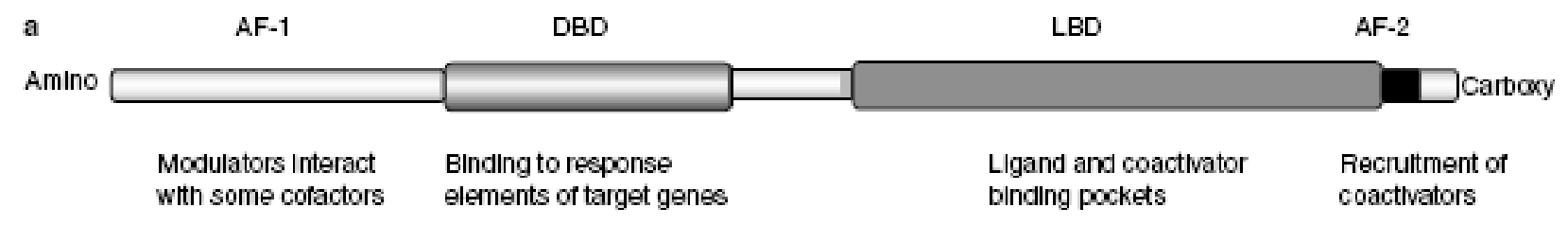

Figure 1-5. Basic Structure of Nuclear Receptors.

$\mathrm{AF}$, activation function; DBD, DNA-binding domain; LBD, ligand binding domain.

Reprinted with permission. Wang, H. and E.L. LeCluyse. "Role of orphan nuclear receptors in the regulation of drug-metabolising enzymes." Clin Pharmacokinet, 2003. 42(15): p. 1331-57. 
In specific aim 2 (Chapter 3), we defined the ontogeny of hepatic drug transporters (Mdr1a, Mdr1b, and Mrp2) and nuclear receptors (Pxr, Car, Fxr, and Hnf4 $\alpha$ ) in SpragueDawley rats in order to better pinpoint the age-specific changes in drug transporter expression hypothesized to occur in newborns and infants. We investigated seven predetermined ages ranging from newborn to adults. We hypothesized that in these rats, there would be lower hepatic drug transporters and nuclear receptors expression early on during development as compared to the older ages.

In specific aim 3 (Chapter 4), we explored the functional consequences and potential clinical implications of low transporter expression as postulated for newborns and infants and determined the effect of MRP2 deficiency on the in vivo pharmacokinetics of ceftriaxone, a Mrp2 substrate frequently used in pediatric pharmacotherapy, in a animal model using wild-type (WT) and Mrp2-deficient (TR-) rats. We hypothesized that in the TR- rats, there would be a decrease in overall clearance $\left(\mathrm{CL}_{\mathrm{T}}\right)$, longer half-life $\left(\mathrm{t}_{1 / 2}\right)$, higher area under the curve (AUC), and no biliary excretion (as determined by fecal drug recovery) as compared to the WT rats. 


\section{CHAPTER 2. AGE-ASSOCIATED EXPRESSION OF HEPATIC ABC DRUG TRANSPORTERS AND NUCLEAR RECEPTORS IN HUMAN PEDIATRIC LIVER}

\section{Introduction}

As discussed in Chapter 1, maturational changes in the physiology of organs involved in drug disposition can translate into profound differences observed in the pharmacokinetic and pharmacodynamic properties of various therapeutic agents often used in pediatric pharmacotherapy. Developmental changes in the gastrointestinal tract, protein binding, drug metabolizing enzymes and drug transporters, and renal filtration are just some examples of factors that can impact the absorption, distribution, metabolism, and elimination (ADME) of drug molecules.

The 1962 Kefauver-Harris amendments to the Food, Drug, and Cosmetics Act (FD\&C) mandated that prior to approval marketed drugs must have documented safety and efficacy for use in humans. However, pharmaceutical manufacturers often excluded children during the clinical trials and labeled the use of such medications only in adults with a disclaimer that safety and efficacy had not been established in children. Unfortunately, deviations in the pharmacokinetic parameters of therapeutic agents often used as "off-label" medications in pediatric pharmacotherapy can lead to adverse risks such as underdosing, overdosing, and unanticipated adverse events. Dr. Harry Shirkey, then chair of the American Academy of Pediatrics Committee on Drugs in 1968, called attention to the exclusion of children and coined the term "therapeutic orphan" [60].

The complexity of physiological and pathophysiological processes which occur during the maturational process certainly adds a level of intricacy in studies involving the pediatric population. The ontogeny of drug metabolizing enzymes and its contribution towards differences seen in pediatric drug biotransformation have been widely studied and reviewed $[2,3,13,61]$. However, studies regarding the ontogeny of drug transporters are still limited. What is known about the development of drug transporters stem from mainly rodent models [61-65]. Furthermore, the animal data mostly focus on the development of transporters in rodent brain, intestine, and kidney rather than liver tissue [61-63, 66]. There are, however, a few human studies on the ontogeny of drug transporters using post-mortem fetal samples [65, 67]. Currently, there are no published studies on the development of human hepatic drug transporters during the early postnatal into childhood ages.

In general, most of the rodent studies suggest the presence of an age associated difference of transporter expression in various organs. One of the most studied ABC transporters thus far, due to its ability to extrude drug substrates from cells, has been MDR1/P-gp. Using a mouse model, Watchko [66] has reported limited intestinal and brain P-gp expression at birth (approximately 20\% of adult), but levels dramatically increased throughout maturation [66]. On the flipside, hepatic and renal levels of P-gp in neonatal mice and throughout development have been quantified at levels comparable to 
adult values [62]. In rats, Mdrla and Mdr1b have also been reported to exhibit age associated differences at the mRNA and protein level in the liver, kidney, brain, heart and lung. Specifically, transcript level ranged two to three folds lower at birth with levels increasing throughout maturation reaching maximal expression by postnatal day 60 [63]. In early gestation (14-20 weeks) human fetal liver samples, van Kalken [65] was able to detect P-gp in the bile canaliculi by as early as 14 weeks through immunostaining. No differences in staining intensity were observed between the specimens between the different fetal stages [65].

Another transporter in the $\mathrm{ABC}$ family with a significant role in hepatobiliary elimination of drug substrates is MRP2. Ontogeny of Mrp2 mRNA expression has been explored in rodent models in recent years. The results showed an approximate $50 \%$ increase in Mrp2 mRNA expression from birth through postnatal day 60 in the rat liver and kidney [63]. A separate study quantified the postnatal Mrp2 protein expression level in rat liver and concluded that at birth, neonate expression of Mrp2 approximated $70 \%$ of adult values, eventually surpassed the adult values within a month and a half, but eventually leveled to adult values within three months [68]. One study noted approximately 50\% Mrp2 mRNA expression in one day old rat liver tissue which dramatically increased to adult levels in one to three weeks. In the same samples, Mrp2 protein levels approximated $<20 \%$ of adults in the same group and increased gradually to those of adults values by 4 weeks of age [69]. For humans, Chen [67] showed a 50\% lower MRP2 genetic expression level in ten human fetal liver samples between $14-20$ weeks as compare to adult liver samples [67].

Nuclear receptors comprise transcriptional factors which regulate the expression of their target genes, several of which include drug metabolizing enzymes and drug transporters [70]. While limited reports of drug transporter ontogeny in animal models and human fetal liver samples are slowly surfacing, studies on the developmental expression of nuclear receptors are even scarcer. PXR and CAR, both members of the NR1 family, are key regulators of genes involved in the metabolism and transport of most xenobiotics, including CYP3A and P-gp/MDR1 [58, 71, 72]. Another member of the NR1 family, FXR, is a bile acid sensor responsible for regulation of bile acid synthesis and enterohepatic recirculation $[56,73,74]$. All three nuclear receptors are associated with the regulation of MRP2 [72]. Another hepatic nuclear receptor, HNF4 $\alpha$, has been reported as a master regulator of PXR [75] and CAR [76]. Vyhlidal [77], in a recent study with limited postmortem pediatric liver samples $(n=20$; ages 4 days to 18 years), reported an age association in mRNA expression of PXR and CAR. Furthermore, expression of PXR and CAR were limited in the first six months of life, but increased several folds after six months of age. In the same study, the authors also quantified mRNA expression of HNF4 $\alpha$ and showed that HNF4 $\alpha$ was positively correlated with both PXR and CAR expression [77].

While the rodent studies provide us some information regarding the developmental expression of $\mathrm{ABC}$ transporters Mdr1/P-gp and Mrp2 in various tissues, studies regarding the development of such transporters and nuclear receptors in humans are rare due to the limited availability of human pediatric liver samples. While the small number of 
available reports based on human fetal and postmortem pediatric liver samples provide a glimpse into some pre- and postnatal transporter and nuclear receptor expression, there still lacks information during other phases of development such as during the newborn and early childhood periods.

The overall object of the present study was to characterize the ontogeny of $\mathrm{ABC}$ transporters MDR1 and MRP2 as well as the nuclear receptors PXR, CAR, FXR, and HNF4 $\alpha$ in human pediatric liver samples ranging from immediately after birth through twelve years of age. Potential age associated changes in hepatobiliary transporters MDR1/P-gp and MRP2 may result in significant differences in the biliary clearance of medications used in pediatric pharmacotherapy. Knowledge regarding the impact of such changes in transporter expression during the newborn and early childhood periods on pharmacokinetic parameters can contribute to more age-appropriate dosing and thus better safety and efficacy profiles especially for those medications with limited or no labeling for pediatric use.

\section{Materials and Methods}

\section{Sample Acquisition}

Human pediatric liver tissues were acquired from two main sources - St. Jude Children's Research Hospital (SJCRH, Memphis, TN) and the Medical College of Wisconsin (MCW, Milwaukee, WI). The samples from SJCRH $(n=62)$ originated from the Liver Tissue Procurement and Distribution System (University of Pittsburgh, Pittsburgh, PA, funded by National Institutes of Health Contract N01-DK-9-2310) and from the Cooperative Human Tissue Network (University of Alabama, Birmingham, AL, funded by the National Cancer Institute). Samples from MCW $(n=67)$ originated from the Brain and Tissue Bank for Developmental Disorders, University of Baltimore and University of Miami (National Institute of Child Health and Human Development contract N01-DK-8-3284). All samples were collected from donors less than twelve years of age. The SJCRH samples were obtained from living donors either through biopsy or within one hour of cross-clamping in the case of organ donors. Harvested tissue was immediately flash frozen in transplant solution. Demographic information on the donor population and health status is provided in Table 2-1. All SJCRH samples were used for the mRNA expression analysis and a subset $(n=45)$ was used for the protein analysis. The unmatched sample numbers between mRNA and protein expression analysis was due to limitations in tissue availability.

Unlike the SJCRH samples, all MCW samples were obtained from deceased donors. Due to the degradation of mRNA during the period from time of death to sample collection - defined as the post-mortem interval (PMI), the postmortem samples were only used for P-gp and MRP2 protein analysis. The postmortem samples from donors with disease processes that could potentially involve liver damage were excluded from 
Table 2-1. Donor Demographics for Human Pediatric Liver Samples Provided by St. Jude Children's Research Hospital (SJCRH).

\begin{tabular}{|c|c|c|}
\hline & $\mathrm{N}$ & $\begin{array}{l}\text { Age }(\mathrm{yrs}) \\
\text { Mean } \pm \text { SD }\end{array}$ \\
\hline \multicolumn{3}{|l|}{ Age Group } \\
\hline $\mathrm{A}(<0.7 \mathrm{Y})$ & 9 & $0.53 \pm 0.18$ \\
\hline $\mathrm{B}(0.7-<3 \mathrm{Y})$ & 19 & $1.69 \pm 0.45$ \\
\hline$C(3-<6 Y)$ & 12 & $3.83 \pm 0.83$ \\
\hline $\mathrm{D}(6-12 \mathrm{Y})$ & 22 & $8.38 \pm 2.04$ \\
\hline \multicolumn{3}{|l|}{ Gender } \\
\hline M & 29 & \\
\hline $\mathrm{F}$ & 22 & \\
\hline Unknown & 11 & \\
\hline \multicolumn{3}{|l|}{ Race } \\
\hline Caucasian & 35 & \\
\hline Black & 7 & \\
\hline Others & 6 & \\
\hline Unknown & 14 & \\
\hline \multicolumn{3}{|l|}{ Disease status } \\
\hline Normal & 36 & \\
\hline Cirrhosis & 10 & \\
\hline Fibrosis & 10 & \\
\hline Acute Hepatitis & 4 & \\
\hline Necrosis & 2 & \\
\hline
\end{tabular}


the study. Demographic information for the MCW samples is provided in Table 2-2. The combined patient demographics from SJCRH and MCW samples used for protein expression analysis are presented in Error! Reference source not found.

\section{Total RNA Isolation and cDNA Synthesis}

Total ribonucleic acid (RNA) from human pediatric liver samples were isolated using the phenol:chloroform method using the Promega RNAgents ${ }^{\circledR}$ Total RNA Isolation Kit (Promega, Madison WI) according to the manufacturer's protocol. Frozen liver tissue (approximately $0.3 \mathrm{~g}$ ) was added to $600 \mu \mathrm{L}$ of denaturing solution per protocol and subjected to homogenization until no fragments of tissue were visible. To each homogenate, $60 \mu \mathrm{L}$ of $2 \mathrm{M}$ sodium acetate $(\mathrm{pH} 4.0)$ was added and mixed thoroughly by inversion. $600 \mu \mathrm{L}$ of phenol:chloroform:isoamyl alcohol was subsequently added to the mixture and mixed by inversion $3-5$ times followed by vigorously shaking for 10 seconds. The samples were then placed on ice for 15 minutes. Thereafter, the samples were subjected to centrifugation at $10,000 \mathrm{~g}$ for 20 minutes at $4^{\circ} \mathrm{C}$ in order to separate the organic and aqueous phases. The top aqueous phase containing RNA was carefully separated to a fresh vial and an equal volume of isopropanol was added to each sample. RNA was pelleted by centrifugation at $10,000 \mathrm{~g}$ for 15 minutes after alcohol precipitation for 30 minutes at $-20^{\circ} \mathrm{C}$. The RNA pellet was then washed with $1.0 \mathrm{~mL}$ of $75 \%$ ethanol, and the pellet was again collected by centrifugation at $10,000 \mathrm{~g}$ for 15 minutes. The pellet was air-dried after discarding the supernatant and evaporating the residual ethanol. Each RNA pellet was re-dissolved in $10-50 \mu \mathrm{L}$ of nuclease-free water depending on the pellet size. RNA concentrations were determined by measuring its ultraviolet absorbance (A) at $260 \mathrm{~nm}$ and $280 \mathrm{~nm}$, respectively, whereby 1 absorbance unit $(\mathrm{A} 260)=40 \mu \mathrm{g}$ of RNA $/ \mathrm{mL}$. The purity of the RNA isolate was estimated by comparing the ratio for A260/A280. Samples were considered to be pure total RNA with only minor protein contamination if the ratio of A260/A280 calculated between 1.7 and 2.0. Integrity of each RNA sample was assessed by agarose gel electrophoresis comparison of intact ribosomal $18 \mathrm{~S}$ and $28 \mathrm{~S}$ bands. The ratio between $28 \mathrm{~S}$ to $18 \mathrm{~S}$ band intensity ranged approximately around $2-$ an indication that no gross degradation of RNA had occurred during processing. Only samples with high purity and integrity were further processed for first strand cDNA synthesis.

First strand complementary deoxyribonucleic acid (cDNA) synthesis was performed by using the Superscript III kit (Invitrogen, Carlsbad, CA) on an Eppendorf $\mathbb{}$ Mastercycler ${ }^{\mathrm{TM}}$ (Westbury, NY). Oligo deoxyribose thymidine (dT) was used as the primer for messenger RNA (mRNA) first-strand synthesis. An aliquot totaling $1 \mu \mathrm{g}$ of

total RNA was mixed with $1 \mu \mathrm{L}$ of $10 \mathrm{mM}$ deoxyribonucleotide triphosphate (dNTP) mix and $1 \mu \mathrm{L}$ of $0.5 \mu \mathrm{g} / \mu \mathrm{L}$ Oligo(dT)12-18. The total mixture was then brought to $10 \mu \mathrm{L}$ with the addition of diethylpyrocarbonate-treated (DEPC) water. The mixture was incubated at $65^{\circ} \mathrm{C}$ for 5 minutes on a heating block, then immediately placed on ice for at least one minute. A mixture of $2 \mu \mathrm{L}$ of $10 \mathrm{x}$ reverse transcriptase (RT) buffer, $4 \mu \mathrm{L}$ of 25 $\mathrm{mM}$ magnesium chloride $(\mathrm{MgCl} 2), 2 \mu \mathrm{L}$ of $0.1 \mathrm{M}$ dithiothreitol (DTT), $1 \mu \mathrm{L}$ of 
Table 2-2. Donor Demographics for Human Pediatric Liver Samples Provided by Medical College of Wisconsin (MCW).

\begin{tabular}{llll}
\hline & & $\begin{array}{l}\text { Age (yrs) } \\
\text { Mean } \pm \text { SD }\end{array}$ & $\begin{array}{l}\text { PMI (hrs) } \\
\text { Mean } \pm \text { SD }\end{array}$ \\
& N & & \\
Age Group & & & \\
A $(<0.7$ Y) & 42 & $0.23 \pm 0.15$ & $18.1 \pm 8.21$ \\
B $(0.7-<3$ Y) & 3 & $2.24 \pm 0.32$ & $15.67 \pm 2.31$ \\
C $(3-<6$ Y) & 7 & $4.22 \pm 0.96$ & $17.43 \pm 9.43$ \\
D $(6-12$ Y) & 16 & $9.20 \pm 1.55$ & $21 \pm 7.28$ \\
Gender & & & \\
M & 45 & & \\
F & 23 & & \\
Unknown & 0 & & \\
Race & & & \\
Caucasian & 42 & & \\
Black & 22 & & \\
Others & 3 & & \\
Unknown & 1 & & \\
& & & \\
\hline PI post-mortem & & & \\
\hline
\end{tabular}

PMI, post-mortem interval. 
Table 2-3. Combined Patient Demographics for Human Pediatric Liver Samples for Protein Analysis.

\begin{tabular}{|c|c|c|}
\hline & $\mathrm{N}$ & $\begin{array}{l}\text { Age (Yrs) } \\
\text { Mean } \pm \text { SD }\end{array}$ \\
\hline \multicolumn{3}{|l|}{ Age Group } \\
\hline $\mathrm{A}(<0.7$ yrs $)$ & 48 & $0.26 \pm 0.17$ \\
\hline $\mathrm{B}(0.7-<3 \mathrm{Y})$ & 15 & $1.64 \pm 0.60$ \\
\hline $\mathrm{C}(3-<6 \mathrm{Y})$ & 16 & $3.97 \pm 0.89$ \\
\hline $\mathrm{D}(6-12 \mathrm{Y})$ & 33 & $9.0 \pm 1.75$ \\
\hline \multicolumn{3}{|l|}{ Donor Status } \\
\hline living & 45 & \\
\hline deceased & 67 & \\
\hline \multicolumn{3}{|l|}{ Gender } \\
\hline M & 61 & \\
\hline $\mathrm{F}$ & 44 & \\
\hline UNK & 7 & \\
\hline \multicolumn{3}{|l|}{ Race } \\
\hline Caucasian & 68 & \\
\hline Black & 28 & \\
\hline Others & 7 & \\
\hline Unknown & 9 & \\
\hline
\end{tabular}


RNAseOUT $^{\mathrm{TM}}$ recombinant RNase inhibitor, and $1 \mu \mathrm{L}$ of SuperScript ${ }^{\mathrm{TM}}$ III reverse transcriptase were added to each reaction vial. The mixture was then incubated for $50^{\circ} \mathrm{C}$ for 50 minutes and the reaction was terminated by increasing the temperature to $85^{\circ} \mathrm{C}$ for 5 minutes. The residual RNA was removed by adding $1 \mu \mathrm{L}$ of RNAse $\mathrm{H}$ and incubating at $37^{\circ} \mathrm{C}$ for 20 minutes. cDNA was stored at $-20^{\circ} \mathrm{C}$ until real-time RT-PCR was performed.

\section{Real Time RT-PCR}

Primers pairs and TaqMan probes for P-gp/MDR1, MRP2, PXR, CAR, FXR, and HNF4 $\alpha$ (TaqMan ${ }^{\circledR}$ Assay-on-Demand ${ }^{\text {TM }}$ Products) as well as the constitutively expressed reference gene cyclophilin A (TaqMan ${ }^{\circledR}$ Pre-Developed Assay Reagents for Gene Expression) were obtained from Applied Biosystems (Foster City, CA). All targeted $\mathrm{ABC}$ transporter and nuclear receptor probes were labeled with 6carboxyfluorescein (FAM)-dye while the cyclophilin A probe was labeled with VICTM dye. All of the probes were quenched by 6-carboxytetramethylrohodamine (TAMRA) on the 3' end. Target gene probe sequences are summarized in Table 2-4. In a 96-well reaction plate, $2.5 \mu \mathrm{L}$ of $20 \mathrm{X}$ TaqMan Probe, $22.5 \mu \mathrm{L}$ of human pediatric liver cDNA, and $25 \mu \mathrm{L}$ of $2 \mathrm{X}$ TaqMan Universal PCR Master Mix were added. The reaction was performed in duplicate for each sample. Real time reverse transcriptase-polymerase chain reaction (RT-PCR) was performed using the ABI Prism ${ }^{\circledR}$ Sequence Detection System 7000 (Applied Biosystems, Foster City, CA) using the default PCR thermal cycling conditions consisting of an initial TaqMan Universal PCR Master Mix activation at $50^{\circ} \mathrm{C}$ for $2 \mathrm{~min}$, followed by an initial denaturation step at $95^{\circ} \mathrm{C}$ for $10 \mathrm{~min}$, then 40 cycles of $95^{\circ} \mathrm{C}$ for $15 \mathrm{sec}$ and $60^{\circ} \mathrm{C}$ for 1 minute.

Relative mRNA quantification was achieved through the standard curve or $\mathrm{C}_{\mathrm{t}}$ (cycle threshold for target or endogenous control gene amplification) slope method. The average $C_{t}$ value was calculated from replicates of each sample using the ABI Sequence Detection System SDS software (Applied Biosystems, Foster City, CA). MRP1, MRP2, PXR, CAR, FXR, HNF4A, and cyclophilin A standard curves were prepared from serial dilutions of cDNA from a HepG2 cell line. Cyclophilin A (Cyc) was validated as the most stably transcribed reference gene across all age groups. Dilutions included 1, 2, 4, 8 , and 20 fold initial cDNA concentration $\left(\mathrm{C}_{0}\right)$. A plot of $\mathrm{C}_{\mathrm{t}}$, the point at which the amplification plot cross the threshold cycle value, vs. $\mathrm{C}_{0}$ was then constructed (Figure $2-1)$ as described by the assay manufacturer [78]. The threshold value was predetermined as 3 times the average baseline cycle value calculated from cycles $6-15$. The log concentration of the unknown samples was then calculated by linear regression from the standard curve. The absolute concentration was then determined by taking its antilog value. The expression level of each target gene was then calculated relative to the reference gene, cyclophilin A. 
Table 2-4. Primer Sequence for Target Gene-Specific 5' -(FAM)-Labeled TaqMan ${ }^{\circledR}$ Assay-on-Demand ${ }^{\mathrm{TM}}$ Human Probes.

\begin{tabular}{|c|c|c|c|c|}
\hline $\begin{array}{l}\text { Gene } \\
\text { Symbol }\end{array}$ & $\begin{array}{l}\text { Alternative } \\
\text { name }\end{array}$ & Probe 5'-3' & $\begin{array}{l}\text { NCBI Gene } \\
\text { Reference }\end{array}$ & $\begin{array}{l}\text { Target } \\
\text { Exons }\end{array}$ \\
\hline $\mathrm{ABCB} 1$ & P-gp/MDR1 & AGGTACCATACAGAAACTCTTTGAG & NM_000927 & 23 \\
\hline $\mathrm{ABCC} 2$ & MRP2 & ACСТCCAACAGGTGGCTTGCAATTC & NM_000392 & 25 \\
\hline NR1I2 & PXR & TACTTCAGGGACTTGCCCATCGAGG & NM_033013.1 & 5 \\
\hline NR1I3 & CAR & GCCCCGGGATCGGTTTCTGTATGCG & NM_005122.2 & 6 \\
\hline NR1H4 & FXR & ACAAAAAAGCTACCAGGATTTCAGA & NM_005123.1 & 8 \\
\hline HNF4A & HNF4A & AAGGAAGCCGTCCAGAATGAGCGGG & NM_178849.1 & 3 \\
\hline
\end{tabular}




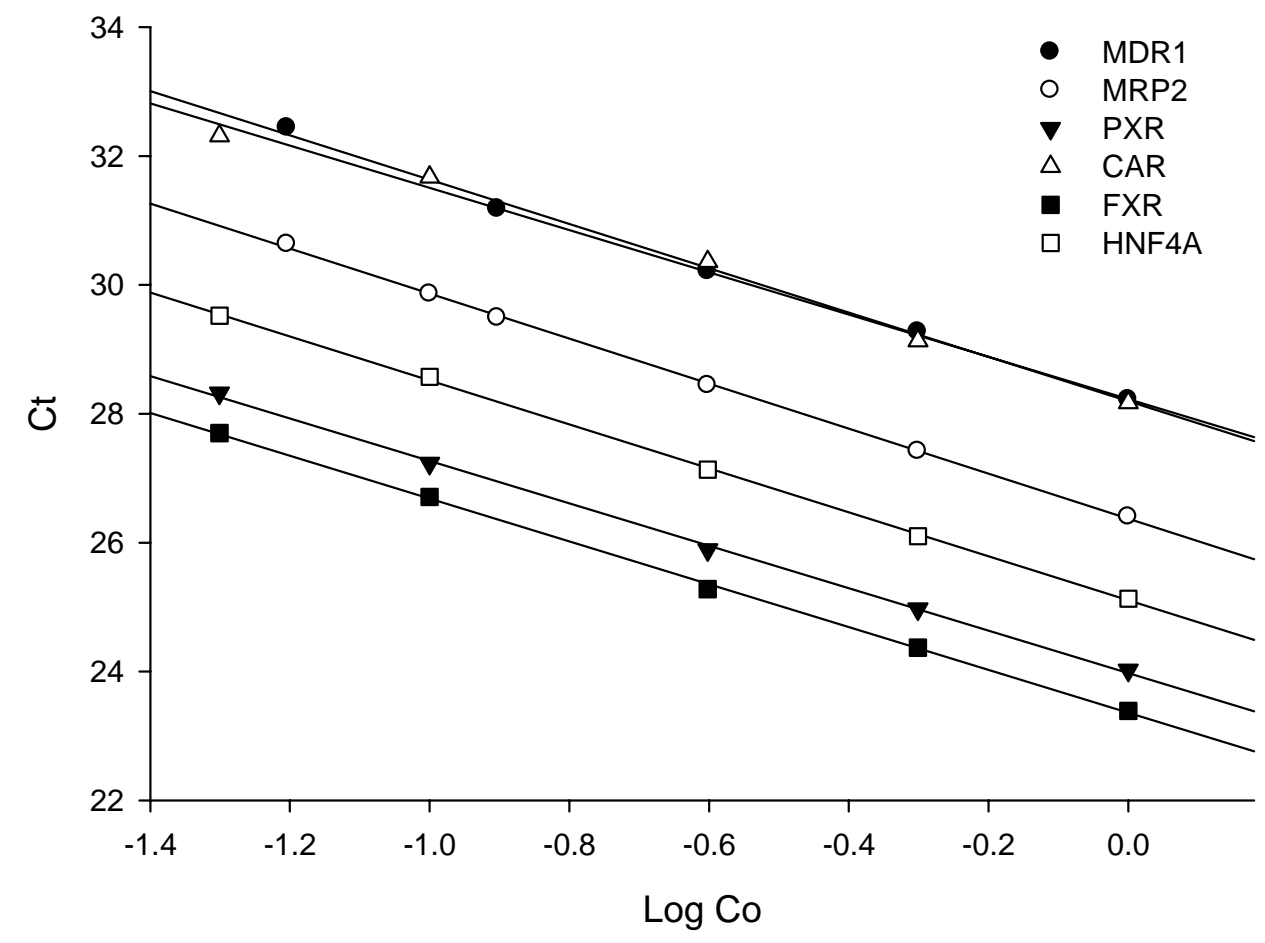

Figure 2-1. Calibration Curve for MDR1, MRP2, PXR, CAR, FXR, and HNF4 $\alpha$. All targeted genes calibration curves have slopes of approximately -3.3 , indicating an amplification efficiency of close to 1 within the linear range. $\mathrm{C}_{t}$, cycle threshold; $\mathrm{C}_{0}$, initial cDNA concentration 


\section{Tissue Membrane Protein Isolation}

Liver tissue membrane protein for all human pediatric samples acquired from St. Jude Liver Bank was extracted by the ultracentrifugation method. Briefly, approximately 2 grams of frozen liver tissue, after quick thawing in a $37^{\circ} \mathrm{C}$ water bath, was homogenized in $10 \mathrm{~mL}$ of homogenization buffer consisting of $0.1 \mathrm{M}$ Tris $\mathrm{pH} 7.4,0.1 \mathrm{M}$ potassium chloride (KCL), $0.02 \mathrm{mM}$ butylated hydroxytoluene (BHT), and $1 \mathrm{mM}$ ethylenediamine tetraacetic acid (EDTA). The tissue was further homogenized with a Teflon pestle at $800 \mathrm{rpm}$. The homogenate was centrifuged at $12,000 \mathrm{~g}$ for $15 \mathrm{~min}$ at $4^{\circ} \mathrm{C}$. The supernatant was discarded and the remaining pellet consisting of membrane proteins was resuspended in $5 \mathrm{~mL}$ of membrane storage buffer consisting of $20 \%$ glycerol, $1 \mathrm{mM}$ DTT, $0.02 \mathrm{mM}$ BHT, and 0.1 potassium phosphate (KPO4) $\mathrm{pH}$ 7.25. Aliquots of the membrane protein were prepared and stored in $-70^{\circ} \mathrm{C}$ freezer until further processing.

All membrane protein for samples received from the Medical College of Wisconsin were extracted by Calbiochem ${ }^{\circledR}$ ProteoExtract ${ }^{\circledR}$ Native Membrane Protein Extraction Kit (M-PEK). Briefly, approximately $50 \mathrm{mg}$ of liver tissue was homogenized in $2 \mathrm{~mL}$ of Extraction Buffer I and incubated for 10 minutes at $4^{\circ} \mathrm{C}$ under gentle agitation on a rotary shaker. The homogenate was centrifuged for 15 minutes at $16,000 \mathrm{~g}$ and $4^{\circ} \mathrm{C}$. The supernatant was discarded and the pellet resuspended in $1 \mathrm{~mL}$ of Extraction Buffer II. The cell pellet was then incubated for 30 minutes at $4{ }^{\circ} \mathrm{C}$ again under gentle agitation on a rotary shaker. The cell suspension was centrifuged a second time at $16,000 \mathrm{x}$ g and $4{ }^{\circ} \mathrm{C}$ for 15 minutes. The resulting supernatant enriched in membrane proteins was then transferred to a fresh tube and stored in aliquots at $-70^{\circ} \mathrm{C}$ until further processing.

Protein quantification was determined through the Bradford assay [79] using bovine serum albumin (BSA; Sigma-Aldrich) as the standard. Using a 96 well plate, stock BSA solution $(0.2 \mathrm{mg} / \mathrm{mL})$ was diluted to a final concentration ranging from $0-30 \mu \mathrm{g} / \mathrm{mL}$ with deionized water $(\mathrm{dH} 20)$ in the standard wells. In the sample wells, $1 \mu \mathrm{L}$ of membrane protein from each pediatric liver sample was diluted in $199 \mu \mathrm{lof} \mathrm{dH} 20.50 \mu \mathrm{L}$ of Protein Assay Dye Reagent Concentrate (Bio-Rad; complete information) was added to each well and mixed thoroughly. All protein standards and unknown samples were repeated in triplicates. The plate was incubated for 5 minutes at room temperature and the protein absorbance was read on a microplate reader at $595 \mathrm{~nm}$. A standard curve using the standard BSA absorbance (A) versus concentration was constructed. All unknown protein concentrations were subsequently calculated by linear regression. 20 $\mu \mathrm{g}$ of membrane protein from each liver sample was used for protein quantification.

\section{SDS-PAGE/Western Blotting}

To $20 \mu \mathrm{g}$ of pediatric liver membrane protein, $2.5 \mathrm{~mL}$ of NuPAGE® LDS Sample Preparation Buffer (Invitrogen, Carlsbad, CA) was added. The samples were fractionated via sodium dodecylsulfate polyacrylamide gel electrophoresis (SDS-PAGE) using NuPAGE® 4 - 12 \% Bis-Tris Polyacrylamide Gel with 1X NuPAGE® MOPS 
Running buffer at $200 \mathrm{~V}$ for 1 hour. On each gel, we also included a MultiMark ${ }^{\circledR}$ MultiColored Protein Standard (Invitrogen, Carlsbad, CA) as well as positive controls for both MDR1/P-gp and MRP2. Human P-gp membrane preparation (Human PGP membranes) and MRP2 membrane preparations (Human MRP2 membranes) were purchased from BD Gentest ${ }^{\mathrm{TM}}$ (Woburn, MA) and served as positive controls. The separated proteins were transferred overnight onto an Invitrolon ${ }^{\mathrm{TM}}$ Polyvinylidene fluoride (PVDF) $0.2 \mu \mathrm{m}$ membrane at $30 \mathrm{~V}$ using NuPAGE® $1 \mathrm{X}$ Transfer Buffer with 10\% methanol.

Nonspecific binding sites on the PVDF membrane were blocked using 5\% nonfat dried milk in phosphate buffered saline (PBS) with $0.1 \%$ Tween $(\mathrm{T})$ for one hour at room temperature. The membrane was then incubated with the primary monoclonal antibody to P-gp (C219) (Alexis Biochemicals, San Diego, CA) diluted 1:100 fold, MRP2 (M2III6) (Alexis Biochemical, San Diego, CA) diluted 1:200 fold, or glyceraldehyde 3phosphate dehydrogenase (GAPDH, Sigma-Aldrich, St. Louis, MO) diluted 1:10000 fold in 5\% nonfat dried milk in PBS with $0.1 \%$ Tween (PBST) for 2 hours at room temperature. After discarding the primary antibody, the membrane was washed 3 times with PBST each time for 5 minutes. The membrane was then incubated for one hour with the secondary antibody, horseradish peroxidase-conjugated (HRP) Anti-Mouse IgG (Cell Signaling Technology, Danvers, MA), diluted in 5\% nonfat dried milk in PBST either 1:5000 fold when probing P-gp and MRP2, or 1:10000 fold when probing for GAPDH. GAPDH was chosen as the reference protein for the relative protein quantification since it was more stably expressed as compared to cyclophilin A. After 3 5 minute washings with PBST, the blots were then incubated with enhanced chemiluminescence ECL plus ${ }^{\mathrm{TM}}$ (GE Healthcare, Piscataway, NJ) for 5 minutes, and developed on Kodak ${ }^{\circledR}$ Biomax ${ }^{\mathrm{TM}}$ XAR autoradiography film (Sigma-Aldrich, St. Louis, $\mathrm{MO}$ ) after 1 minute and 3 minute exposure times. Protein band density was quantified using ImageJ [80] after digitizing the image using a flatbed scanner.

\section{Statistical Analysis}

All statistical analysis was performed using SPSS 14.0 (SPSS Inc., Chicago, IL). During real time PCR, an amplification plot, reported as $\Delta \mathrm{Rn} v \mathrm{vs}$. $\mathrm{C}_{\mathrm{t}}$, was generated for each sample (Figure 2-2). $\Delta \mathrm{Rn}$ represented the fluorescence emission intensity of the reporter minus the threshold Rn. Threshold Rn was determined from the pre-set baseline. The $C_{t}$ value for each sample was then used to back calculate an initial input amount by using the equation derived from the calibration curve regression line. All data were back$\log$ transformed in order to achieve homoscedasticity, and target gene values were then normalized to the endogenous control cyclophilin A. In order to achieve adequate power for statistical analysis, the liver samples were divided into four different age groups (A D). Group A included infants less than 8 months of age $(<0.7$ years), group B represented infants from 8 months to 3 years of age $(0.7-<3$ years), group $C$ included those in the early childhood period from 3 years to 6 years of age ( $3-<6$ years), and group D included those in the late childhood period from 6 to 12 years of age (6-12 year). Samples where relative expression values were 1.5 times outside the 25 th and 75 th percentiles were considered outliers and removed prior to statistical analysis. Less than 


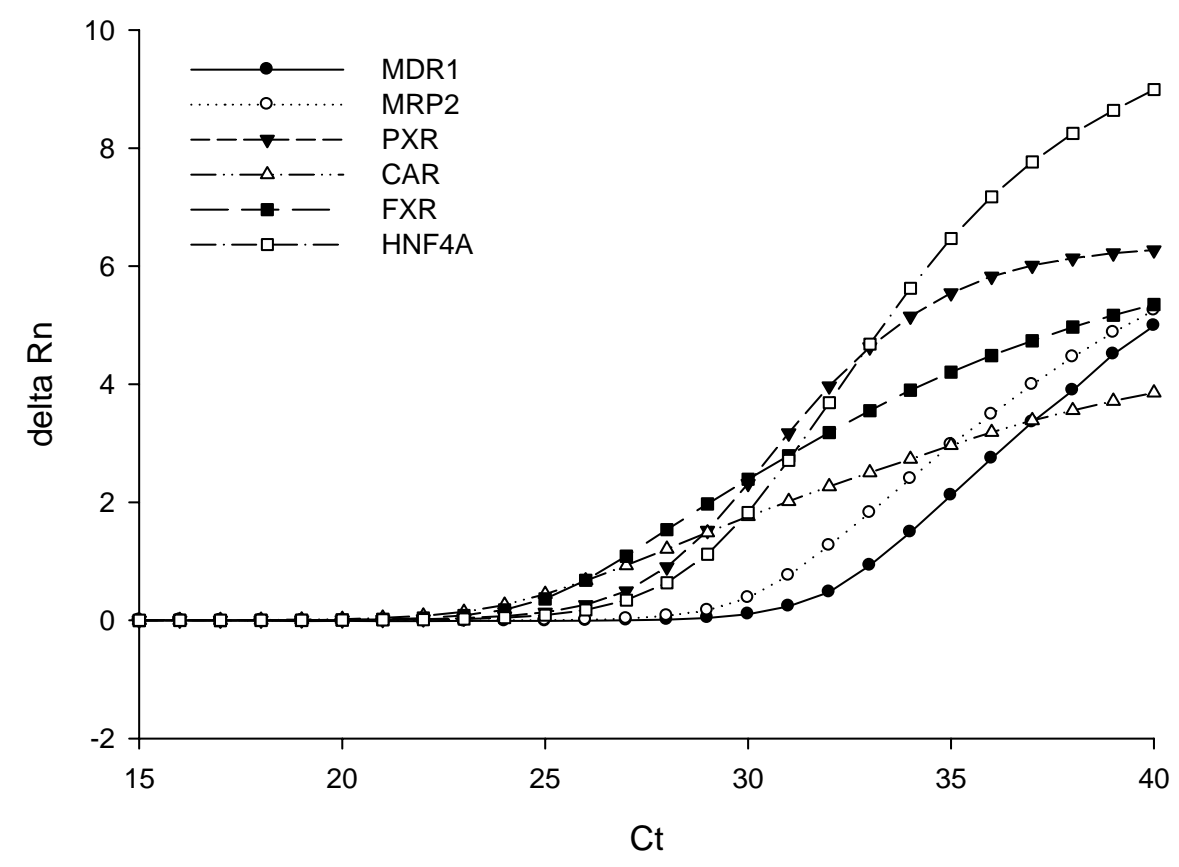

Figure 2-2. Representative Real Time PCR Amplification Plot for Target Human Genes.

$C_{t}$, cycle threshold; $\Delta R_{n}$, emission intensity of the reporter minus the threshold $R_{n}$. 
$15 \%$ of the total sample size was considered outliers for each of the targeted gene expression. Statistical comparison of mean values for target gene expression between each group was performed using one-way ANOVA with Bonferroni post-hoc test.

$$
\text { Target gene mRNA expression }=\frac{\text { Initial amount of } t \text { arg } \text { et gene }}{\text { Initial amount of reference gene }}
$$

Mean \pm standard deviation (SD) values for all relative target gene mRNA expression were calculated for each age group. Asterisks represent statistically significant differences $(\mathrm{p}<0.05)$ in mean normalized mRNA expression between group $\mathrm{A}$ and the other age group(s). Correlation between the nuclear receptors themselves and between the nuclear receptors and MDR1/P-gp and MRP2 was determined by linear regression analysis. The goodness of fit is denoted by the $r^{2}$ value and significance determined by the $F$ test for simple linear regression.

P-gp and MRP2 protein expression was detected by immunoblotting and quantified by band density. The GAPDH bands were included in order to verify equal amount of protein loading for each sample. Additionally, GAPDH was used as a reference gene in order to normalize the P-gp and MRP2 protein density. Each blot was verified as within the linear range by comparing the 1 minute versus the 3 minute exposure. Linearity curves constructed from known protein concentrations of control P-gp and MRP2 membranes were also performed in order to verify linearity. Non-detectable sample values were assigned a zero value and all data points were included in the analysis. 


\section{Results}

\section{mRNA Expression of MDR1/P-gp and MRP2 in Human Pediatric Liver Samples}

Using real time RT-PCR methodology, we were able to detect both ABC transporters MDR1 and MRP2 in all human pediatric liver samples. Limited MDR1 and MRP2 mRNA expression was detected in the youngest age group - A (age range from $0.25-<0.7$ years old; approximately $4-8$ months) but markedly increased with maturation (Figure 2-3). Ontogenic mRNA expression of MDR1 and MRP2 was statistically significant between the youngest age group A and age group B.

Interestingly, age group B MDR1 and MRP2 mRNA expression level surpassed not only age group $\mathrm{A}$, but also age groups $\mathrm{C}$ and $\mathrm{D}$. For MDR1, age groups $\mathrm{A}, \mathrm{B}$, and $\mathrm{C}$ were $36 \%, 157 \%$, and $129 \%$ relative to age group $\mathrm{D}$, respectively. In a similar pattern, MRP2 gene expression for age groups $\mathrm{A}, \mathrm{B}$, and $\mathrm{C}$ were $25 \%, 127 \%, 118 \%$ relative to age group D. Though relative expression values in age groups $\mathrm{C}$ and $\mathrm{D}$ for MDR1 and MRP2 were higher than those in age group A, it was not statistically significant. There appeared to be high variability in expression of the ABC transporters regardless of age group. Coefficient of variation for MDR 1 ranged from $44-77 \%$ while those of MRP2 ranged from $13-72 \%$. Normalized mRNA expression values for individual human pediatric liver samples for MDR1 and MRP2 within each age group are represented in scatterplots. The values are also summarized in box and whiskers plots within each age group (Figure 2-4 and Figure 2-5).

\section{mRNA Expression of Orphan Nuclear Receptors (NRs) in Human Pediatric Liver Samples}

Nuclear receptors PXR, CAR, FXR, and HNF4 $\alpha$ mRNA expression overall showed very little age associated development as compared to the ontogenic expression exhibited by MDR1 and MRP2 (Figure 2-6 to Figure 2-9). However, a general trend was observed for PXR, FXR, and HNF4 $\alpha$ where expression levels were lowest in the youngest age group but increased to maximal levels by age groups $\mathrm{B}$ or $\mathrm{C}$, and eventually decreased by age group D. CAR expression appeared considerably different than the other nuclear receptors. Expression level for CAR was actually highest in the youngest age group and gradually decreased with an increase in age. Of all the nuclear receptors, FXR mRNA expression in the youngest age group A was the only group which exhibited significantly a lower expression value than the other age groups.

In accordance with a recently published study [77], we were able to confirm the coexpression between the mRNA expression of PXR, CAR, and HNF4 $\alpha$ (Figure 2-10). Specifically, in human pediatric liver samples, $\mathrm{HNF} 4 \alpha$ was positively correlated with $\operatorname{PXR}\left(\mathrm{r}^{2}=0.16, \mathrm{p}=0.002\right)$ and $\operatorname{CAR}\left(\mathrm{r}^{2}=0.14, \mathrm{p}=0.003\right)$. While the literature supports evidence of HNF4 $\alpha$ regulation of PXR and CAR, there have been no reports of HNF4 $\alpha$ associated regulation of FXR. We were able to provide evidence for the lack of correlation between HNF4 $\alpha$ and FXR $\left(r^{2}=0.008, p=0.49\right)$. 


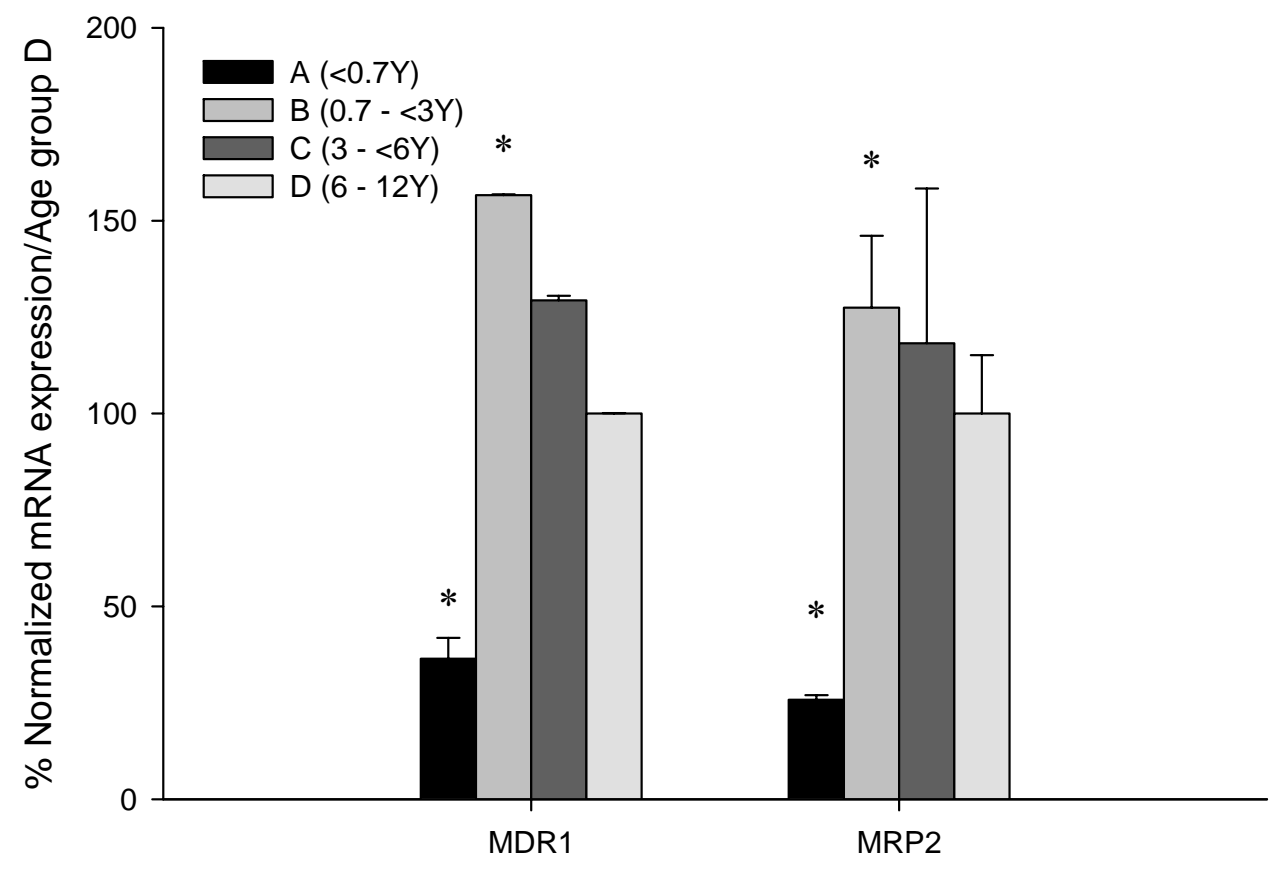

Figure 2-3. Normalized Target Gene Expression.

Relative target gene expression levels in human pediatric liver samples are represented as percentages (mean $\pm \mathrm{SEM}$ ) of those observed for the oldest age group D. Asterisks represent significant differences $(\mathrm{p}<0.05)$ in mean normalized target gene expression between age group A versus the other age group(s). Y, years. 

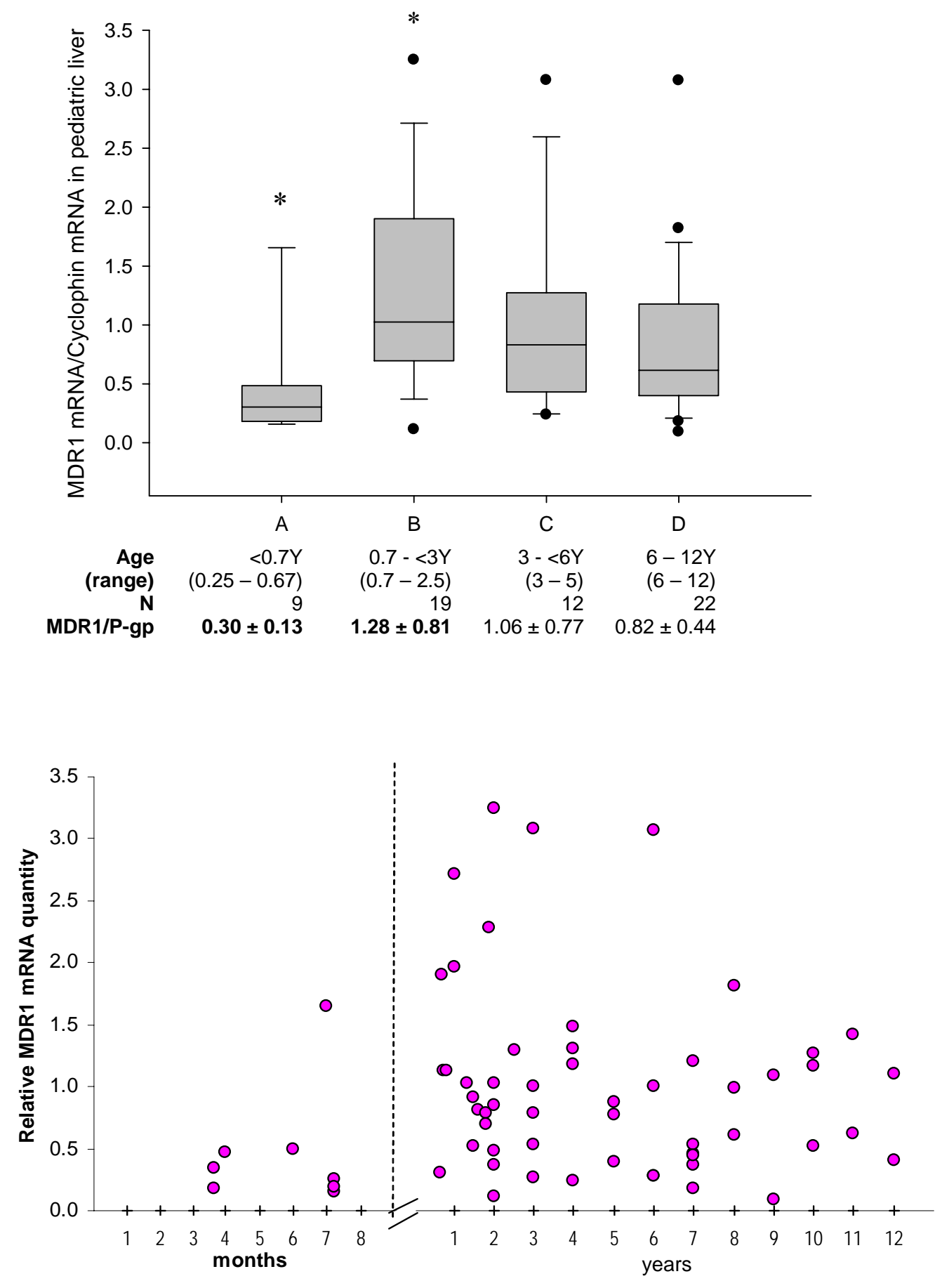

Figure 2-4. mRNA Expression of MDR1/P-gp in Human Pediatric Liver Samples. Upper panel, box and whisker plot of cyclophilin A normalized MDR1 mRNA expression. Boxes represent 25 th and 75 th percentiles and horizontal bars represent 10th and 90th percentiles while open circles represent outliers. Mean \pm SD for each age group are reported. Lower panel, scatterplot of cyclophilin A normalized MDR1 mRNA expression versus age. $\mathrm{X}$-axis is on a discontinuous scale ranging from $0-8$ months and $>8$ months -12 years. 

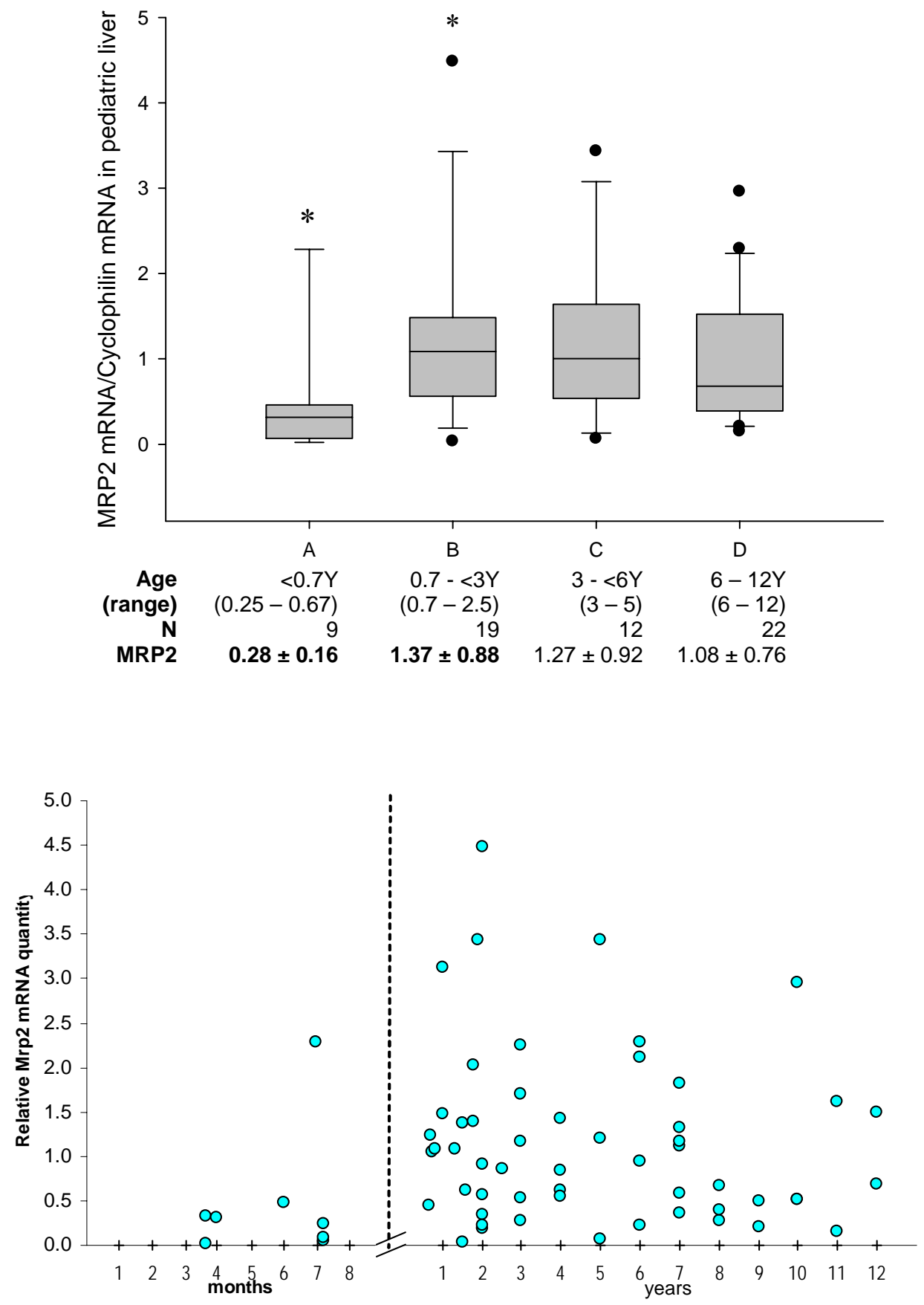

Figure 2-5. mRNA Expression of MRP2 in Human Pediatric Liver Samples. Upper panel, box and whisker plot of cyclophilin A normalized MRP2 mRNA expression. Boxes represent 25th and 75th percentiles and horizontal bars represent 10th and 90th percentiles while open circles represent outliers. Mean \pm SD for each age group are reported. Lower panel, Scatterplot of cyclophilin A normalized MRP2 mRNA expression versus age. $\mathrm{X}$-axis is on a discontinuous scale ranging from $0-8$ months and $>8$ months -12 years. 

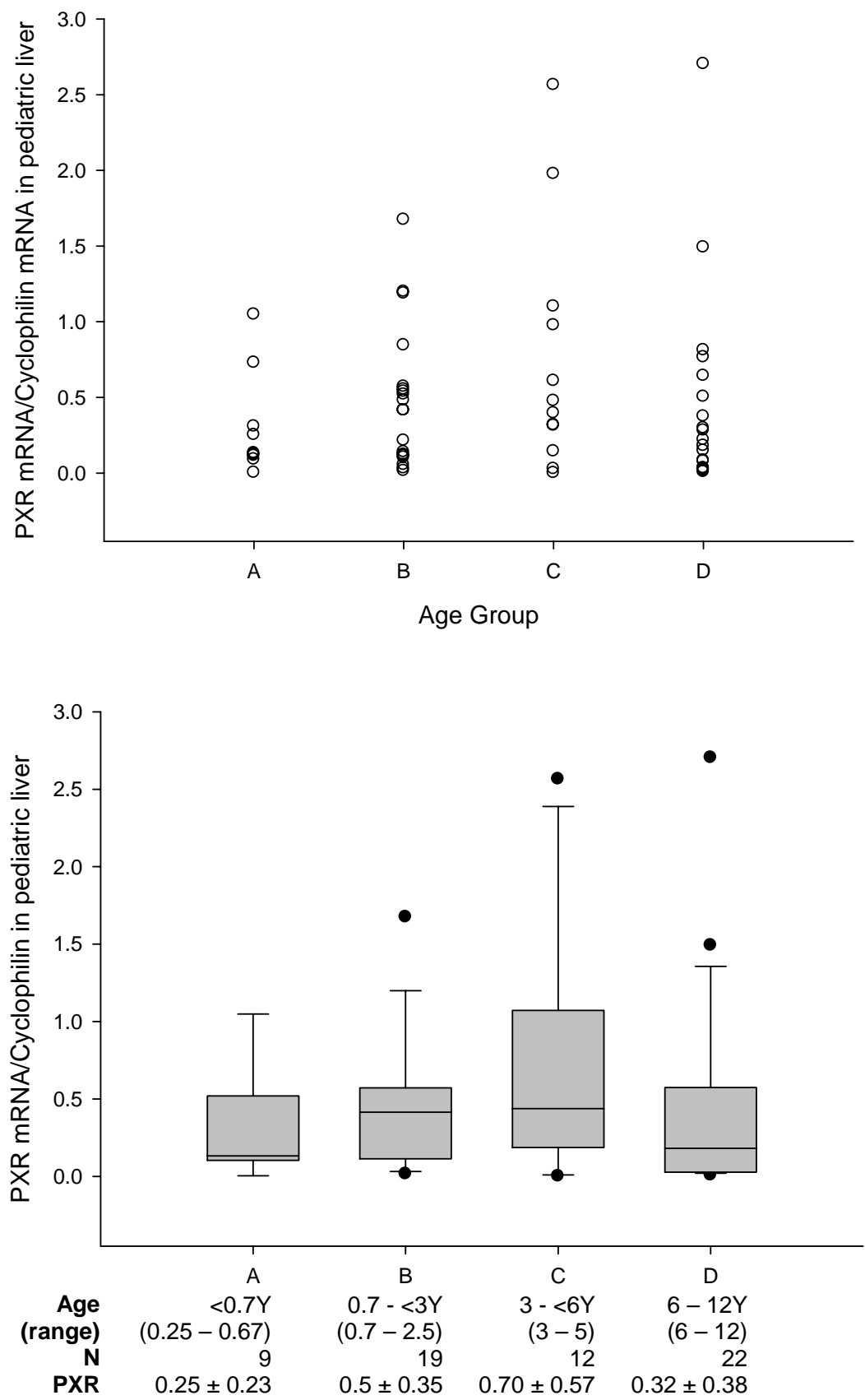

Figure 2-6. $\quad$ mRNA Expression of PXR in Human Pediatric Liver Samples. Upper panel, scatterplot representation of cyclophilin A normalized PXR mRNA expression for individual liver samples vs. Age group. Lower panel, box and whiskers plot of cyclophilin A normalized PXR mRNA expression in each age group. Boxes represent 25 th and 75 th percentiles, horizontal bars represent 10th and 90th percentiles, and circles represent outliers. Values indicate mean \pm SD excluding outliers. 

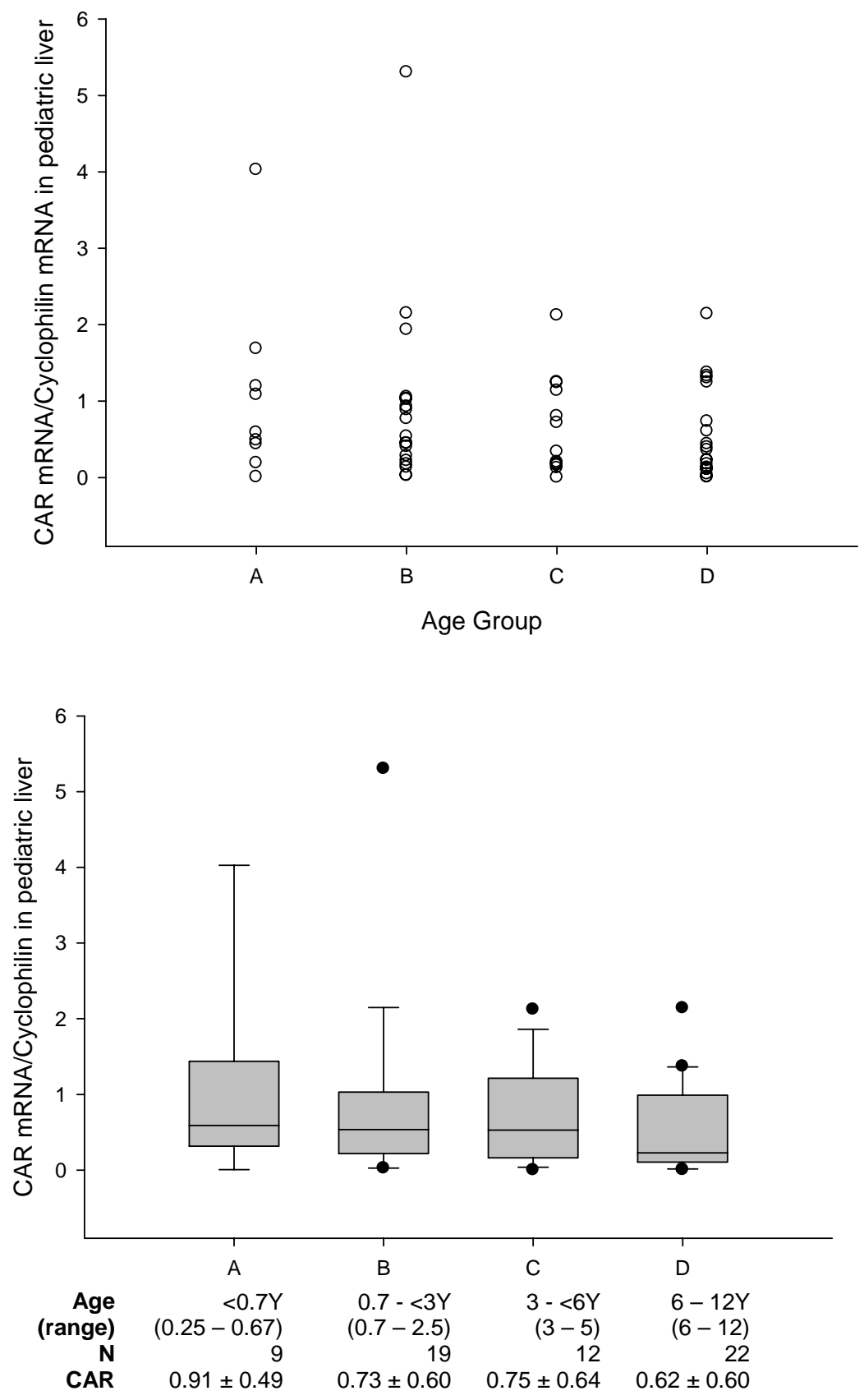

Figure 2-7. mRNA Expression of CAR in Human Pediatric Liver Samples. Upper panel, scatterplot representation of cyclophilin A normalized CAR mRNA expression for individual liver samples vs. Age group. Lower panel, box and whiskers plot of cyclophilin A normalized CAR mRNA expression in each age group. Boxes represent 25 th and 75 th percentiles, horizontal bars represent 10 th and 90th percentiles, and circles represent outliers. Values indicate mean \pm SD excluding outliers. 

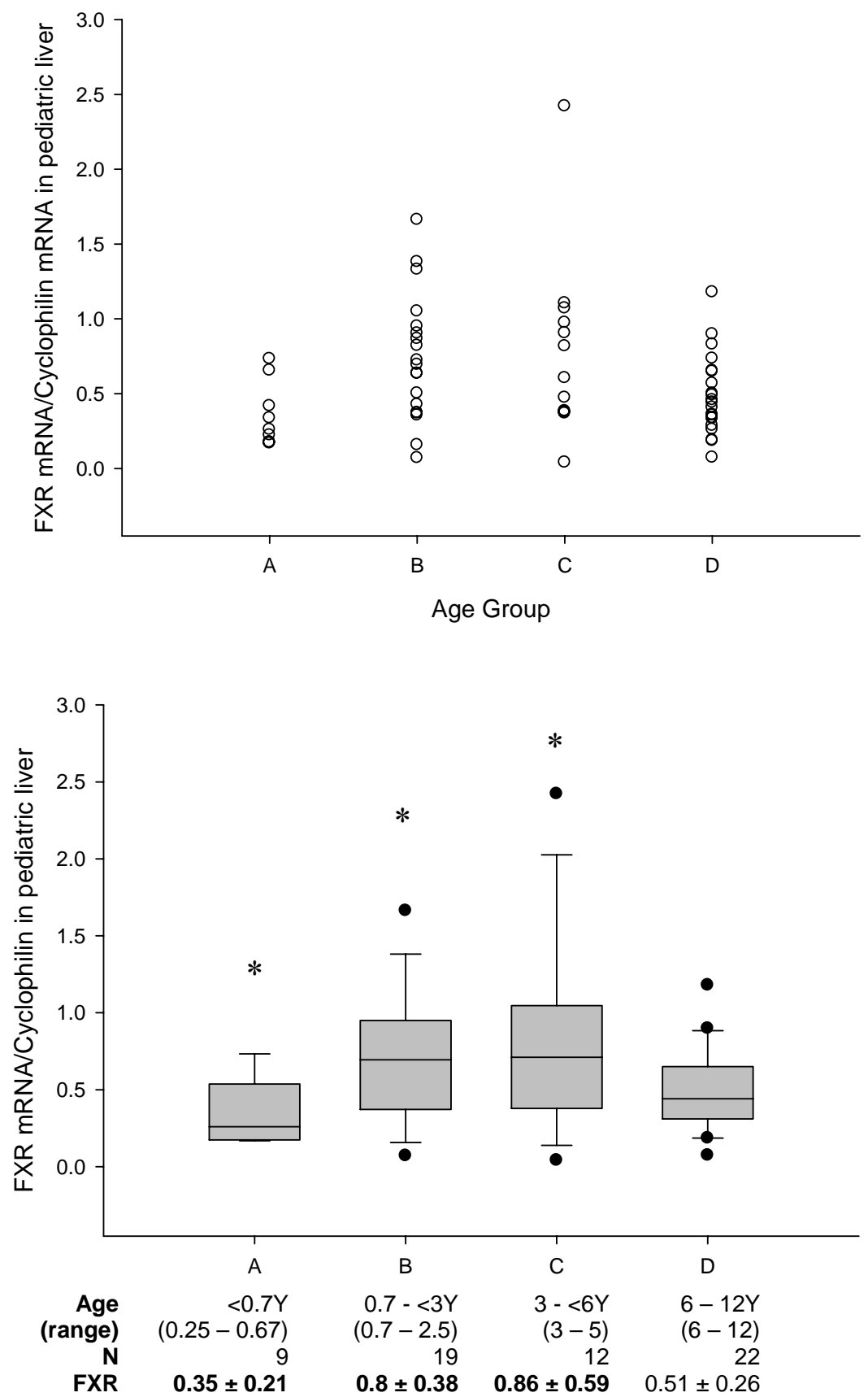

Figure 2-8. mRNA Expression of FXR in Human Pediatric Liver Samples.

Upper panel, scatterplot representation of cyclophilin A normalized FXR mRNA expression for individual liver samples vs. Age group. Lower panel, box and whiskers plot of cyclophilin A normalized FXR mRNA expression in each age group. Boxes represent 25 th and 75 th percentiles, horizontal bars represent 10 th and 90th percentiles, and circles represent outliers. Values indicate mean \pm SD excluding outliers. Asterisks indicate significant differences in mean target gene expression between age group A and the other age group(s) indicated. 

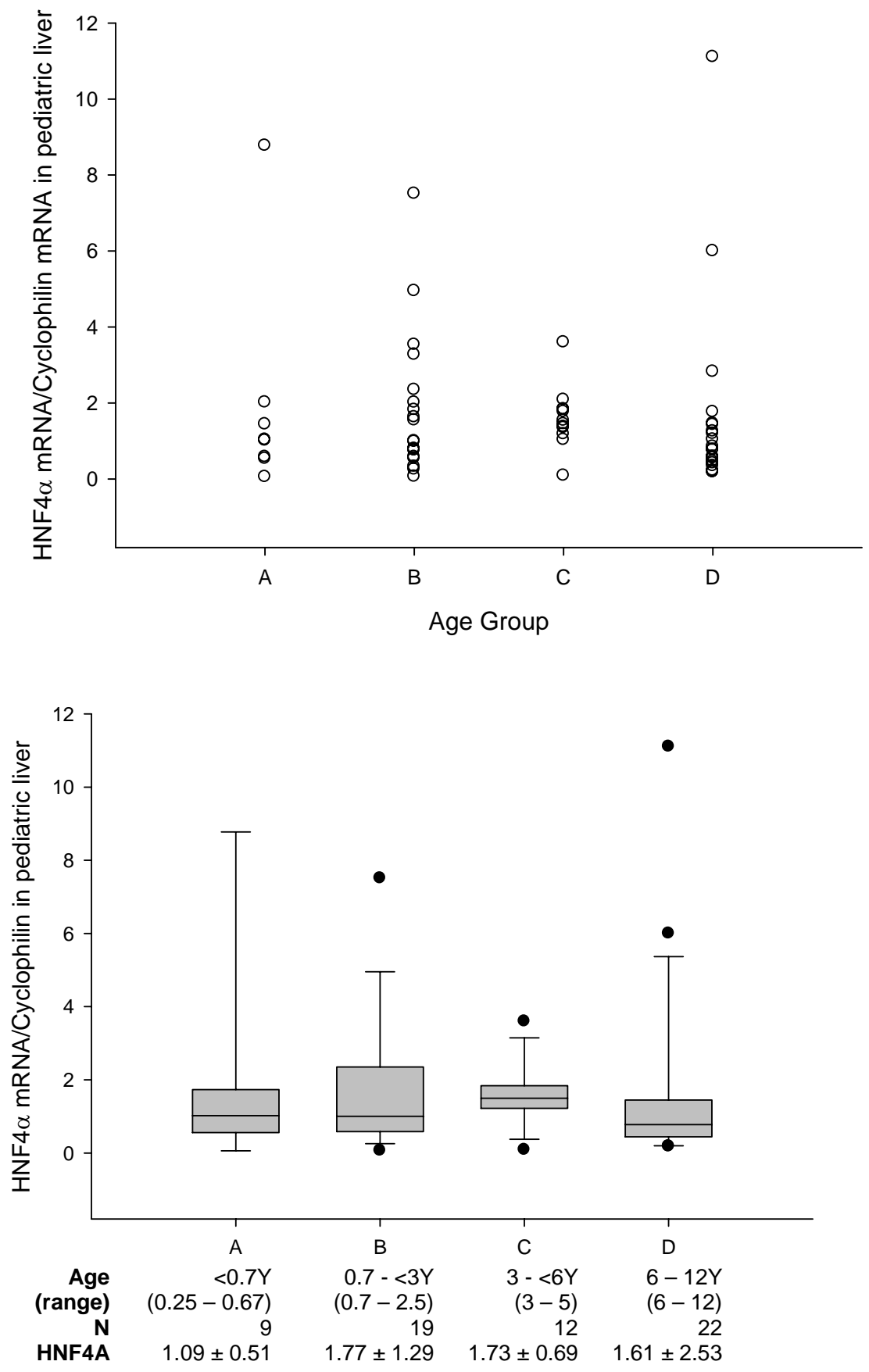

Figure 2-9. mRNA Expression of HNF4 $\alpha$ in Human Pediatric Liver Samples. Upper panel, scatterplot representation of cyclophilin A normalized HNF4 $\alpha$ mRNA expression for individual liver samples vs. Age group. Lower panel, box and whiskers plot of cyclophilin A normalized HNF4 $\alpha$ mRNA expression in each age group. Boxes represent 25 th and 75 th percentiles, horizontal bars represent 10 th and 90 th percentiles, and circles represent outliers. Values indicate mean \pm SD excluding outliers. 


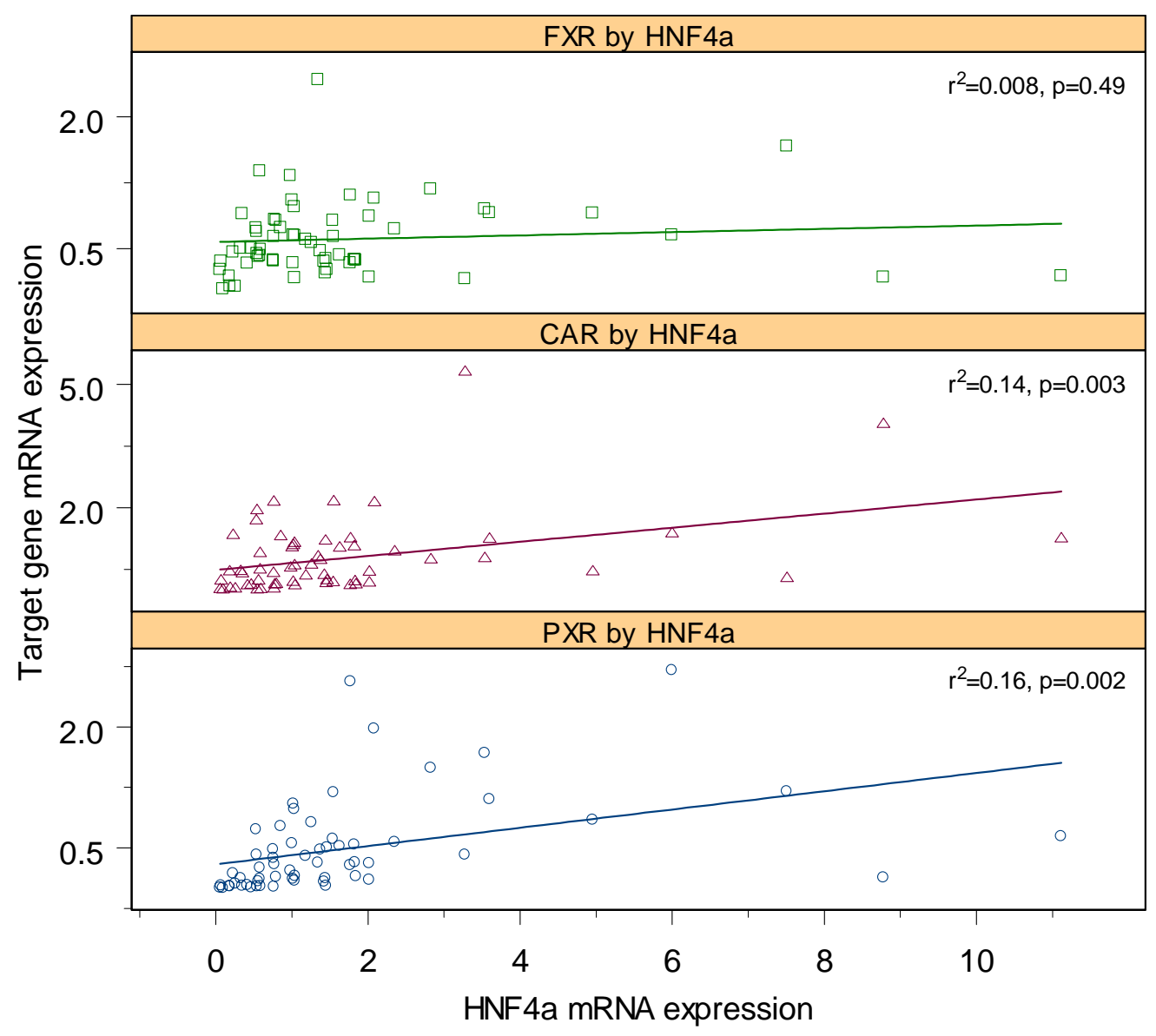

Figure 2-10. HNF4 $\alpha$ Correlations in Human Pediatric Liver Samples.

Correlations between normalized target mRNA expression for nuclear receptors PXR, CAR, and FXR versus normalized HNF4 $\alpha$ mRNA levels. X-axis represents normalized HNF4 $\alpha$ mRNA expression levels. Y-axis is split into 3 different panels each representing normalized PXR, CAR, or FXR mRNA expression values. Correlation between HNF4 $\alpha$ and the corresponding nuclear receptor is indicated by the $\mathrm{r} 2$ value. P-values are reported as well. 
We also explored the correlations between the nuclear receptors and the drug transporters (Figure 2-11 to Figure 2-13). Expression of PXR was positively correlation with MDR1 $\left(r^{2}=0.20, p=0.001\right)$ and to a lesser extent with MRP2 $\left(r^{2}=0.07, p=0.04\right)$. In contrast, expression of CAR did not correlate with the expression of either drug transporters. FXR expression in the human pediatric liver positively correlated with both MDR1 $\left(\mathrm{r}^{2}=0.19, \mathrm{p}=0.001\right)$ and MRP2 $\left(\mathrm{r}^{2}=0.13, \mathrm{p}=0.01\right)$ mRNA expression.

\section{Protein Expression of MDR1 and MRP2}

Western blot analysis of human pediatric liver samples revealed a single band at $\sim 170 \mathrm{kDa}, \sim 190 \mathrm{kDa}$, and $\sim 40 \mathrm{kDa}$ corresponding to P-gp, MRP2, and GAPDH, respectively (Figure 2-14). The successful detection of P-gp and MRP2 was verified by their positive controls. Normalized protein expression was lowest in age group A as compared to the other age groups for both P-gp and MRP2 (Figure 2-15). Age group B had the highest measured P-gp and MRP2 protein expression as compared to all other age groups. After reaching the maximal expression level in age group B, both P-gp and MRP2 protein levels gradually decreased with increase in age. Variability in protein expression for both transporters was high regardless of age group. Coefficient of variation for P-gp ranged from 59-67\% while those of MRP2 ranged from $46-90 \%$.

P-gp was non-detectable for $2 \%$ of the samples in age group A, but $100 \%$ was detected in all other age groups (Figure 2-15). MRP2 was non-detectable in 50\% of the samples in age group A, but detectable in $87 \%, 94 \%$ and $97 \%$ in age group B, C, and D (Figure 2-16). There were no significant differences in $\mathrm{P}$-gp protein expression between the various age groups. However for MRP2, protein expression was significantly higher in age groups $B(p<0.001), C(p<0.01)$, and $D(p<0.05)$ than age group A.

\section{Discussion}

This study described the ontogeny of ABC transporters MDR1, MRP2, and of orphan nuclear receptors PXR, CAR, FXR, and HNF4 $\alpha$ in human pediatric liver samples using real time RT-PCR and Western immunoblotting techniques. While there have been some published reports on the age associated expression of Mdr1/P-gp, Mrp2, as well as selected nuclear receptors in animal models, there lacked sufficient evidence for the same association in human transporter development. One of the main barriers in conducting such studies in humans has been simply the lack of availability of human pediatric samples. Furthermore, archived samples in human tissue banks have often originated from donors diagnosed with disease (i.e. cancer), tissue pathologies, or exposure to drug therapy which may alter the expression of drug transporters or nuclear factors. Also, a majority of samples stored in tissue banks originated from post-mortem donors. Unfortunately, RNA from post-mortem samples often has been unusable due to their rapid degradation by RNAses prior to cryopreservation. In the present study, we were fortunate to obtain a large number of pediatric liver tissues preserved from living donors. As such, we were able to extract intact RNA as well as membrane proteins from these liver biopsies. However, in order to gather more information regarding transporter 


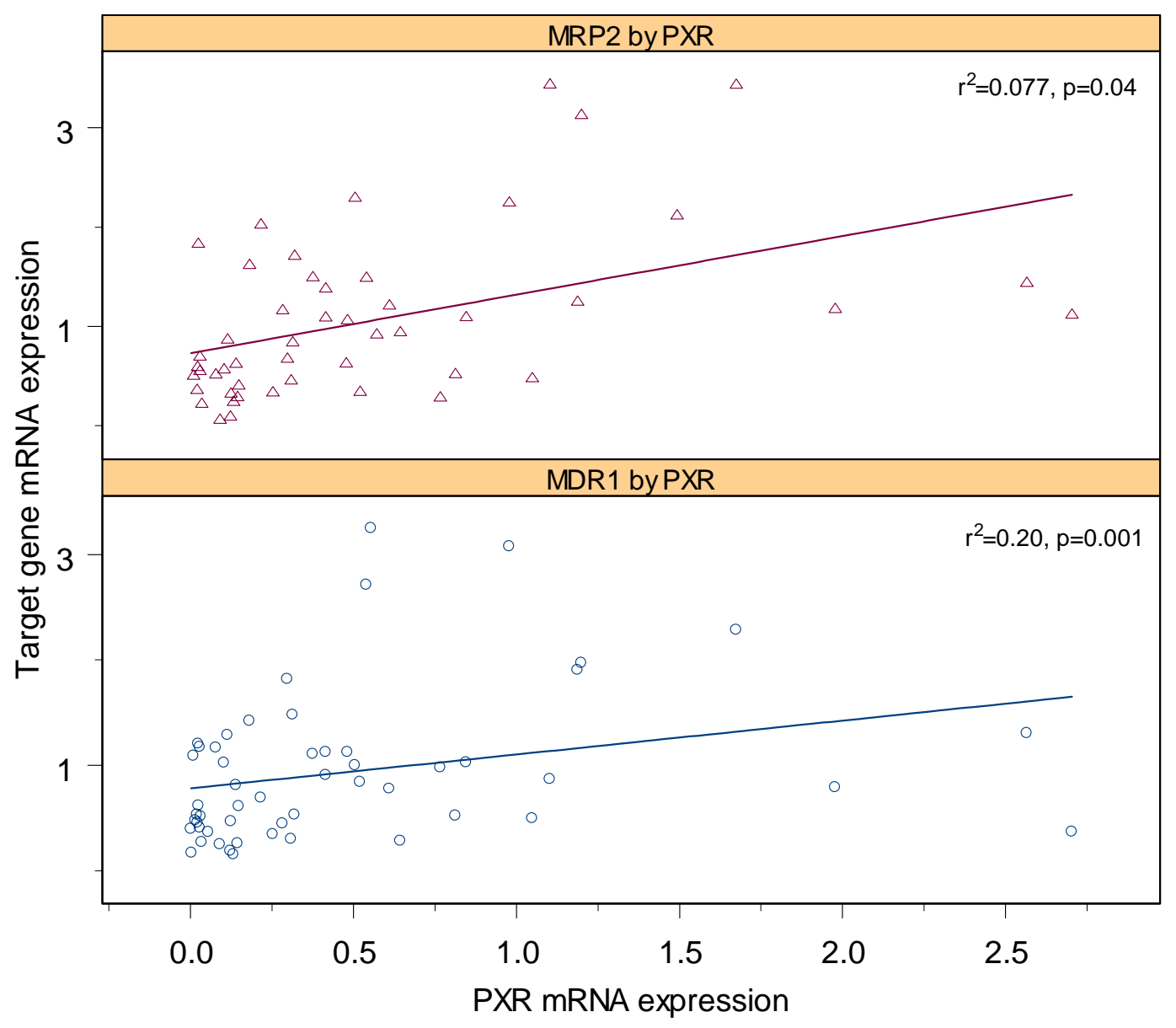

Figure 2-11. PXR Correlations to MDR1 and MRP2.

Correlation between normalized target mRNA expression for MDR1 and MRP2 mRNA expression versus normalized PXR mRNA levels. 


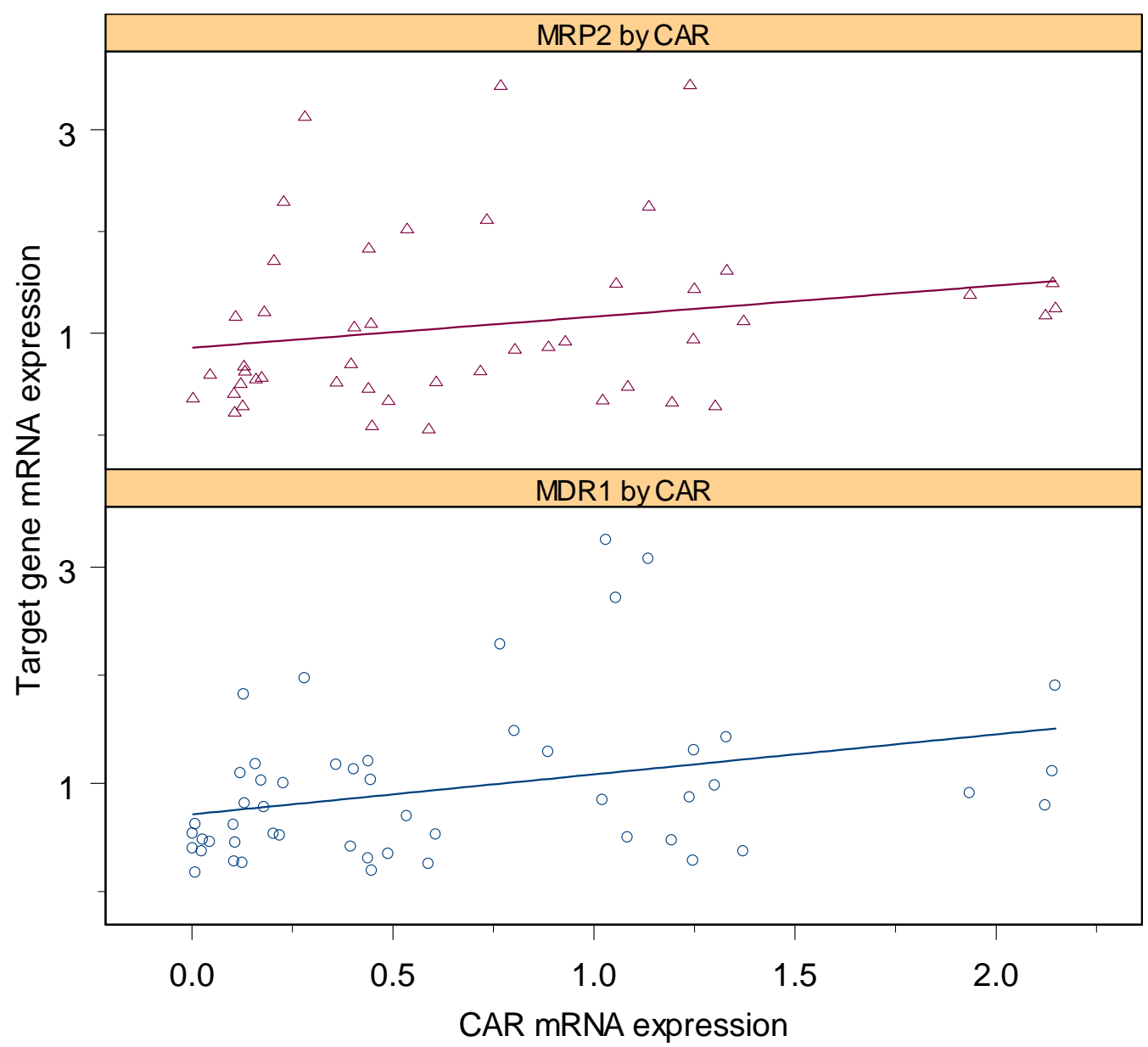

Figure 2-12. CAR correlations to MDR1 and MRP2.

Correlation between normalized target mRNA expression for MDR1 and MRP2 mRNA expression versus normalized CAR mRNA levels. 


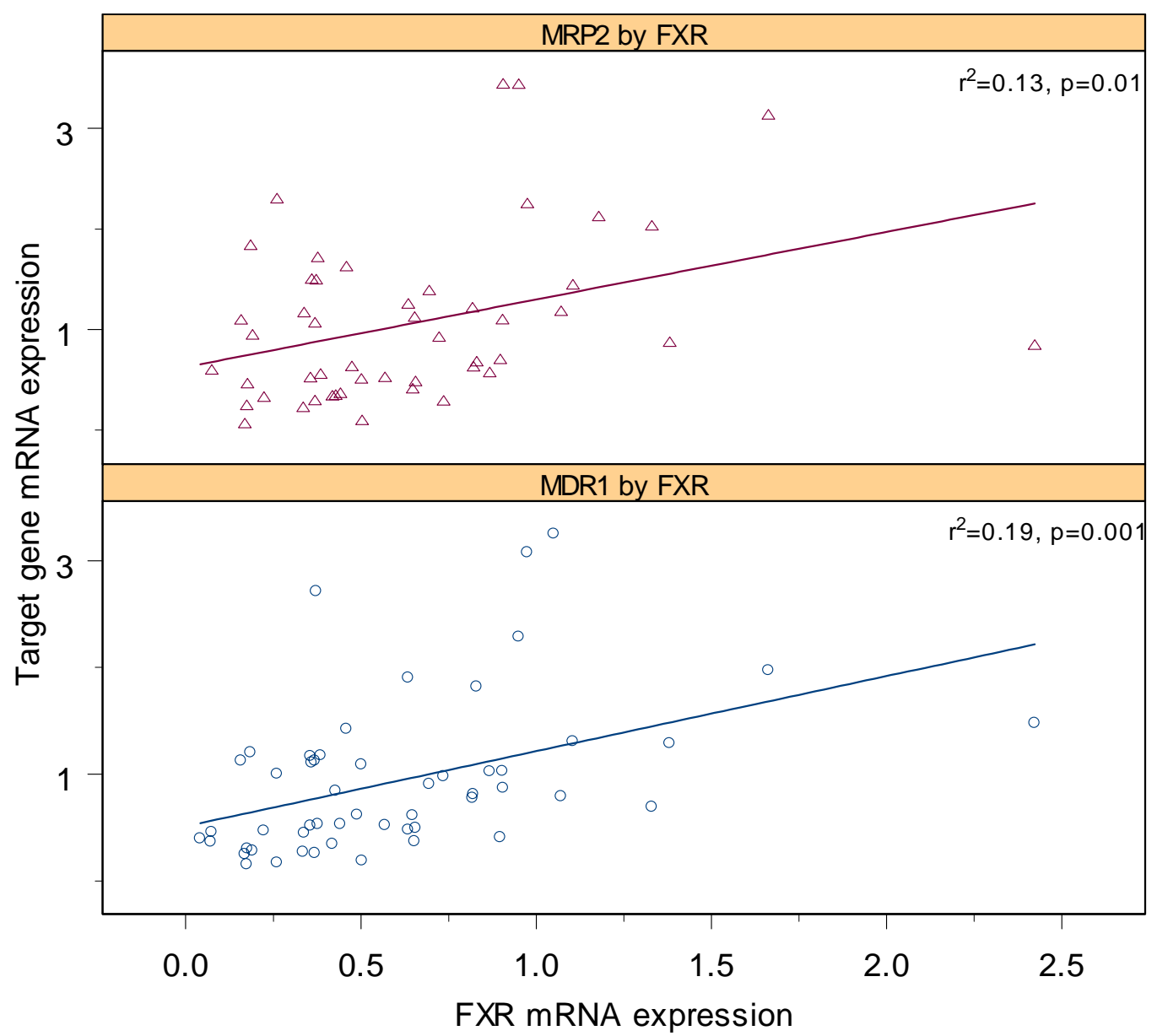

Figure 2-13. FXR Correlations to MDR1 and MRP2.

Correlation between normalized target mRNA expression for MDR1 and MRP2 mRNA expression versus normalized FXR mRNA levels. 


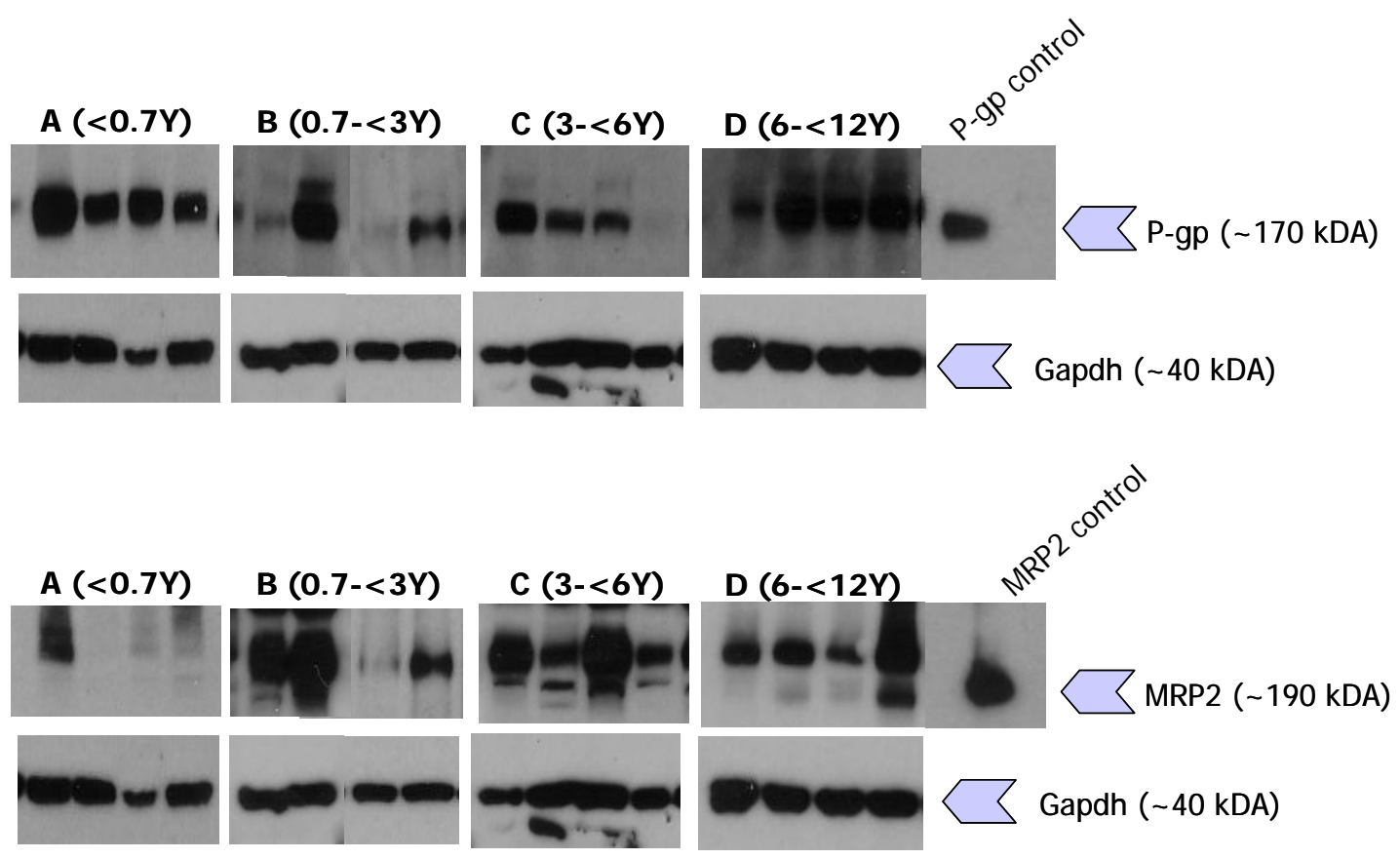

Figure 2-14. Representative Western Immunoblots of MDR1/P-gp and MRP2 in Human Pediatric Liver Samples.

Each column is a representative blot from each of the four age groups. Human MDR1/ $\mathrm{P}$-gp and MRP2 control membranes were included in each blot as a reference. 

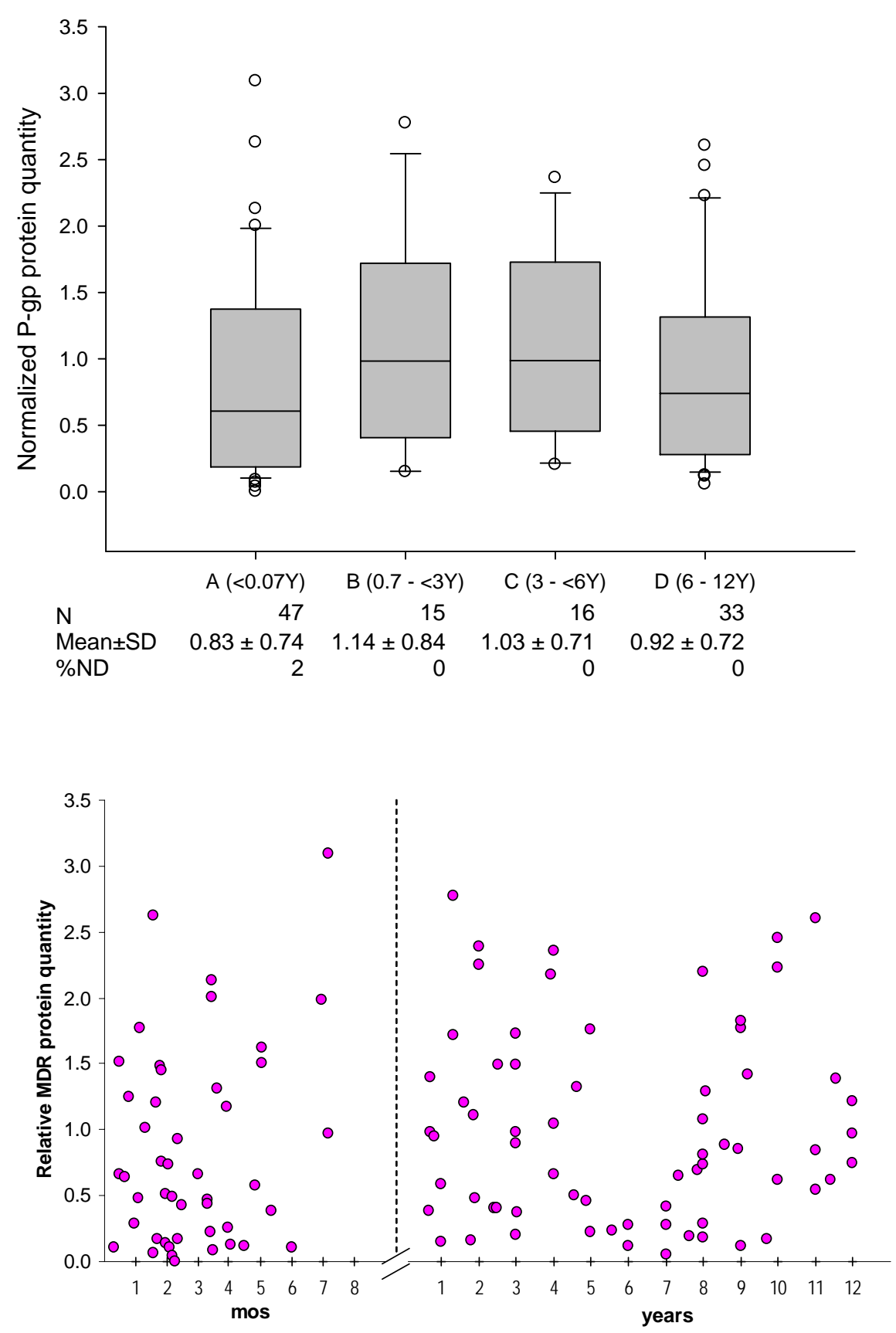

Figure 2-15. MDR1/P-gp Protein Expression in Human Pediatric Liver Samples. Upper panel, Box and whisker plot of normalized P-gp protein expression. Boxes represent 25 th and 75 th percentiles and horizontal bars represent 10th and 90th percentiles while open circles represent outliers. Mean \pm SD for each age group are also shown as well as the percent of sample not detected within each age group (\%ND).

Lower panel, Scatterplot of normalized P-gp protein expression versus age. X-axis is on a discontinuous scale ranging from $0-8$ months and $>8$ months -12 years. 

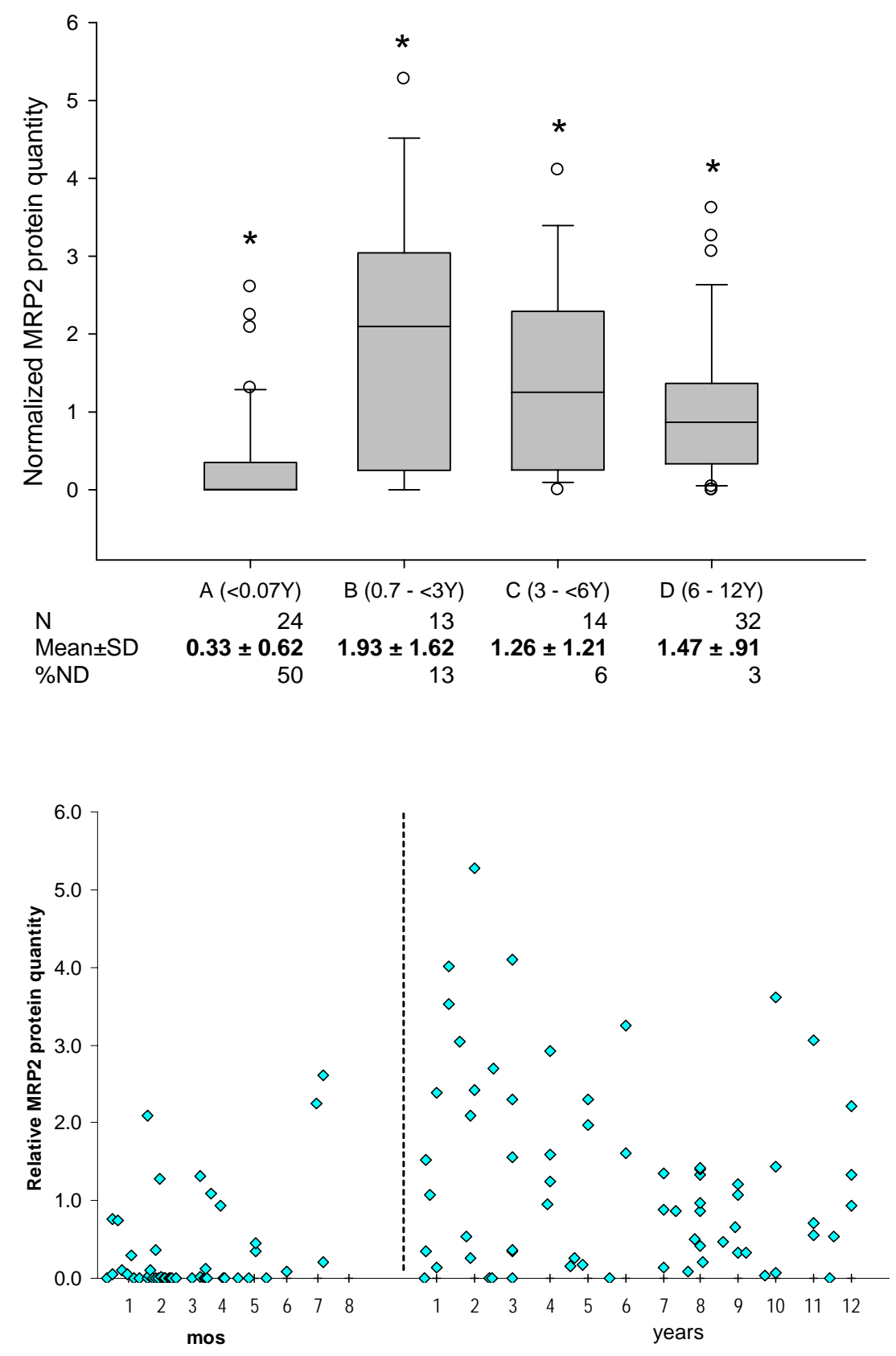

Figure 2-16. MRP2 Protein Expression in Human Pediatric Liver Samples.

Upper panel, Box and whisker plot of normalized MRP2 protein expression. Boxes represent 25th and 75th percentiles and horizontal bars represent 10th and 90th percentiles while open circles represent outliers. Bold print in text and asterisks within graph represent significant differences between the age group A versus the other indicated age groups $(\mathrm{p}<0.05)$. Mean \pm SD for each age group are also shown as well as the percent of sample not detected within each age group (\%ND). Lower panel, Scatterplot of normalized MRP2 protein expression versus age. X-axis is on a discontinuous scale ranging from $0-8$ months and $>8$ months -12 years. 
ontogeny in the early weeks after birth, we added postmortem liver samples to our original mRNA data set. Due to RNA degradation in the postmortem samples, we were only able to measure protein and not mRNA content in those samples.

For MDR1/P-gp gene expression, we were able to identify significantly lower mRNA expression between the early infant (before 8 months) and early childhood period ( 8 months -3 years). Our MDR1/P-gp protein expression in the pediatric liver samples, however, was not significantly different across the various age groups in our subset of protein samples. The discordance in the relative expression of MDR1/P-gp mRNA and P-glycoprotein has been described in various cancer cell lines [81, 82]. This raises the possibility of post-transcriptional regulation of MDR1 as a potential source of variation for mRNA and protein expression in human pediatric liver samples. van Kalken et al. reports a strong expression of P-gp in early human fetal liver development [65]. Our protein data extends their findings and supports high P-gp expression in the human pediatric liver from the neonatal throughout late childhood ages. The crucial protective role P-gp plays in preventing intracellular endogenous or exogenous substrate accumulation would support its strong presence at birth especially in organs with excretory functions such as the liver and kidneys.

Similar to MDR1/P-gp, MRP2 mRNA expression was significantly lower in the early infant months as compared to the early childhood period. Furthermore, we were able to characterize the same relationship for MRP2 protein samples whereby the early infant period (birth -8 months) exhibited the lowest MRP2 protein expression compared to all the other developmental periods. The high occurrence of jaundice or hyperbilirubinemia often observed in premature infants and newborns may be partially attributed to the immature development of MRP2 at birth since MRP2 is the primary hepatic canalicular transporter that mediates various organic anions as well as sulfated or glucuronidated bile salts and bilirubin. Our findings provide direct physiologic evidence of immature MRP2 expression in the early infant period of development. Aside from bilirubin, immaturity of MRP2 expression at birth could also potentially impact the elimination of drug molecules that are substrates of MRP2. Therefore, in the pediatric population, especially for newborns, medications with high biliary excretion may exhibit altered pharmacokinetic properties and thus, may necessitate special pediatric dosing or monitoring.

The nuclear receptors PXR, CAR, and FXR are all involved in the co-regulation of drug metabolizing enzymes and drug transporters through activation of the response elements of their target genes. Furthermore, there is a considerable level of overlap in the inducers of both PXR and CAR. This 'cross-talk' or 'cross-regulation' between PXR and CAR provides redundancy in the regulation of their target gene expression such as the coexpression of CYP3A4 and P-gp [56]. Though PXR, CAR, and FXR all have roles in human bile acid and lipid metabolism, FXR appears to be the main nuclear receptor charged with direct bile acid and cholesterol homeostasis. Transcriptional targets of FXR include ileal bile acid binding protein (IBABP), bile salt export pump (BSEP), sodium taurocholate contransporting peptide (NTCP), cholesterol 7- $\alpha$ hydroxylase (CYP7A1), and MRP2 - all metabolizing enzymes or transporters directly involved in bile acid 
absorption, synthesis, or secretion $[57,71,83]$. In the present study, both the mean and median mRNA expression values for PXR and FXR were lowest in the youngest age group and increased over time. Our results support an ontogenically regulated expression of PXR and FXR and appears to coincide with another study with limited human fetal liver samples which shows lower FXR mRNA expression as compared to adult liver samples [67]. However, unlike the PXR and FXR gene expression, CAR mRNA expression remained relatively constant throughout the different age groups. CAR has been reported to be constitutively expressed and localized in the cytoplasm of hepatocytes. Unlike PXR and FXR, CAR must translocate into the cell nucleus before activation of its target gene response elements [84]. Our results support a constitutive expression of CAR which does not appear to fluctuate with age.

Apart from the developmental patterns in nuclear receptor expression, we also described a positive correlation between HNF4 $\alpha$, PXR, and CAR mRNA expression. The results agree with a previous study linking the co-expression between the nuclear receptors [77] and also support other findings that HNF4 $\alpha$ is an important master regulator in coordinating the nuclear receptor mediated response to xenobiotics specifically in the liver [76]. HNF4 $\alpha$, as a critical determinant of PXR and CAR induction of CYP3A, may also play a significant role in the upregulation of $\mathrm{P}$-gp given that CYP3A and P-gp are often co-expressed and co-induced. To date, there are no studies which suggest the regulation of FXR through HNF4 $\alpha$. This is echoed by the lack of correlation between HNF $4 \alpha$ and FXR in the current study.

Besides exploring the relationships between the nuclear receptors themselves, we wished to also examine the correlations between the nuclear receptors PXR, CAR, and FXR and the drug transporters MDR1/P-gp and MRP2. Significant correlations were detected between PXR and FXR along with MDR1/P-gp and MRP2. In particular, the relationship between PXR and MDR1/P-gp was strongly correlated $(\mathrm{p}=0.0001)$ while PXR and MRP2 was moderated associated $(\mathrm{p}=0.04)$. This corresponds with the role PXR plays in the coordinated regulation of drug metabolizing enzymes and drug transporters. Conversely, CAR expression lacked correlation with either P-gp or MRP2. This was somewhat surprising given that CAR, similar to PXR, also serves as a crucial regulator of Phase I through Phase III drug disposition mechanisms. Our findings support CAR as a constitutively expressed nuclear receptor whose activation of target gene receptors potentially occurs through a different mechanism as compared to PXR. In particular, the lack of direct correlation between CAR and drug transporter expression might be due to a multifaceted process whereby other co-regulators may be involved in CAR activation. In contrast to CAR, both MDR1/P-gp and MRP2 were highly correlated with FXR expression. Our findings support the role of FXR in maintaining bile acid homeostasis through its regulation of MDR1/P-gp as well as MRP2.

The aims of the current study were to characterize the age associated development for $\mathrm{ABC}$ transporters MDR1/P-gp and MRP2 as well as nuclear receptors PXR, CAR, FXR, and HNF4 $\alpha$ in human pediatric livers. Our relatively large sample size included liver tissue from both living as well as deceased donors. The liver samples from the living donors were analyzed for both mRNA and protein expression studies while the 
liver samples from the deceased donors were acquired in order to better characterize the $\mathrm{ABC}$ transporter protein expression especially in the newborn and infant periods. Our results revealed an age-associated expression whereby the youngest age group exhibited the lowest gene transcript level for MDR1/P-gp and MRP2 mRNA expression. Protein expression data, however, indicated only a significant age dependent expression of MRP2. The dissociation in mRNA and protein expression in our MDR1/P-gp samples might be the result of post-transcriptional regulation which would need to be substantiated with further research.

For the nuclear receptors, we were able to establish a positive correlation between HNF4 $\alpha$ along with PXR and CAR, but not for FXR. This appeared consistent with published literature which supports HNF4 $\alpha$ as a master-regulator of PXR and CAR. We also explored the relationships between the nuclear receptors and drug transporters in order to ascribe the potential regulatory control of the nuclear receptors on the developmental patterns observed for MDR1/P-gp and MRP2. We identified positive correlations between the nuclear receptors PXR and FXR with MDR1/P-gp and MRP2. However, we were not able to detect correlations between CAR and the ABC transporters. The correlations between PXR and ABC transporters seem consistent with the role of PXR as a major transcriptional regulator of drug metabolizing enzymes and drug transporters. The role FXR serves as a main regulator of bile acid homeostasis in the liver also supports its associations with MDR1/P-gp and MRP2. The lack of correlations between $\mathrm{CAR}$ and the $\mathrm{ABC}$ transporters suggest the possibility of additional co-regulators that may be involved in the activation of MDR1/P-gp and MRP2.

The immaturity of human hepatic MRP2 in the early postnatal period described in this study provides a partial explanation for the high incidence of hyperbilirubinemia in newborns. Besides endogenous substrates such as bilirubin and bile acids, the role of MRP2 as a major hepatic transporter of organic anions might also result in altered clearance of such pharmacological agents, particularly in newborns. An important extension of the current study will be to examine the variability in the pharmacokinetic parameters of medications with high biliary clearance in a system with impaired or deficient MRP2 expression. 


\section{CHAPTER 3. AGE-ASSOCIATED EXPRESSION OF HEPATIC ABC DRUG TRANSPORTERS AND NUCLEAR RECEPTORS IN RAT LIVER}

\section{Introduction}

Similar to humans, rodents also express the ABC drug transporters MDR1/P-gp and MRP2. Unlike humans, however, rodent multidrug resistance protein MDR1/P-gp is encoded by two isoforms - Mdrla (as referred to as Mdr3) and Mdr1b (Mdr1) [85-88]. Mouse Mdr1a is highly expressed in the intestinal epithelium and at the blood-brain and blood-testis barriers, whereas Mdr1b is highly expressed in the adrenal gland, pregnant uterus, and ovaries. In addition, both genes are substantially expressed in many other tissues, including liver, kidney, lung, heart, and spleen $[89,90]$. While tissue distribution of Mdr1a/1b varies widely, these two highly homologous gene isoforms appear to be coexpressed in the mouse liver and contribute equally in the overall hepatic MDR1/P-gp function. The sequence homology between rodent and human Mdr1-type genes is virtually complete [90-92]. Furthermore, rodent P-gp transport of various chemotherapeutic agents, endogenous glucocorticoids, as well as various exogenous drug substrates are analogous to the function of human P-gp [88, 90, 93].

Although it shares less than 20\% amino acid identity with Mdr1/P-gp, Mrp2 localization is very similar to Mdr1/P-gp including the intestines, liver, and kidney [41, 94]. Similar to human MRP2 in both localization and function, rodent Mrp2 also plays a central role in the hepatobiliary excretion of various endogenous and exogenous substrates including bile acids, bilirubin, various organic anions, as wells as conjugates of glucuronates, glutathiones, or sulfates [95, 96]. Mutations in the MRP2 gene can cause an autosomal recessive disorder which results in hereditary hyperbilirubinemia. The human form of the mutation causes Dubin-Johnson syndrome, while in rats, a similar mutation results in the EHBR (Esai hyperbillirubinemic rat) and the TR-strain of MRP2deficient rats [97].

Ontogenic regulation of $\mathrm{ABC}$ transporters Mdr1a/1b (P-gp) and Mrp2 has previously been explored in humans as detailed in Chapter 2. Due to the limited availability of human pediatric liver biopsies, however, the use of animal tissues from various ages is often used as an alternative to gain knowledge about the ontogeny of drug disposition processes and has provided great insight into the developmental process of these drug transporters. While there is a general consensus from the currently published animal studies on the fact that transporter expression is age-associated, some of the reported results are equivocal. According to Rosati [63], gene expression of Mdr1a/1b increases around postnatal day 21 in the rat liver and reaches maximum expression by postnatal day 60 . However, western blots of mouse liver for P-gp indicates an abundance of P-gp at birth and throughout maturation into adulthood [62]. An age associated expression pattern has also been described for Mrp2 in the rat liver whereby Mrp2 gene expression increase significantly between postnatal days $6-12$ and approaches a maximal expression value by day 30 [61, 63]. Similar to the studies by Rosati [63] and Gao [61], we have reported an ontogenic process in MRP2 mRNA and protein expression 
in human pediatric liver samples of varying ages. We also reported a significant age associated mRNA expression for MDR1/P-gp in the same pediatric liver samples.

As mentioned in Chapter 2, orphan nuclear receptors include a gene superfamily of transcriptional factors that regulate the expression of its target genes, many of which include drug metabolizing enzymes and drug transporters [70]. Paving the molecular regulatory pathway for their target gene expression, nuclear receptors may partly contribute to the interindividual and ontogenic variability observed in drug transporter expression. Nuclear receptors that target the expression of MDR1/P-gp and MRP2 include PXR, CAR, and FXR [57, 58, 71, 72], while HNF4 $\alpha$ appears to be a master regulator of PXR and CAR [76]. Many of the ligands which activate transcription factors within the nuclear receptors are drug substrates frequently used in pediatric pharmacotherapy including rifampin, phenobarbital, clotrimazole, and dexamethasone [98]. Even endogenous substrates such as bile acids and their precursors can modulate the downstream expression of drug transporters through activation or inhibition of nuclear receptors [72].

Only two studies have so far investigated the ontogenic expression of nuclear receptors [71,77]. No study to date has examined the developmental patterns of nuclear receptors and their correlation to drug transporter development. From our human pediatric liver samples, we were able to measure the mRNA expression of four different nuclear receptors involved in the regulation of MDR1/P-gp and MRP2 including PXR, CAR, FXR, and HNF4 $\alpha$. We were able to show a positive correlation between $\mathrm{HNF} 4 \alpha$, a master regulator of other nuclear receptor, and PXR and CAR expression. Along the same lines, we were also able to identify positive correlations between the nuclear receptors PXR and FXR to both ABC transporters.

Knowledge regarding the developmental expression of $\mathrm{ABC}$ transporters as well their regulation by nuclear receptors can provide crucial information regarding differences observed between pediatric and adult pharmacotherapy. In the present study, we characterized the ontogeny of rat liver Mdr1a/1b and Mrp2 by performing relative quantification for both mRNA and protein expression. These data are generated to supplement our previous findings on the ontogeny of MDR1/P-gp and MRP2 in human livers. The rat was chosen as model animal as it is the most established and wellcharacterized model species for drug disposition, metabolism and toxicology. To describe their developmental pattern of Mdr1a/1b and Mrp2 in more detail, we expanded upon the previous published studies by including more age groups ranging from postnatal day $0,3,7,14,21,28$, and adult rats (considered by sexual maturity by postnatal day 60 ) [99]. In addition, we also characterized the mRNA expression of regulatory transcriptional factors Pxr, Car, Fxr, and Hnf4 $\alpha$ for the same rat liver samples. We then compared the mRNA expression between the four nuclear receptors in order to characterize their co-regulation. Lastly, we investigated the correlations between the mRNA expression of the nuclear receptors and the drug transporters Mdrla, Mdr1b, and Mrp2. 


\section{Materials and Methods}

\section{Sample Acquisition}

Pregnant Sprague-Dawley (SD), 28 day-old, and adult aged (60 day-old) rats were acquired from Harland (Indianapolis, IN) and housed at $25^{\circ} \mathrm{C}$ on a 12-hour light/dark cycle. All animals were housed in standard laboratory cages and had free access to food and water throughout the entire study. Pups delivered by the pregnant rats were raised to pre-determined ages including newborn, 3, 7, 14, and 21 days of age. After reaching the appropriate pre-determined age, six rats were selected at random and anesthetized with isoflurane . Liver biopsies were dissected out and immediately frozen in liquid nitrogen. All rats were sacrificed by creating a pneumothorax. All frozen liver samples were stored at $-70^{\circ} \mathrm{C}$ until further processing. The experimental protocol was approved by the Animal Care and Use Committee (ACUC) of the University of Tennessee Health Science Center. All procedures related to the sample acquisition were performed by Dr. Wenhui Zhang [100].

\section{Total RNA Isolation and cDNA Synthesis}

Total RNA from the rat livers was isolated using RNAgents ${ }^{\circledR}$ Total RNA Isolation Kit (Promega, Madison, WI) according to manufacturer's protocol. Briefly, approximately $0.3 \mathrm{~g}$ of frozen liver was added to $600 \mu \mathrm{L}$ of denaturing solution and homogenized using a handheld homogenizer for approximately 15 seconds or until no fragments of tissue were visible. Next, $60 \mu \mathrm{L}$ of $2 \mathrm{M}$ sodium acetate followed by $600 \mu \mathrm{L}$ of phenol:chloroform:isoamyl alcohol was added to each homogenate, mixed thoroughly, and then vigorously shaken for 10 seconds. After chilling the entire mixture on ice for 15 minutes, the vials were centrifuged at $10,000 \mathrm{~g}$ for 20 minutes at $4^{\circ} \mathrm{C}$. The top aqueous phase was transferred to a fresh centrifuge tube, and an equal amount of ice-cold isopropanol was then added in order to precipitate total RNA from the aqueous phase. Total RNA was precipitated for 30 minutes in a $-20^{\circ} \mathrm{C}$ freezer followed by a second centrifugation step at $10,000 \mathrm{~g}$ for 15 minutes. The resulting RNA pellet was then washed with ice-cold $75 \%$ ethanol and re-pelleted by centrifugation. After discarding the ethanol, the RNA pellet was air dried and finally each RNA pellet was dissolved in $10-$ $50 \mu \mathrm{L}$ of nuclease-free water depending on the pellet size. RNA concentrations were estimated by measuring its ultraviolet absorbance (A) at $260 \mathrm{~nm}$ and $280 \mathrm{~nm}$, whereby 1 absorbance unit $\left(\mathrm{A}_{260}\right)=40 \mu \mathrm{g}$ of $\mathrm{RNA} / \mathrm{mL}$. The purity of the RNA isolate was estimated by comparing the ratio for $\mathrm{A}_{260} / \mathrm{A}_{280}$. RNA samples were considered pure with only minor protein contamination if the calculated ratio of $\mathrm{A}_{260} / \mathrm{A}_{280}$ was between 1.7 and 2.0. Only samples with high purity were further processed for first strand cDNA synthesis.

First strand cDNA synthesis was performed by using the Superscript III kit (Invitrogen, Carlsbad, CA) on an Eppendorf ${ }^{\circledR}$ Mastercycler $^{\mathrm{TM}}$ (Westbury, NY). Oligo dT was used as the primer for mRNA first-strand synthesis. An aliquot totaling $1 \mu \mathrm{g}$ of total 
RNA was mixed with $1 \mu \mathrm{L}$ of $10 \mathrm{mM}$ dNTP mix and $1 \mu \mathrm{L}$ of $0.5 \mu \mathrm{g} / \mu \mathrm{L}$ Oligo(dT) $)_{12-18}$. The total mixture was then brought to $10 \mu \mathrm{L}$ with the addition of DEPC-treated water. The mixture was incubated at $65^{\circ} \mathrm{C}$ for 5 minutes on a heating block, then immediately placed on ice for at least 1 minute. A mixture of $2 \mu \mathrm{L}$ of $10 \mathrm{x}$ RT buffer, $4 \mu \mathrm{L}$ of $25 \mathrm{mM}$ $\mathrm{MgCl}_{2}, 2 \mu \mathrm{L}$ of $0.1 \mathrm{M}$ DTT, $1 \mu \mathrm{L}$ of RNAseOUT ${ }^{\mathrm{TM}}$ recombinant RNase inhibitor, and 1 $\mu \mathrm{L}$ of SuperScript ${ }^{\mathrm{TM}}$ III reverse transcriptase was added to each reaction vial. The entire mixture was then incubated for $50^{\circ} \mathrm{C}$ for 50 minutes and the reaction was terminated by increasing the temperature to $85^{\circ} \mathrm{C}$ for 5 minutes. Residual RNA was removed by adding $1 \mathrm{uL}$ of RNAse $\mathrm{H}$ and incubating at $37^{\circ} \mathrm{C}$ for 20 minutes. The resulting cDNA was stored at $-20^{\circ} \mathrm{C}$ until real-time RT-PCR was performed.

\section{Real Time PCR}

Primers pairs and TaqMan probes for Mdr1a, Mdr1b, Mrp2, Pxr, Car, Fxr, and $\mathrm{Hnf} 4 \alpha$ (TaqMan ${ }^{\circledR}$ Assay-on-Demand ${ }^{\mathrm{TM}}$ Products) as well as the constitutively expressed housekeeping gene Cyclophilin A (TaqMan ${ }^{\circledR}$ Pre-Developed Assay Reagents for Gene Expression) were obtained from Applied Biosystems (Foster City, CA). All targeted $\mathrm{ABC}$ transporter and nuclear receptor probes were labeled with 6-carboxyfluorescein (FAM)-dye while the cyclophilin probe was labeled with VICTM-dye. All of the probes were quenched by 6-carboxytetramethylrohodamine (TAMRA) on the 3' end. Target gene probe sequences are summarized in Table 3-1. In a 96-well reaction plate, $2.5 \mu \mathrm{L}$ of 20X TaqMan Probe, $22.5 \mu \mathrm{L}$ of cDNA created from the rat liver, and $25 \mu \mathrm{L}$ of $2 \mathrm{X}$ TaqMan Universal PCR Master Mix were added. The reaction was performed in duplicate for each sample. Real time RT-PCR was performed using the ABI Prism ${ }^{\circledR}$ Sequence Detection System 7000 (Applied Biosystems, Foster City, CA) using the default PCR thermal cycling conditions consisting of an initial TaqMan Universal PCR Master Mix activation at $50^{\circ} \mathrm{C}$ for $2 \mathrm{~min}$, followed by an initial denaturation step at $95^{\circ} \mathrm{C}$ for $10 \mathrm{~min}$, then 40 cycles of $95^{\circ} \mathrm{C}$ for $15 \mathrm{sec}$ and $60^{\circ} \mathrm{C}$ for $1 \mathrm{~min}$.

Relative mRNA quantification was achieved through the standard curve or $\mathrm{C}_{\mathrm{t}}$ (cycle threshold for target or endogenous control gene amplification) slope method. The average $C_{t}$ value was calculated from replicates of each sample using the ABI Sequence Detection System SDS software (Applied Biosystems, Foster City, CA). Mdrla, Mdr1b, Mrp2, Pxr, Car, Fxr, Hnf4a, and cyclophilin A standard curves were prepared from serial dilutions of cDNA from a standard adult rat sample. Dilutions included 1,2, 4, 10, and 20 fold initial cDNA concentration $\left(\mathrm{C}_{0}\right)$. A plot of $\mathrm{Ct}$, the point at which the amplification plot cross the threshold cycle value, vs $\mathrm{C}_{0}$ was then constructed (Figure 3-1) as described by the assay manufacturer [78]. The threshold value was predetermined as 3 times the average baseline cycle value calculated from cycles $6-15$. The log concentration of the unknown samples was then calculated by linear regression from the standard curve. The absolute concentration was then determined by taking its antilog value. The expression level of each target gene was then calculated relative to the reference gene, cyclophilin A. 
Table 3-1. Primer Sequence for Target Gene-Specific 5'-(FAM)-Labeled TaqMan ${ }^{\circledR}$ Assay-on-Demand ${ }^{\mathrm{TM}}$ Rat Probes.

\begin{tabular}{lllll}
\hline $\begin{array}{l}\text { Gene } \\
\text { Symbol }\end{array}$ & $\begin{array}{l}\text { Alternative } \\
\text { name }\end{array}$ & Probe 5'-3' & $\begin{array}{l}\text { NCBI Gene } \\
\text { Reference }\end{array}$ & $\begin{array}{l}\text { Target } \\
\text { Exons }\end{array}$ \\
\hline & & & & \\
Abcb1a & Mdr1a & TGAAAGGGGCTACAGGGTCTAGGCT & NM_133401.1 & 20 \\
Abcb1 & Mdr1b & ACATGGCCATGTACGCCTACTATTA & NM_012623.2 & 5 \\
Abcc2 & Mrp2 & TCACCATCCAGGGATCCACAGCCTA & NM_012833.1 & 14 \\
Nr1i2 & Pxr & CTATCCTGCACACAGGTCCTGTTC & NM_052980.1 & 8 \\
Nr1i3 & Car & TCAAGACTCCAAAGTCGGTTCTGT & NM_022941.2 & 7 \\
Nr1h4 & Fxr & GGGCTGCAAAGGTTTCTTCCGAAGA & NM_021745.1 & 3 \\
Hnf4 $\alpha$ & Hnf4 $\alpha$ & CATGAAGAAAGAAGCCGTCCAAAAT & NM_022180.1 & 3 \\
& & & & \\
\hline
\end{tabular}




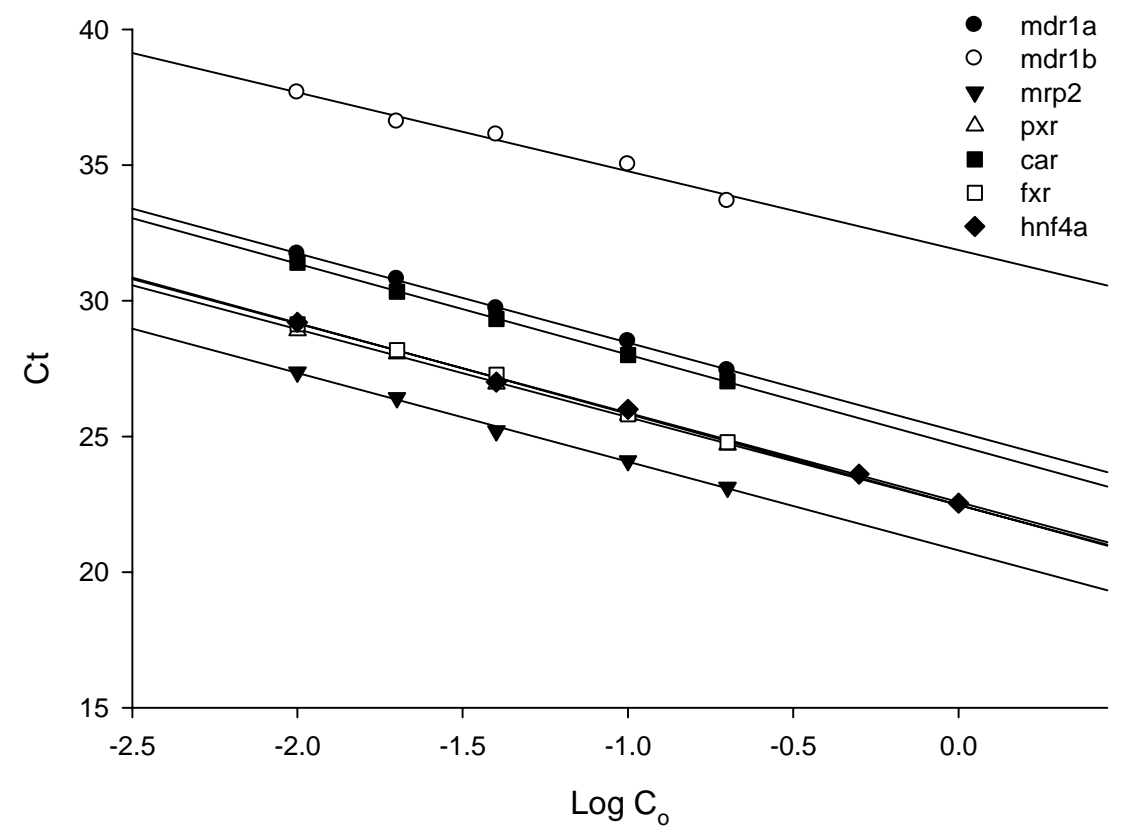

Figure 3-1. Calibration Curve for Mdr1a, Mdr1b, Mrp2, Pxr, Car, Fxr, and Hnf4a. Serial dilutions of cDNA created from a reference sample taken from an adult rat. All targeted genes calibration curves have slopes of approximately -3.3 , indicating an amplification efficiency of close to 1 within the linear range. 


\section{Tissue Membrane Protein Isolation}

Membrane proteins for all rat liver samples were extracted through the Calbiochem ${ }^{\circledR}$ ProteoExtract ${ }^{\circledR}$ Native Membrane Protein Extraction Kit (M-PEK) according to the manufacturer protocol. Briefly, approximately $50 \mathrm{mg}$ of liver tissue was homogenized in $2 \mathrm{mLs}$ of Extraction Buffer I and incubated for 10 minutes at $4^{\circ} \mathrm{C}$ under gentle agitation on a rotary shaker. The homogenate was centrifuged for 15 minutes at $16,000 \mathrm{~g}$ and $4^{\circ} \mathrm{C}$. The supernatant was discarded and the pellet resuspended in $1 \mathrm{~mL}$ of Extraction Buffer II. The cell pellet containing membrane and cytosolic proteins was then incubated for 30 minutes at $4^{\circ} \mathrm{C}$ again under gentle agitation on a rotary shaker. The cell suspension was centrifuged a second time at $16,000 \mathrm{x}$ g and $4{ }^{\circ} \mathrm{C}$ for 15 minutes. The resulting supernatant enriched in membrane proteins was then transferred to a fresh tube and stored in aliquots at $-70^{\circ} \mathrm{C}$ until further processing.

Protein quantification was determined by the method of Bradford Assay [79] using bovine serum albumin (BSA; Sigma-Aldrich) as the standard. Using a 96 well plate, stock BSA solution $(0.2 \mathrm{mg} / \mathrm{mL})$ was diluted to a final concentration ranging from $0-30$ $\mu \mathrm{g} / \mathrm{mL}$ with $\mathrm{dH}_{2} \mathrm{O}$ in the standard wells. In the sample wells, $1 \mu \mathrm{L}$ of membrane protein from each pediatric liver sample was dilute in $199 \mu 1$ of $\mathrm{dH}_{2} 0.50 \mu \mathrm{L}$ of Protein Assay Dye Reagent Concentrate (Bio-Rad) was added to each well and mixed thoroughly. All protein standards and unknown samples were measured in triplicates. The plate was incubated for 5 minutes at room temperature and the protein absorbance was read on a microplate reader at $595 \mathrm{~nm}$. A standard curve using the standard BSA absorbance (A) versus concentration was constructed. All unknown protein concentrations were subsequently calculated using the standard curve. $20 \mu \mathrm{g}$ of membrane protein from each liver sample was used for protein quantification.

\section{SDS-PAGE/Western Blotting}

To $20 \mu \mathrm{g}$ of rat liver membrane protein, $2.5 \mathrm{~mL}$ of NuPAGE ${ }^{\circledR}$ LDS Sample Preparation Buffer (Invitrogen, Carlsbad, CA) was added. The samples were fractionated via SDS-PAGE using NuPAGE ${ }^{\circledR} 4-12 \%$ Bis-Tris Gel with $1 \mathrm{X} \mathrm{NuPAGE}^{\circledR}$

MOPS Running buffer at $200 \mathrm{~V}$ for 1 hour. On each gel, we also included a MultiMark ${ }^{\circledR}$ Multi-Colored Protein Standard molecular weight ladder (Invitrogen, Carlsbad, CA). Human P-gp membrane preparation (Human PGP membranes) and MRP2 membrane preparations (Human MRP2 membranes) purchased from BD Gentest ${ }^{\mathrm{TM}}$ (Woburn, MA) were also included on each gel as positive controls. The separated proteins were transferred overnight onto a Invitrolon ${ }^{\mathrm{TM}}$ PVDF $0.2 \mathrm{um}$ membrane at $30 \mathrm{~V}$ using NuPAGE $^{\circledR} 1 \mathrm{X}$ Transfer Buffer with 10\% methanol.

Nonspecific binding sites on the PVDF membrane were blocked using 5\% nonfat dried milk in phosphate buffered saline (PBS; $\mathrm{pH} 7.4$ ) with $0.1 \%$ Tween for 1 hour at room temperature. The membrane was then incubated with a primary monoclonal antibody to P-gp (C219) (Alexis Biochemicals, San Diego, CA) diluted 1:100 fold, MRP2 (M 2 III-6) (Alexis Biochemical, San Diego, CA) diluted 1:200 fold, or GAPDH 
(Sigma-Aldrich, St. Louis, MO) diluted 1:10000 fold in 5\% nonfat dried milk in PBS with $0.1 \%$ Tween (PBST) for 2 hours at room temperature. After discarding the primary antibody, the membrane was washed 3 times with PBST each time for 5 minutes. The membrane was then incubated for 1 hour with the secondary antibody, HRP-conjugated Anti-Mouse IgG (Cell Signaling Technology, Danvers, MA), diluted in 5\% nonfat dried milk in PBST either 1:5000 fold when probing P-gp and MRP2, or 1:10000 fold when probing for GAPDH. After 3-5 minute washings with PBST, the blots were then incubated with enhanced chemiluminescence ECL plus ${ }^{\mathrm{TM}}$ (GE Healthcare, Piscataway, NJ) for 5 minutes, then developed on $\operatorname{Kodak}^{\circledR}{ }^{\circledR}$ Biomax ${ }^{\mathrm{TM}}$ XAR autoradiography film (Sigma-Aldrich, St. Louis, MO) after 1 minute and 3 minute exposure times. Protein band density was quantified using Image $J[80]$ after digitizing the image using a flatbed scanner.

\section{Statistical Analysis}

All statistical analysis was performed using SPSS 14.0 (SPSS Inc., Chicago, IL). During real time PCR, an amplification plot, reported as $\Delta \mathrm{Rn}$ vs. $\mathrm{C}_{\mathrm{t}}$, was generated for each sample (Figure 3-2). $\Delta \mathrm{Rn}$ represented the fluorescence emission intensity of the reporter minus the threshold $\mathrm{R}_{\mathrm{n}}$. Threshold $\mathrm{R}_{\mathrm{n}}$ was determined from the pre-set baseline. The $\mathrm{C}_{t}$ value for each sample was then used to back calculate an initial input amount by using the equation derived from the calibration curve regression line. All data were back$\log$ transformed in order to achieve homoscedasticity, and target gene values were then normalized to the endogenous control cyclophilin A. The rat liver samples were divided into seven age groups $(0,3,7,14,21,28$ day-old, and adult). Statistical comparison of mean value for target gene expression between each group was performed using one-way ANOVA with Bonferroni post-hoc test.

$$
\text { Target gene mRNA expression }=\frac{\text { Initial amount of } t \text { arg et gene }}{\text { Initial amount of reference gene }}
$$

Mean \pm standard deviation (SD) values for all relative target gene mRNA expression were calculated for each rat age group. Statistically significant results $(\mathrm{p}<$ $0.05)$ are denoted with asterisks. Correlation between the nuclear receptors themselves and between the nuclear receptors and the $\mathrm{ABC}$ transporters was determined. The goodness of fit is denoted by the $r^{2}$ value and significance determined by the $F$ test for simple linear regression.

P-gp and Mrp2 protein expression was detected by immunoblotting and quantified by band density. The Gapdh bands were included in order to verify equal amount of protein loading for each sample. Additionally, Gapdh was used as a reference gene in order to normalize the P-gp and Mrp2 protein density. Each blot was verified as within the linear range by comparing the 1 minute versus the 3 minute exposure. Samples where relative expression values were 1.5 times outside the $25^{\text {th }}$ and $75^{\text {th }}$ percentiles were 


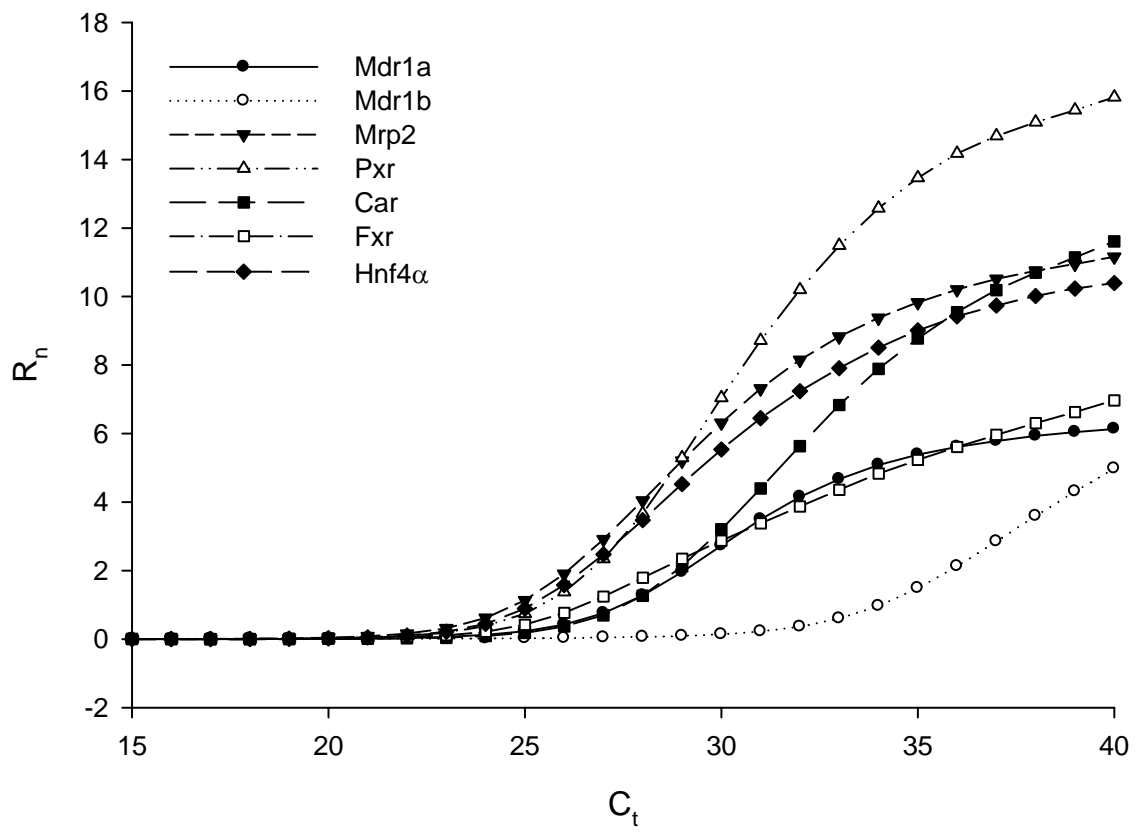

Figure 3-2. Sample Real Time PCR Amplification Plot for Target Rat Genes.

$\Delta R_{n}$ represents the fluorescence emission intensity of the reporter minus the threshold $R$. 
considered outliers and removed prior to analysis. Again, statistical analysis was performed using one-way ANOVA followed by Bonferroni post-hoc test. Statistically significant results $(\mathrm{p}<0.05)$ are denoted with asterisks.

\section{Results}

\section{mRNA Expression of Mdr1a, Mdr1b, and Mrp2 in Rat Liver Samples}

Using real time RT-PCR methodology, we were able to detect ABC transporters Mdr1a, Mdr1b and Mrp2 in all rat liver samples. Compared to the adult rat group, the relative Mdr1a expression in $0,3,7,14,21$, and 28 day-old age groups were $10.6 \%$, $7.0 \%, 23.6 \%, 26.1 \%, 96.5 \%$, and $157.5 \%$, respectively (Figure 3-3). Limited Mdr1a mRNA expression was detected for 0 and 3 days old rats followed by a gradual increase in the 7 and 14 days old age groups (Figure 3-4). Mdr1a mRNA expression dramatically increased between 14 and 21 days, and eventually reached maximal expression level by 28 days. Significant differences in mean Mdrla mRNA expression values were detected for 0,3 and 7 day-old rat groups as compared to the 28 day-old group.

Low expression values were measured for Mdr1b in the early age groups $0,3,7$, throughout 14 days-old rats which then increased to a maximal expression value by 28 days of age (Figure 3-5). Mdr1b mRNA expression then increased between 14 and 21 days and reached a peak in 28 days of age. Mdr1b expression values were $39.2 \%, 11.3 \%$, $49.6 \%, 52.1 \%, 76.2 \%$, and $169.5 \%$ of the adult group for groups $0,3,7,14,21$, and 28 days-old (Figure 3-3). Though mean values suggested an age-associated gene expression for Mdr1b, statistical analysis revealed no significant differences between any of the age groups.

Similar to Mdr1a and Mdr1b, rat liver Mrp2 expression remained low in the younger age groups from 0 days throughout 21 days. However, Mrp2 expression dramatically increased between 21 day- and 28 day-old rats and eventually reached maximal values by adult age (Figure 3-6). When compared to adult aged rats, expression values were $10.7 \%, 11.9 \%, 22.1 \%, 12.4 \%, 26.1 \%$, and $75.4 \%$ in the $0,3,7,14,21$, and 28 day-old rats, respectively (Figure 3-3). Statistical analysis revealed significant differences between age groups $0,3,7,14$, and 21 days-old versus the adult rats. There was no difference detected for Mrp2 mRNA expression between 28 day-old and adult rats.

\section{mRNA Expression of Orphan Nuclear Receptors (NRs) in Rat Liver Samples}

Similar to the rat hepatic ABC transporters, the nuclear receptors Pxr, Car, and Fxr all exhibited age-associated expression. Pxr gene expression for newborn rats was approximately $49 \%$ of adult Pxr expression but decreased gradually to between $25 \%$ $35 \%$ between 3 through 21 days of age before increasing back to approximately $56 \%$ of 


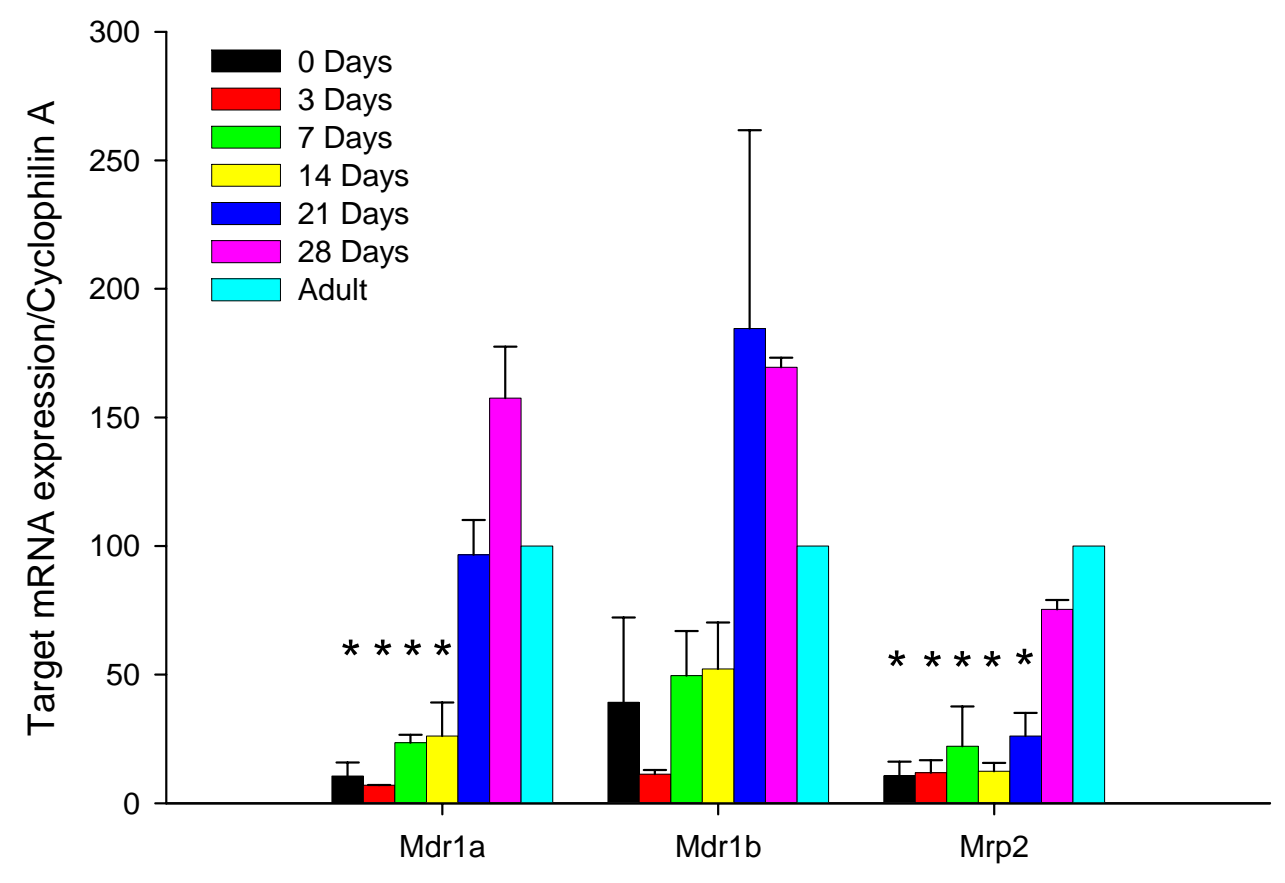

Figure 3-3. Ontogeny of Mdr1a, Mdr1b, and Mrp2 Expression in Rat Liver Samples. Values are normalized target gene expression relative to the adult liver group. Asterisks $\left.{ }^{*}\right)$ represents significant differences $(p<0.05)$ between the various age groups as compared to the adult group. 

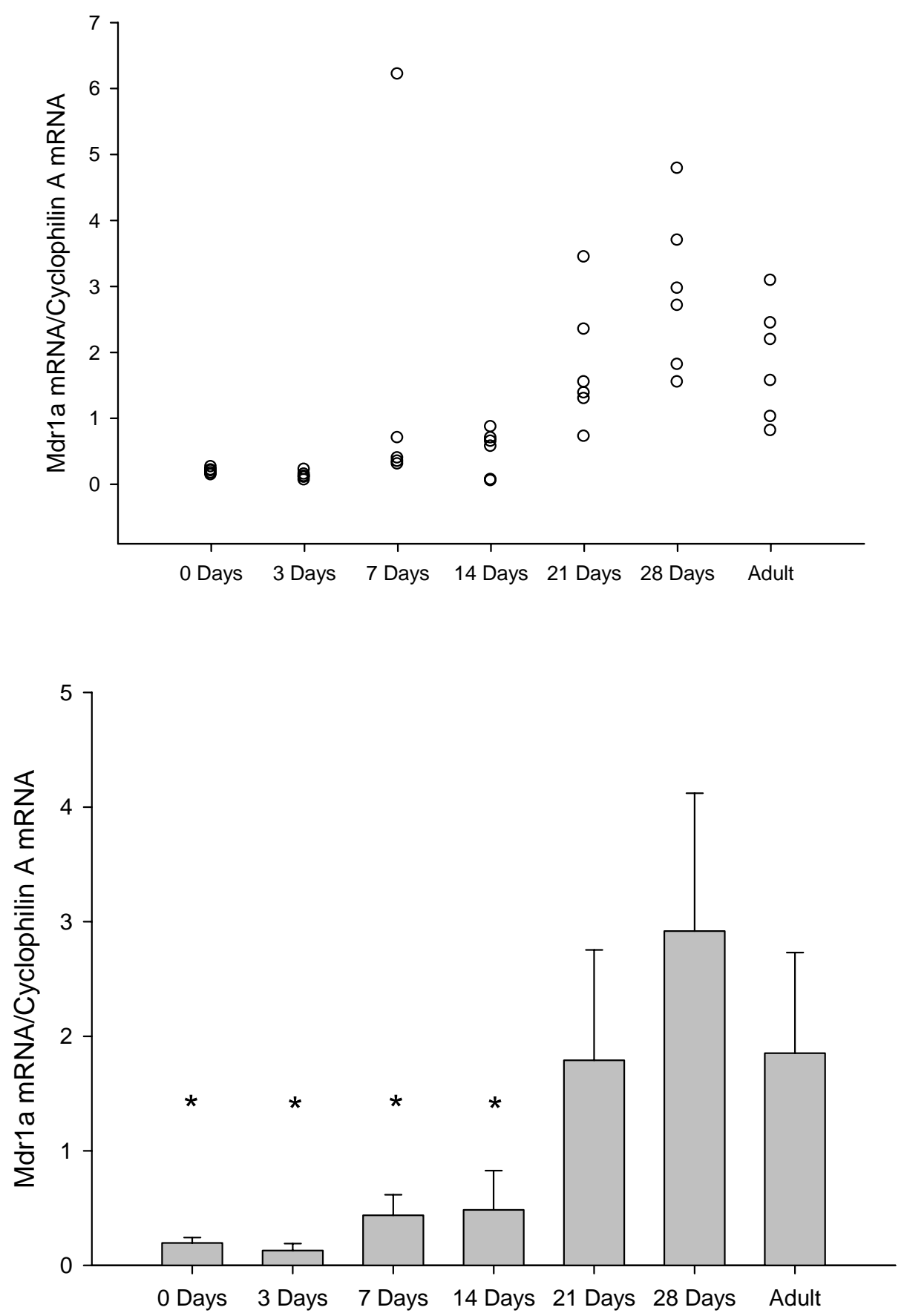

Figure 3-4. Ontogeny of Normalized Mdrla mRNA Expression in Rat Liver Samples. Upper panel. scatterplot of normalized Mdr1a mRNA expression of individual rats by each age group. Lower panel, bar graph presenting mean \pm standard deviation from six rat liver samples in each age group. Mdrla, mdr1-type isoform a of the rat multidrug resistance gene P-glycoprotein. 

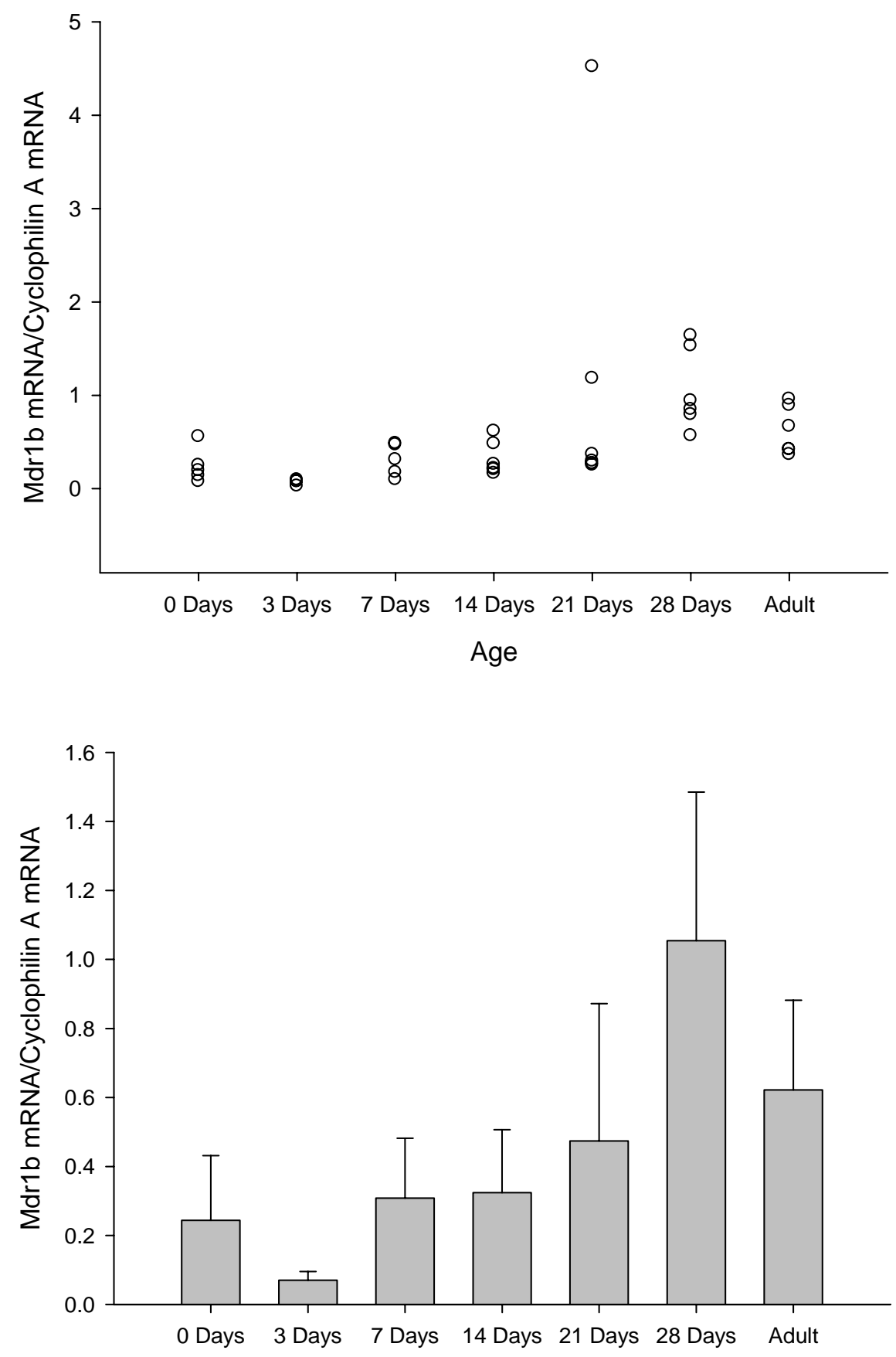

Figure 3-5. Ontogeny of Normalized Mdr1b mRNA Expression in Rat Liver Samples. Upper panel. scatterplot of normalized Mdr1b mRNA expression of individual rats by each age group. Lower panel, bar graph presenting mean \pm standard deviation from six rat liver samples in each age group. Mdr1b, mdrl-type isoform b of the rat multidrug resistance gene P-glycoprotein. 

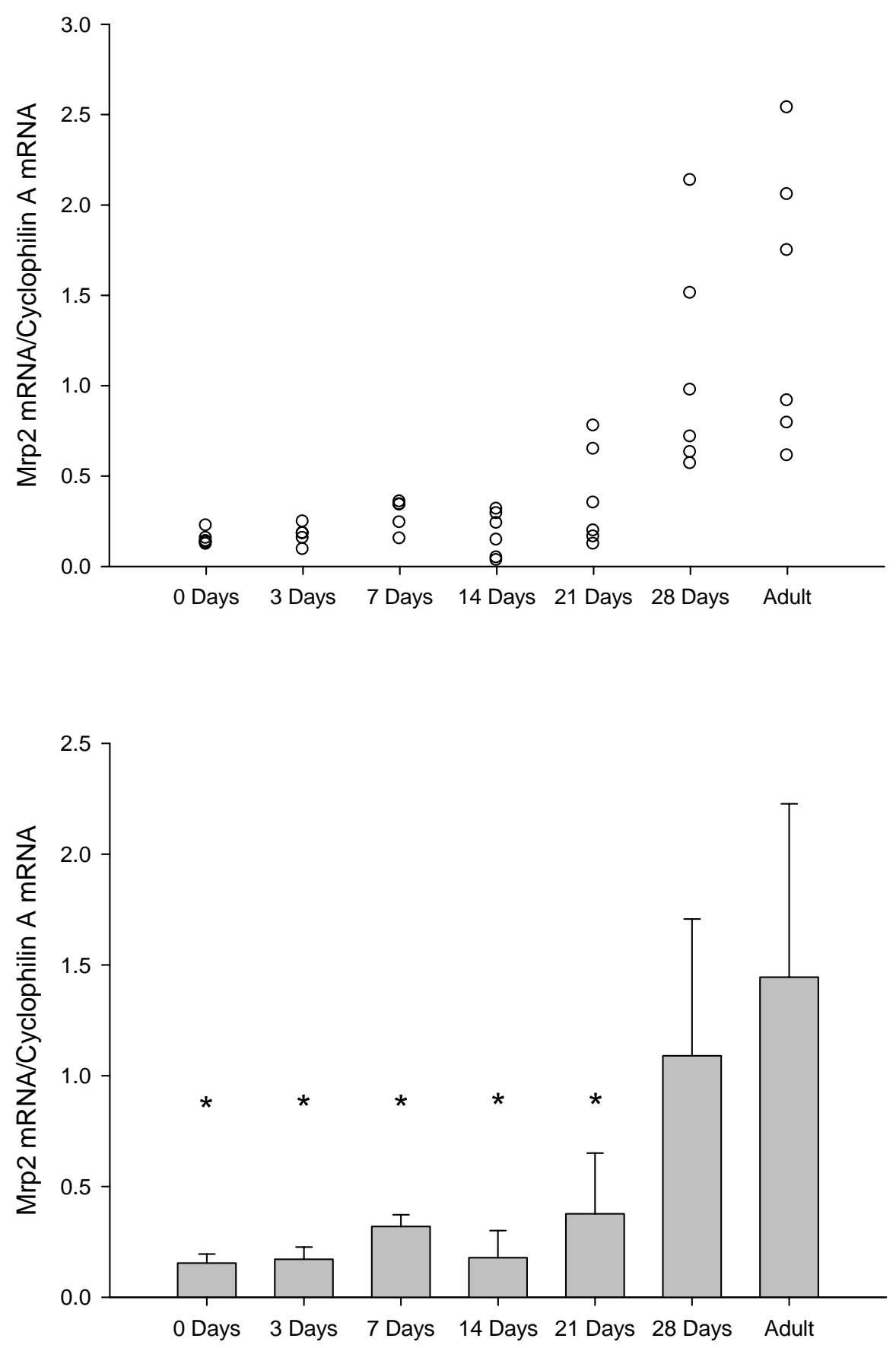

Figure 3-6. Ontogeny of Normalized Mrp2 mRNA Expression in Rat Liver Samples. Upper panel. scatterplot of normalized Mrp2 mRNA expression of individual rats by each age group. Lower panel, bar graph presenting mean \pm standard deviation from six rat liver samples in each age group. Mrp2, rat multidrug resistance-associated protein 2. 
adult values by 28 days of age. Car gene expression followed a similar developmental pattern as Pxr. Newborn rat liver Car mRNA expression was approximately $20-25 \%$ of adult expression in the first 3 weeks of life, but dramatically increased to approximately $59 \%$ by 28 days of age. Fxr mRNA expression was initially $30 \%$ of adult at birth through 3 days of age. Expression then spiked to $40 \%$ in 7 days of age before decreasing to $26 \%$ in 14 day-old rats. By 21 days, Fxr gene expression had climbed to 45\%, and by 28 days it had reached $65 \%$ of adult Fxr expression. Age associated mRNA expression for Hnf $4 \alpha$ in the same rat livers, however, was slightly different then the other nuclear factors. Newborn rat liver Hnf $4 \alpha$ was only $50 \%$ of adult values at birth, but decreased to $26 \%$ by 3 days of age, and eventually increased back to $56 \%$ by 7 days of age before dropping back to $25 \%$ by 14 days of age. Hnf $4 \alpha$ in rat livers then increased from $69 \%$ to $93 \%$ of adult expression by 21 and 28 days of age, respectively (Figure 3-7).

Statistical comparisons revealed significance in Pxr expression between all age groups ranging from newborn through 28 days-old rats as compared to adult rats (Figure 3-8). The same was true for Car where significant differences were detected in mRNA expression between newborn through 21 day-old rat livers versus adult rat livers (Figure 3-9). Fxr mRNA expression in newborns through 21 day-old rat livers were significantly different than adult liver expression as well (Figure 3-10). Unlike all the other nuclear receptors, Hnf $4 \alpha$ did not exhibit any significant age associated expression between any of the age groups examined (Figure 3-11).

In order to investigate the coordinated regulation between nuclear receptors, we also compared the normalized mRNA expression of Pxr, Car, and Fxr versus Hnf4 $\alpha$. We were able to detect a positive correlation between all three nuclear receptors and $\mathrm{Hnf} 4 \alpha$ in the rat liver samples. Pxr was positively correlated with $\operatorname{Hnf} 4 \alpha\left(\mathrm{r}^{2}=0.22, \mathrm{p}=0.003\right)$ and Car $\left(r^{2}=0.28, p<0.001\right)$. Fxr also exhibited a positive correlation to Hnf $4 \alpha$ with $\left(r^{2}\right.$ $=0.59, \mathrm{p}<0.001)$. Next, we compared the correlations between the rat hepatic nuclear receptors and the $\mathrm{ABC}$ transporters (Figure 3-12 to Figure 3-15). mRNA expression of all three nuclear receptors (Pxr, Car, and Fxr) were positively correlated with those of the ABC transporters (Mdr1a, Mdr1b, and Mrp2). Expression of Pxr was positively correlated with Mdr1a $\left(\mathrm{r}^{2}=0.28, \mathrm{p}<0.001\right), \operatorname{Mdr} 1 \mathrm{~b}\left(\mathrm{r}^{2}=0.32, \mathrm{p}<0.001\right)$, and $\operatorname{Mrp} 2\left(\mathrm{r}^{2}\right.$ $=0.29, \mathrm{p}<0.001)$. Similar, but weaker correlations were observed for Car and Mdr1a $\left(\mathrm{r}^{2}\right.$ $=0.22, \mathrm{p}<0.01), \operatorname{Mdr} 1 \mathrm{~b}\left(\mathrm{r}^{2}=0.23, \mathrm{p}<0.01\right)$, and Mrp2 $\left(\mathrm{r}^{2}=0.26, \mathrm{p}<0.01\right)$. Much stronger correlations were detected between Fxr and Mdr1a $\left(\mathrm{r}^{2}=0.44, \mathrm{p}<0.01\right), \operatorname{Mdr} 1 \mathrm{~b}$ $\left(\mathrm{r}^{2}=0.34, \mathrm{p}<0.01\right)$, and $\operatorname{Mrp} 2\left(\mathrm{r}^{2}=0.83, \mathrm{p}<0.01\right)$.

\section{Protein Expression of Mdr1/P-gp and Mrp2 in Rat Liver Samples}

We were successful in quantifying Mdr1/P-gp and Mrp2 protein expression for rat liver samples ranging from newborns throughout adults. For Mdr1/P-gp, relative protein expression was highest in the 28 days-old group followed by the 14 and 21 day-old groups. The lowest Mdr1/P-gp protein expression occurred in the 0,3 , and 7 day-old rat livers at $25 \%$ and $46 \%$ of adult protein levels, respectively (Figure 3-16). Statistically, 0 , 


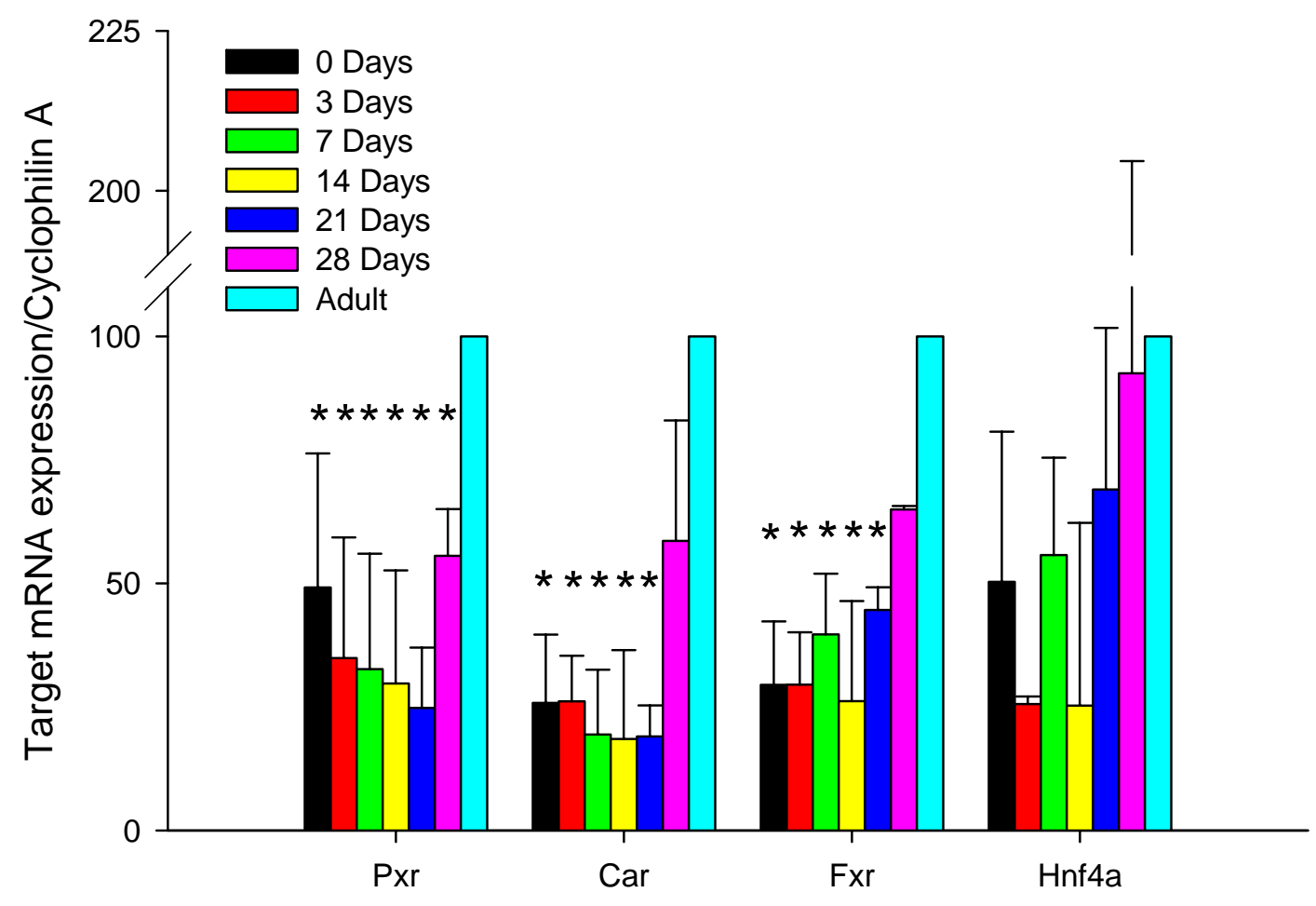

Figure 3-7. Ontogeny of Nuclear Receptors Pxr, Car, Fxr, and Hnf4 $\alpha$ in Rat Liver Samples.

Values are normalized target gene expression relative to the adult liver group. Asterisk (*) represents a significant difference as compared to the adult group $(\mathrm{p}<0.05)$. Pxr, pregnane $\mathrm{X}$ receptor; Car, constitutive androstane receptor; Fxr, farnesoid X receptor; Hnf $4 \alpha$, hepatic nuclear factor $4 \alpha$. 

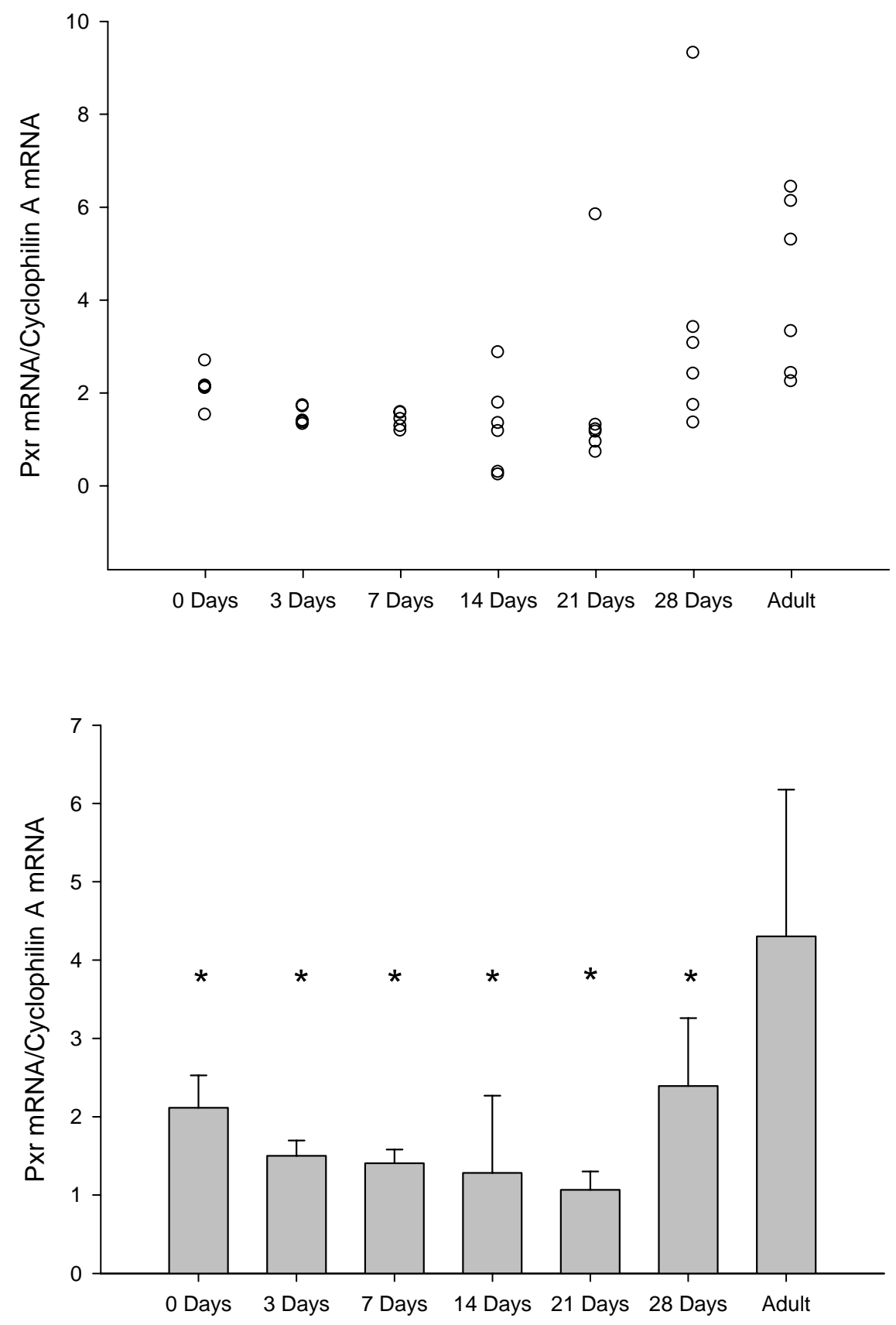

Figure 3-8. Ontogeny of Normalized Pxr mRNA Expression in Rat Liver Samples. Upper panel. scatterplot of normalized Pxr mRNA expression of individual rats by each age group. Lower panel, bar graph presenting mean \pm standard deviation from six rat liver samples in each age group. Pxr, pregnane $\mathrm{X}$ receptor. 

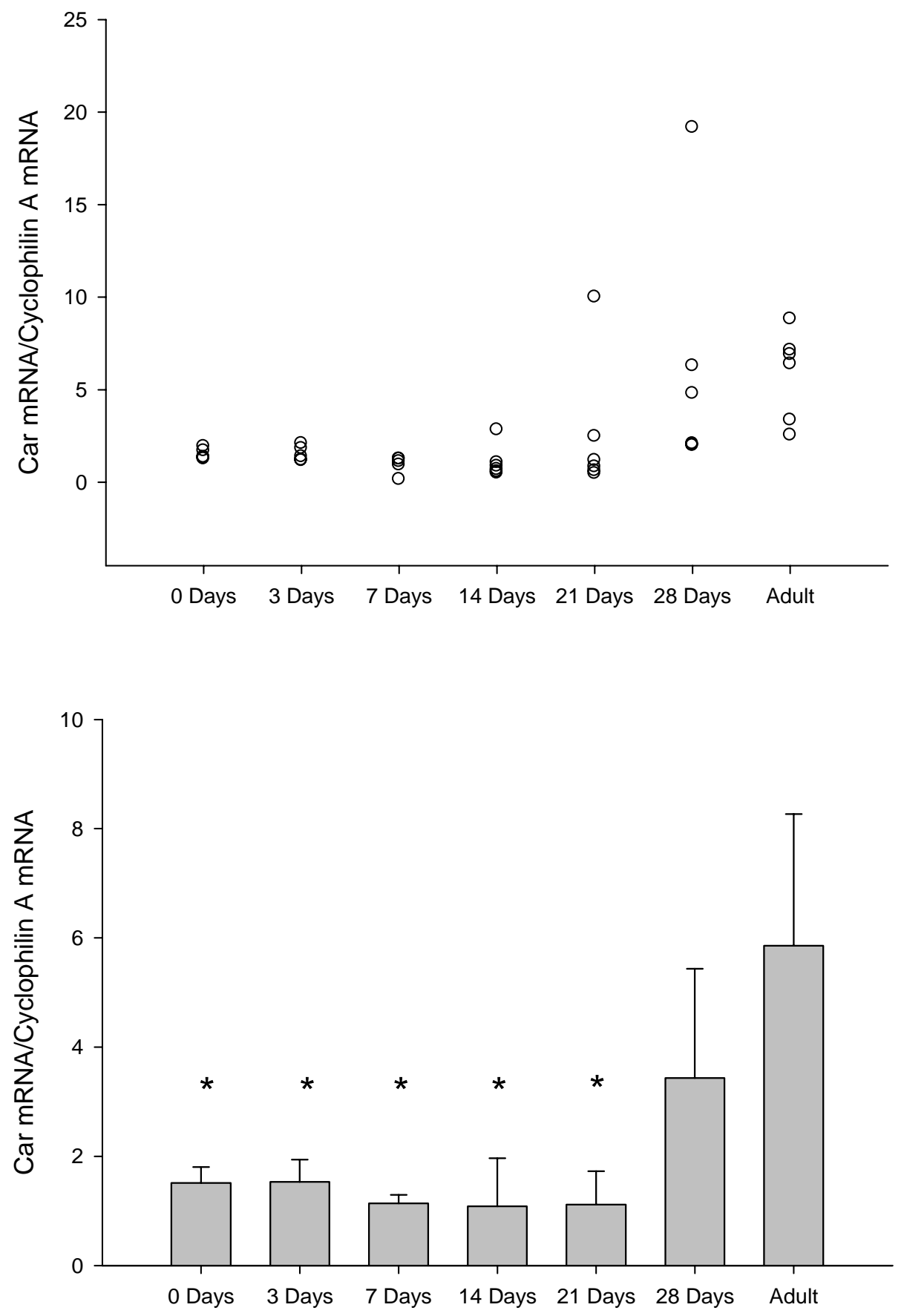

Figure 3-9. Ontogeny of Normalized Car mRNA Expression in Rat Liver Samples. Upper panel. scatterplot of normalized Car mRNA expression of individual rats by each age group. Lower panel, bar graph presenting mean \pm standard deviation from six rat liver samples in each age group. Car, constitutive androstane receptor. 

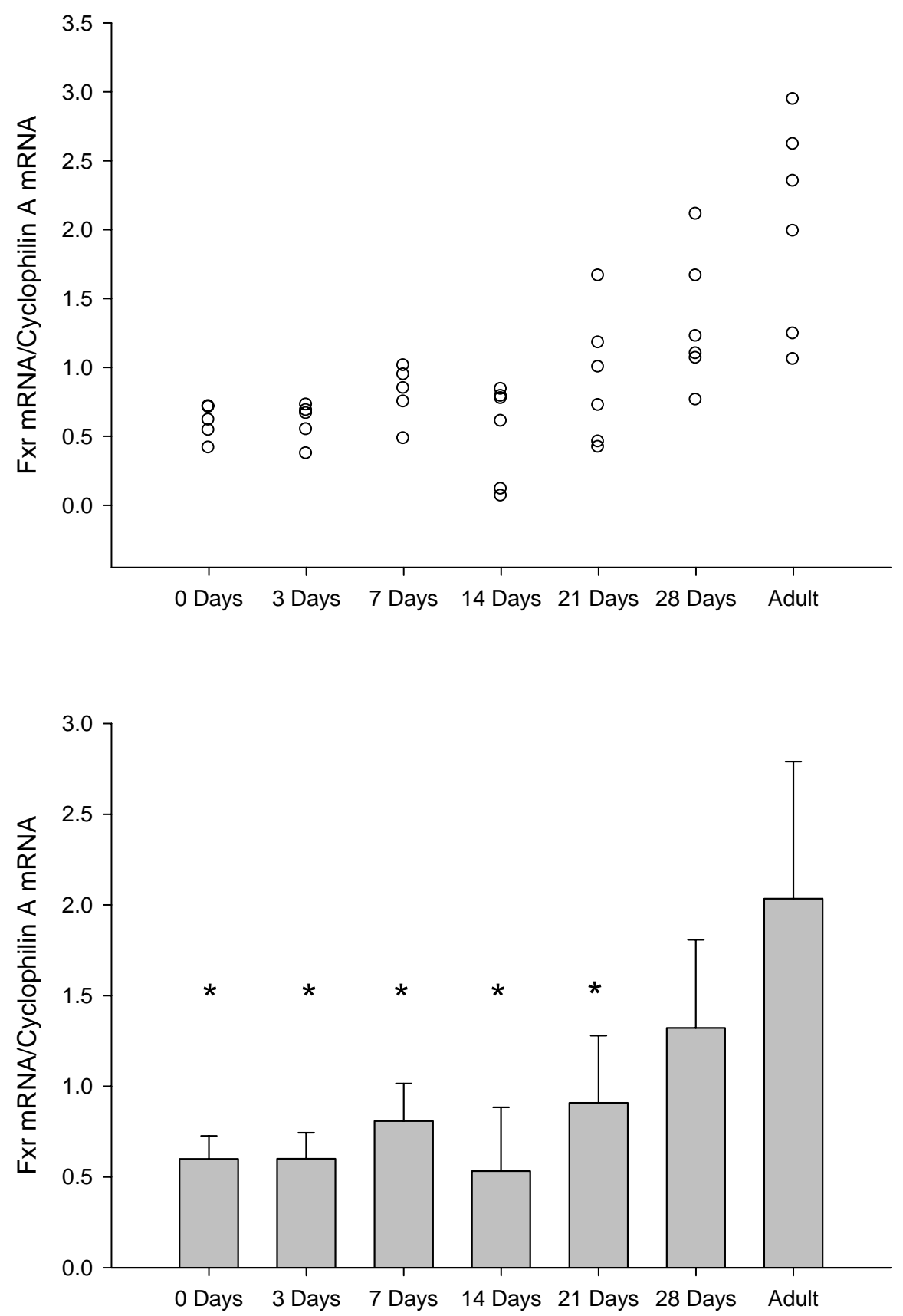

Figure 3-10. Ontogeny of Normalized Fxr mRNA Expression in Rat Liver Samples. Upper panel. scatterplot of normalized Fxr mRNA expression of individual rats by each age group. Lower panel, bar graph presenting mean \pm standard deviation from six rat liver samples in each age group. Fxr, farnesoid $\mathrm{X}$ receptor. 

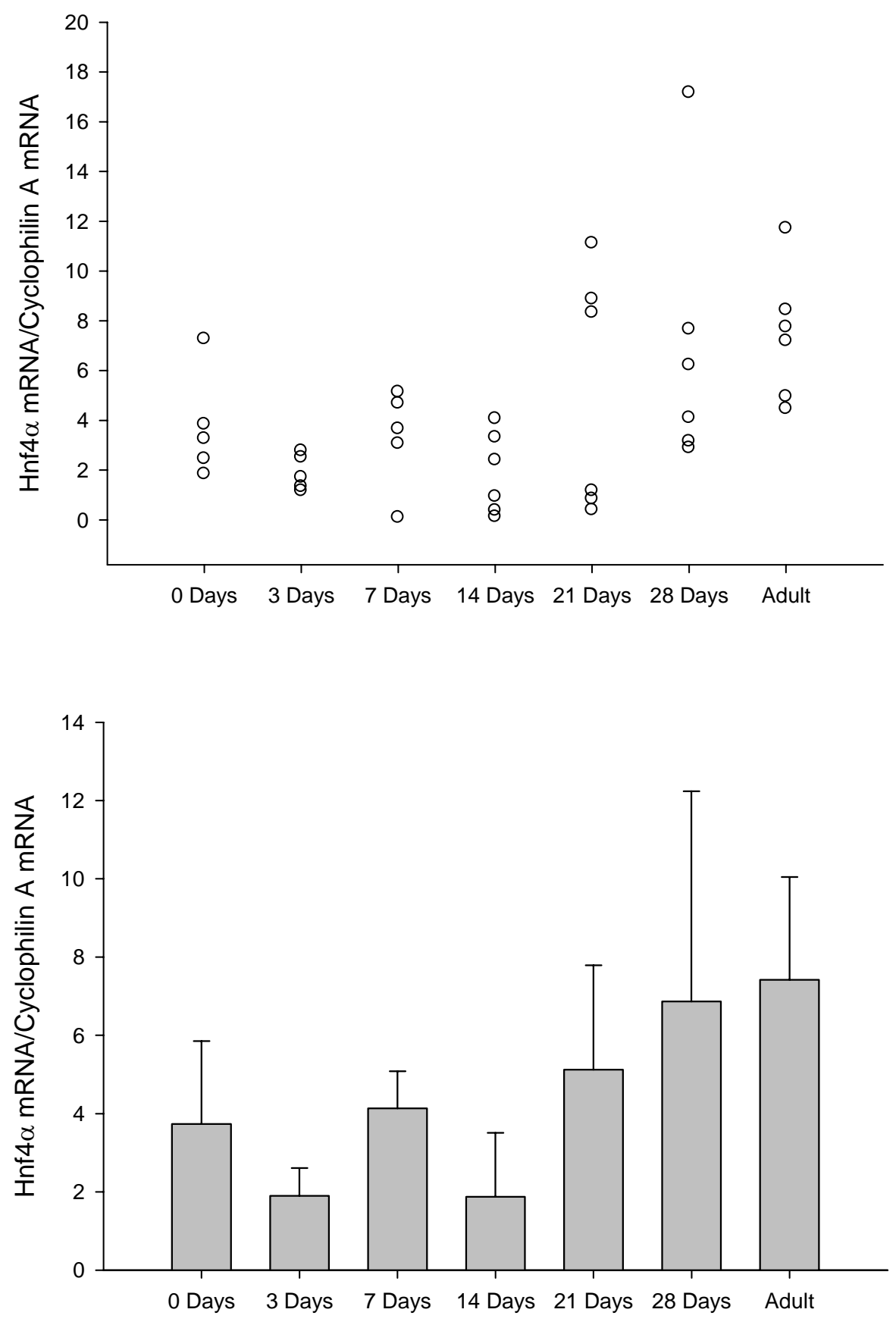

Figure 3-11. Ontogeny of Normalized Hnf $4 \alpha$ mRNA Expression in Rat Liver Samples. Upper panel. scatterplot of normalized Hnf $4 \boldsymbol{\alpha}$ mRNA expression of individual rats by each age group. Lower panel, bar graph presenting mean \pm standard deviation from six rat liver samples in each age group. Hnf $4 \alpha$, hepatic nuclear factor $4 \alpha$. 


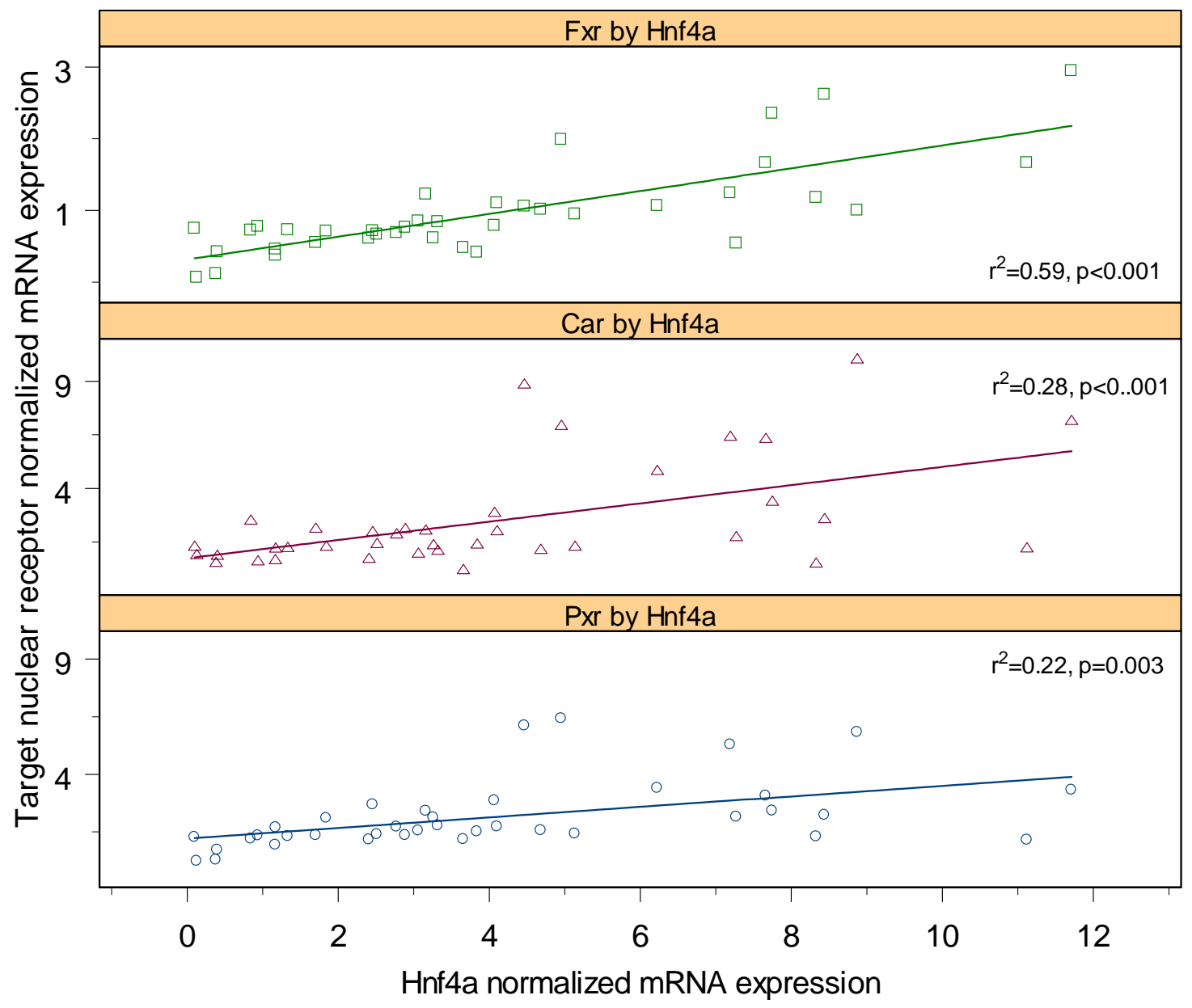

Figure 3-12. Hnf4 $\alpha$ Correlation Analysis in Rat Liver Samples.

Correlation between normalized target mRNA expression for nuclear receptors Pxr, Car, and Fxr versus normalized Hnf4 $\alpha$ (Hnf4a) mRNA levels. X-axis represents normalized Hnf $4 \alpha$ mRNA expression levels. Y-axis is split into 3 different panels each representing normalized Pxr, Car, or Fxr mRNA expression values. Correlation between Hnf4 $\alpha$ and the corresponding nuclear receptor is indicated by the $r^{2}$ value. A p-value for each correlation is reported as well. 


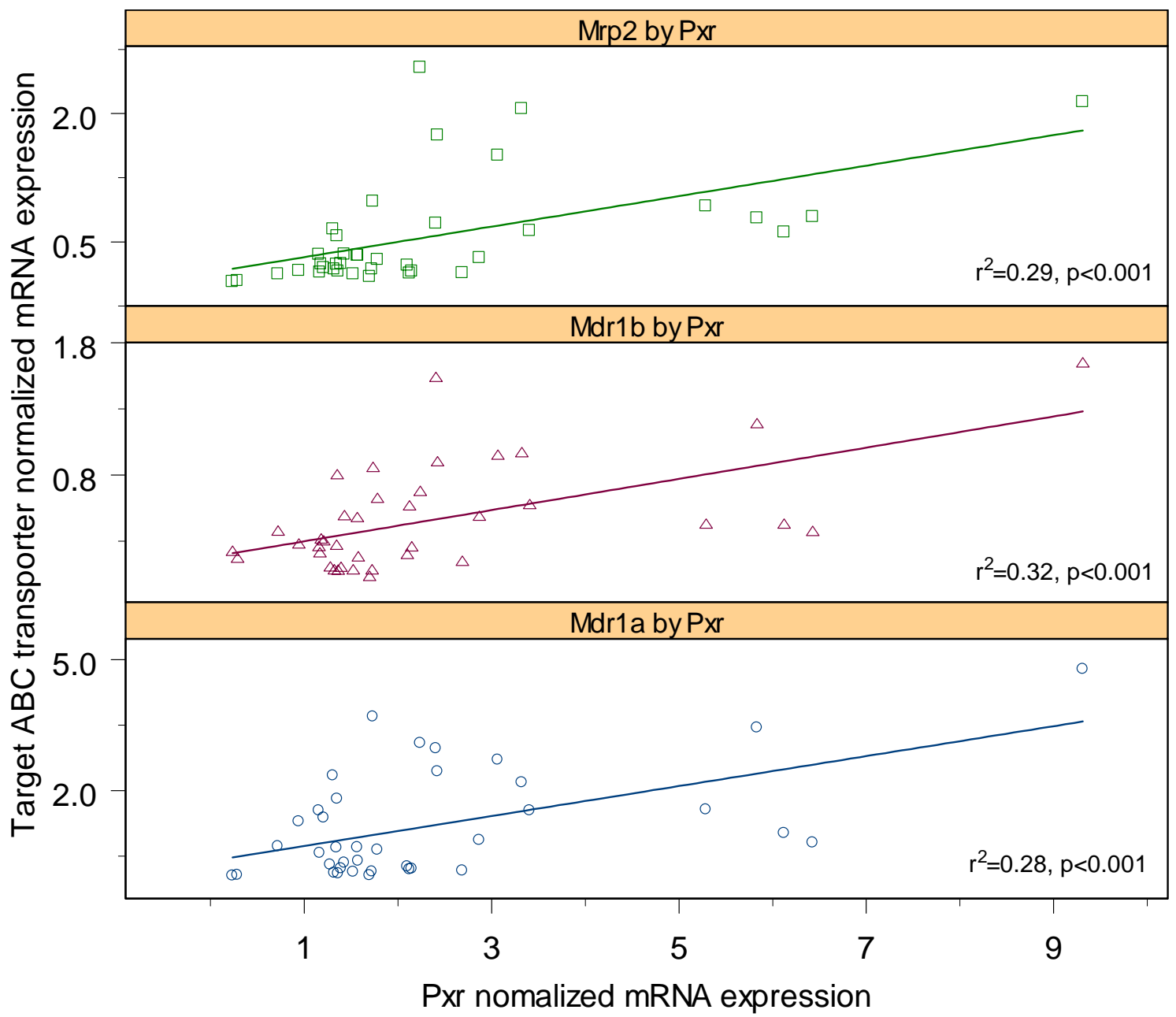

Figure 3-13. Pxr Correlations to Mdr1a, Mdr1b, and Mrp2.

Correlation between normalized target mRNA expression for Pxr versus normalized target $\mathrm{ABC}$ transporter levels. X-axis represents normalized Pxr mRNA expression levels. Y-axis is split into 3 different panels each representing normalized Mdr1a, Mdr1b, or Mrp2 mRNA expression values. Correlation between Pxr and the corresponding $\mathrm{ABC}$ transporter is indicated by the $r^{2}$ value. A p-value for each correlation is reported as well. 


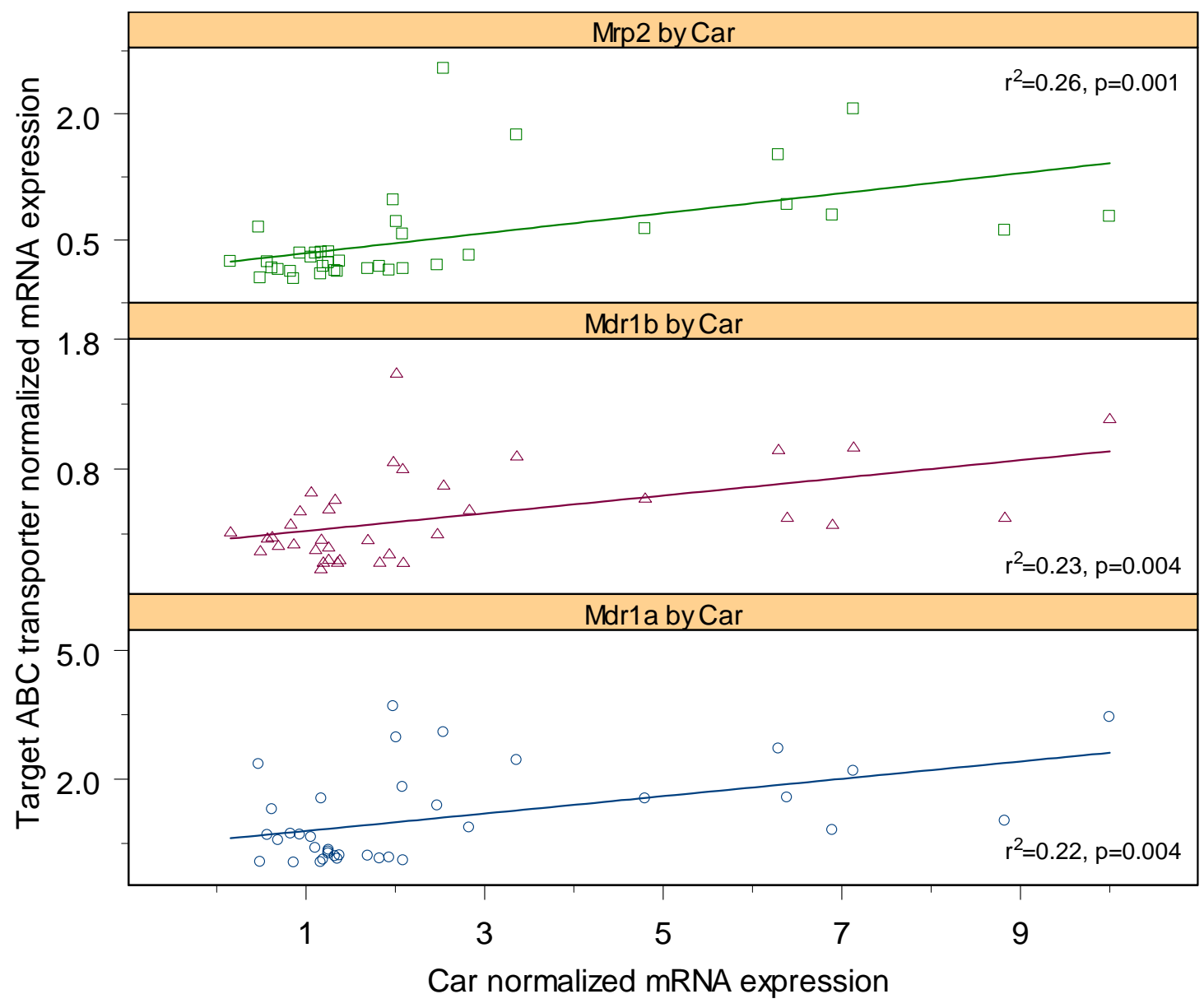

Figure 3-14. Car Correlations to Mdr1a, Mdr1b, and Mrp2.

Correlation between normalized target mRNA expression for Pxr versus normalized target $\mathrm{ABC}$ transporter levels. $\mathrm{X}$-axis represents normalized Car mRNA expression levels. Y-axis is split into 3 different panels each representing normalized Mdrla, Mdr1b, or Mrp2 mRNA expression values. Correlation between Car and the corresponding $\mathrm{ABC}$ transporter is indicated by the $r^{2}$ value. A p-value for each correlation is reported as well. 


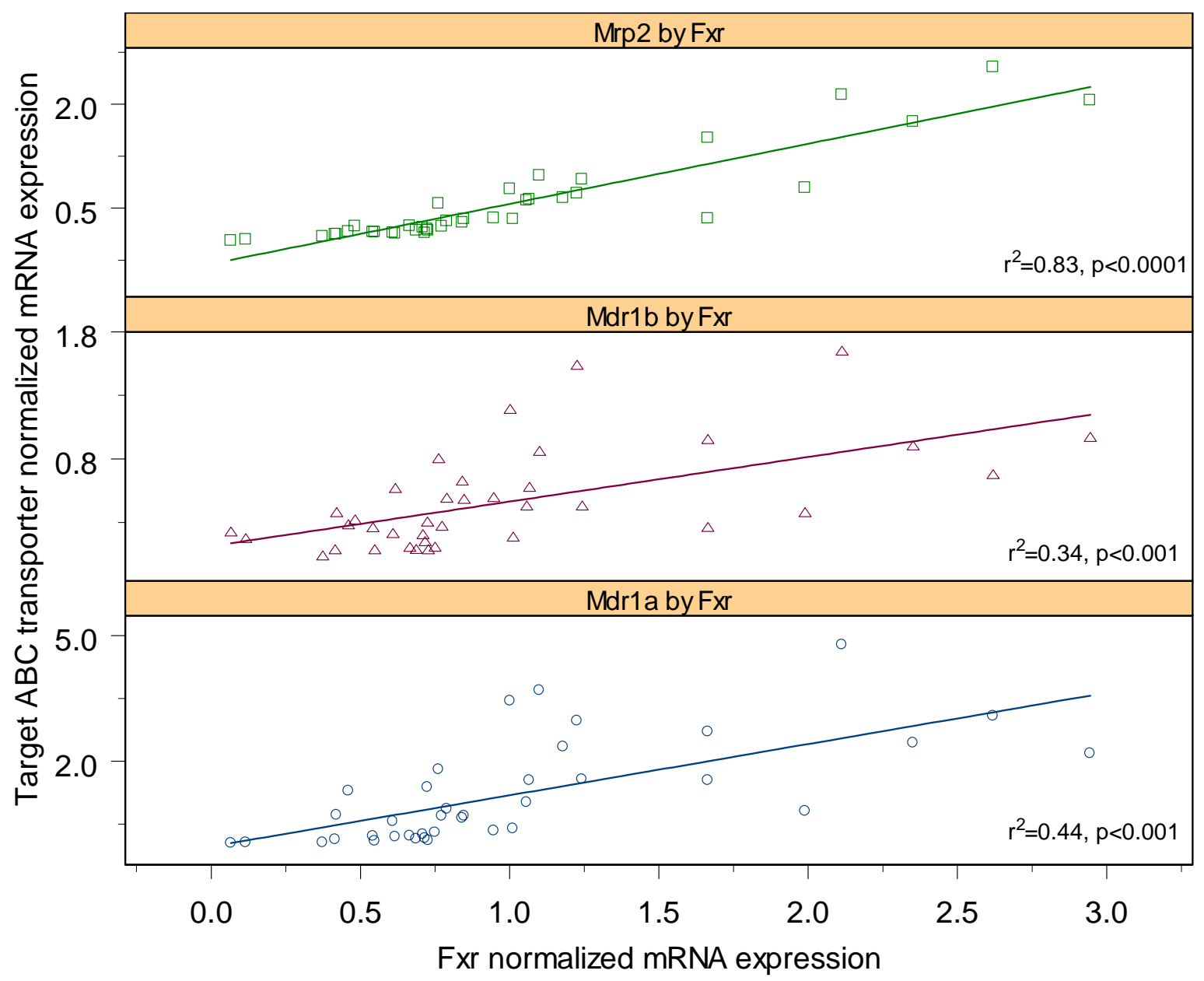

Figure 3-15. Fxr Correlations to Mdr1a, Mdr1b, and Mrp2.

Correlation between normalized target mRNA expression for Pxr versus normalized target $\mathrm{ABC}$ transporter levels. $\mathrm{X}$-axis represents normalized Fxr mRNA expression levels. Y-axis is split into 3 different panels each representing normalized Mdrla, Mdr1b, or Mrp2 mRNA expression values. Correlation between Fxr and the corresponding $\mathrm{ABC}$ transporter is indicated by the $r^{2}$ value. A p-value for each correlation is reported as well. 


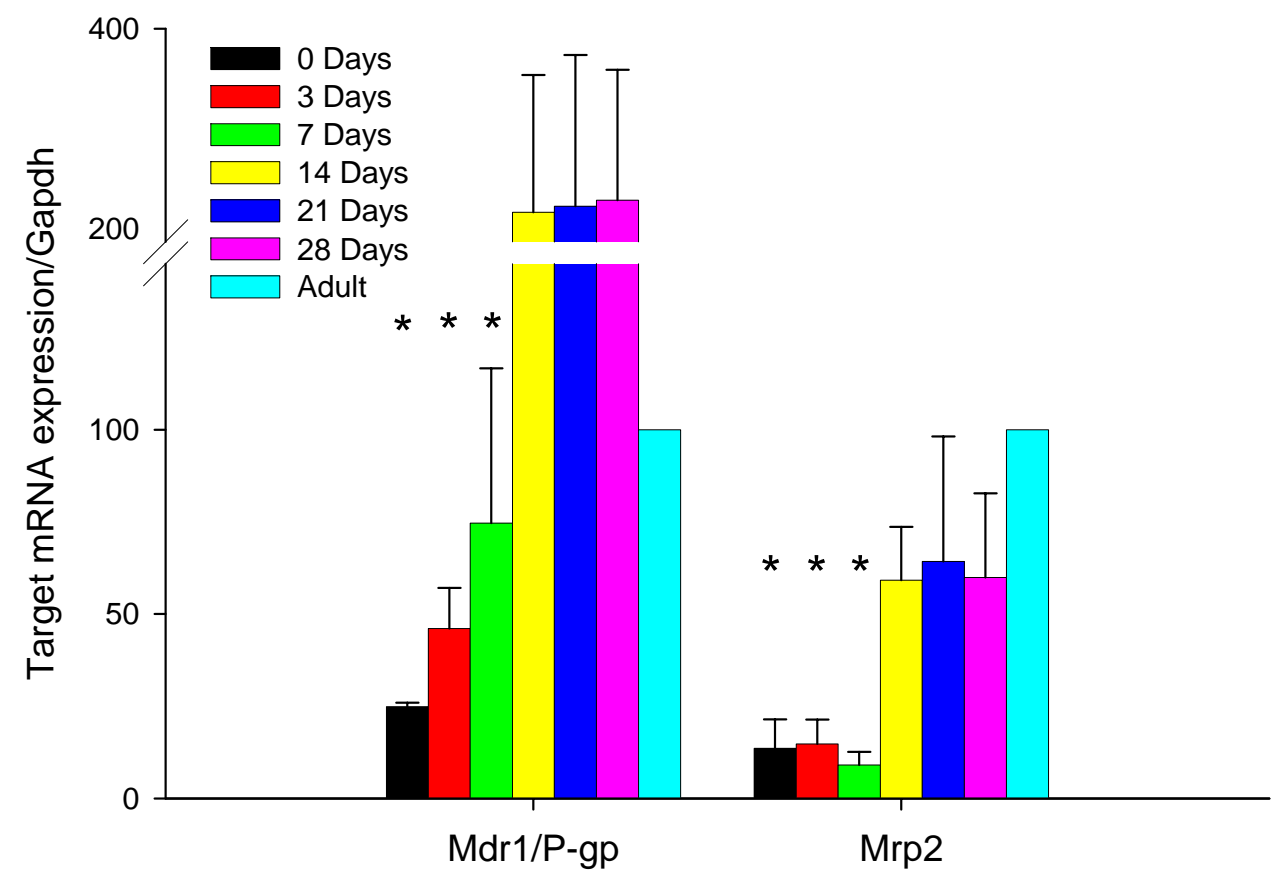

Figure 3-16. Ontogeny of Mdr1a and Mrp2 Protein Expression in Rat Liver Samples. Values are normalized target gene expression relative to the highest expression group. Asterisks $(*)$ represent significant differences $(p<0.05)$ between the various age groups as compared to the adult group. 
3 , and 7 day-old rat liver samples all had significantly lower Mdr1/P-gp expression ( $\mathrm{p}<$ 0.05 ) than the 28 day-old rat livers (Figure 3-17).

Mrp2 relative protein expression in the rat liver remained low in the first weeks of life and eventually reached maximal value by adulthood. 0 and 3 day-old livers expressed $14 \%$ and $15 \%$ of adult liver Mrp2, while 7 day-old rat livers expressed almost $10 \%$ of adult Mrp2 content. Mrp2 protein expression increased gradually to approximately $60 \%$ of adult expression between 14 and 28 days of age (Figure 3-16). Significant differences $(\mathrm{p}<0.05)$ were detected between the 0,3 , and 7 day-old versus adult liver groups (Figure 3-18).

Protein expression for both Mdr1 and Mrp2 overall matched those from the relative mRNA expression in the same liver samples. In general, Mdr1/P-gp protein and mRNA expression were low in the 0,3 , and 7 day-old groups and increased to a maximal level later in during postnatal development. Likewise, Mrp2 values for both mRNA and protein expression remained low early in life and gradually increased to maximal values throughout postnatal maturation. For Mdr1/P-gp protein expression, 14 day-old rat liver samples did not exhibit a significant difference as compared to 28 day samples as was for the Mdr1a mRNA expression data. Similarly for Mrp2, 14 and 21 day-old liver protein expression was not significantly different from the adult samples as suggested by the Mrp2 mRNA expression data.

\section{Discussion}

In the current study, we examined the ontogeny of $\mathrm{ABC}$ transporters Mdrla, Mdr1b, and Mrp2 as well as nuclear receptors Pxr, Fxr, Car, and Hnf4 $\alpha$ in rats during seven specific time points throughout maturation ranging from newborn to adult. For the transporters, we performed both real-time RT-PCR as well as Western immunoblots in order to semi-quantitate their mRNA and protein expression. For the nuclear receptors, we characterized their mRNA expression using real-time RT-PCR. We were able to describe an ontogenic process in rat liver Mdr1/P-gp as well as Mrp2 mRNA and protein expression. An age-associated expression was also described for the nuclear receptors Pxr, Car, and Fxr.

Overall, mRNA expression for Mdr1a, Mdr1b, and Mrp2 were low throughout the first three weeks of life. For Mdrla and Mdrlb, normalized mRNA expression increased from 21 day-olds liver samples to a maximal expression level by 28 days of age before declining to adult levels. The Mdrla results were similar to those reported by Rosati [63] where mRNA levels were less than $50 \%$ of 60 days-old rats from birth until approximately 12 days-old in the rat liver. While the Mdr1b mRNA expression pattern was similar to that obtained by Rosati [63], we could not detect significant differences between the age groups. Mrp2 expression in the rat liver increased gradually from 0 days-old through 21 days of age before reaching $75 \%$ of adult expression values by 28 

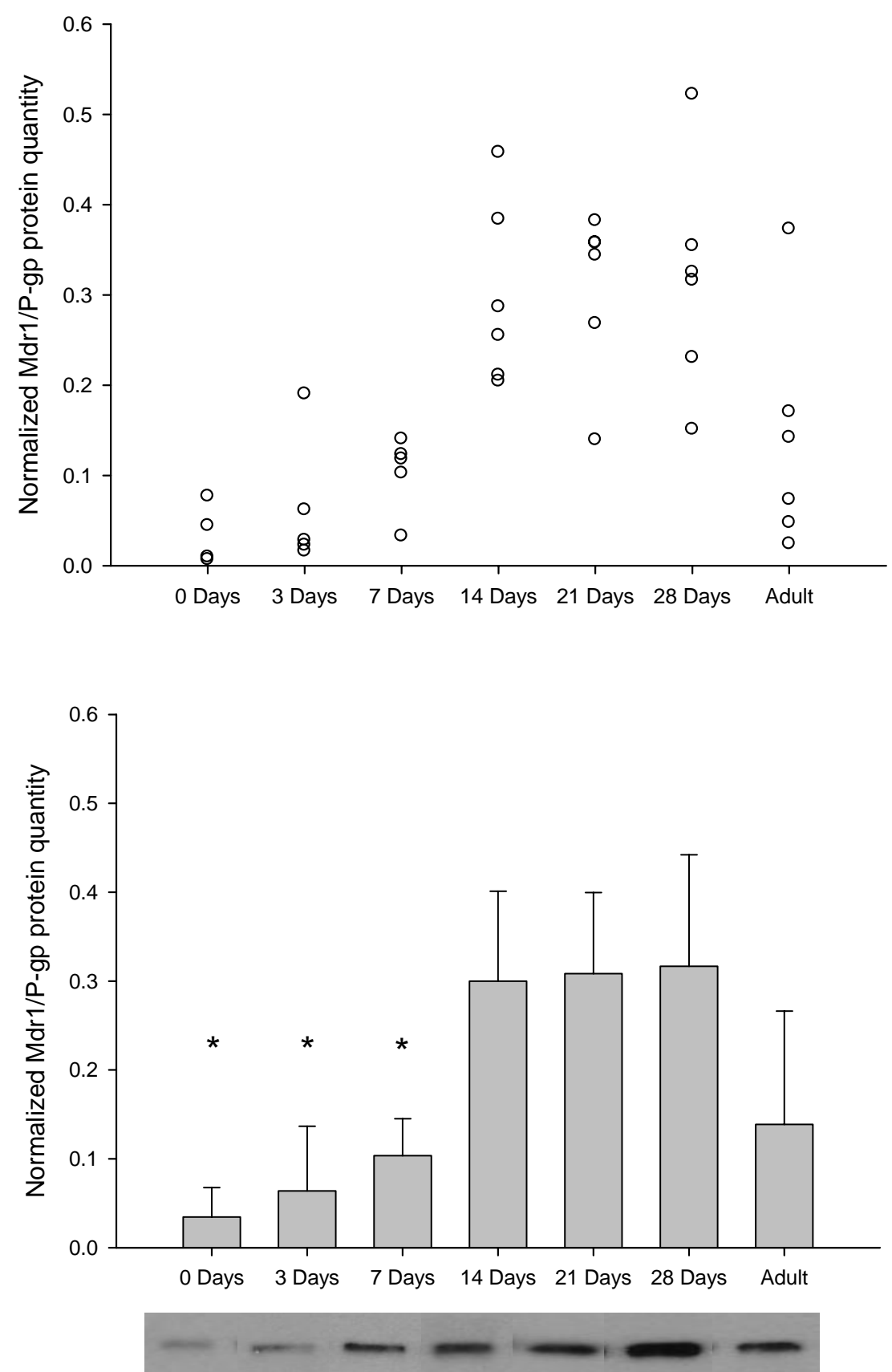

Figure 3-17. Ontogeny of Normalized Mdr1/P-gp Protein Expression in Rat Liver Samples.

Upper panel. scatterplot of normalized Mdr1/P-gp protein expression of individual rats by each age group. Lower panel, bar graph presenting mean \pm standard deviation from six rat liver samples in each age group. Asterisks $\left(^{*}\right)$ represents a significant difference (p $<0.05$ ) compared to the 28 day-old group. Underneath the mean \pm standard deviation bar graph is a representative western immunoblot of two Mdr1/P-gp samples from each corresponding age group. Mdr1, multidrug resistance 1 gene/P-glycoprotein. 

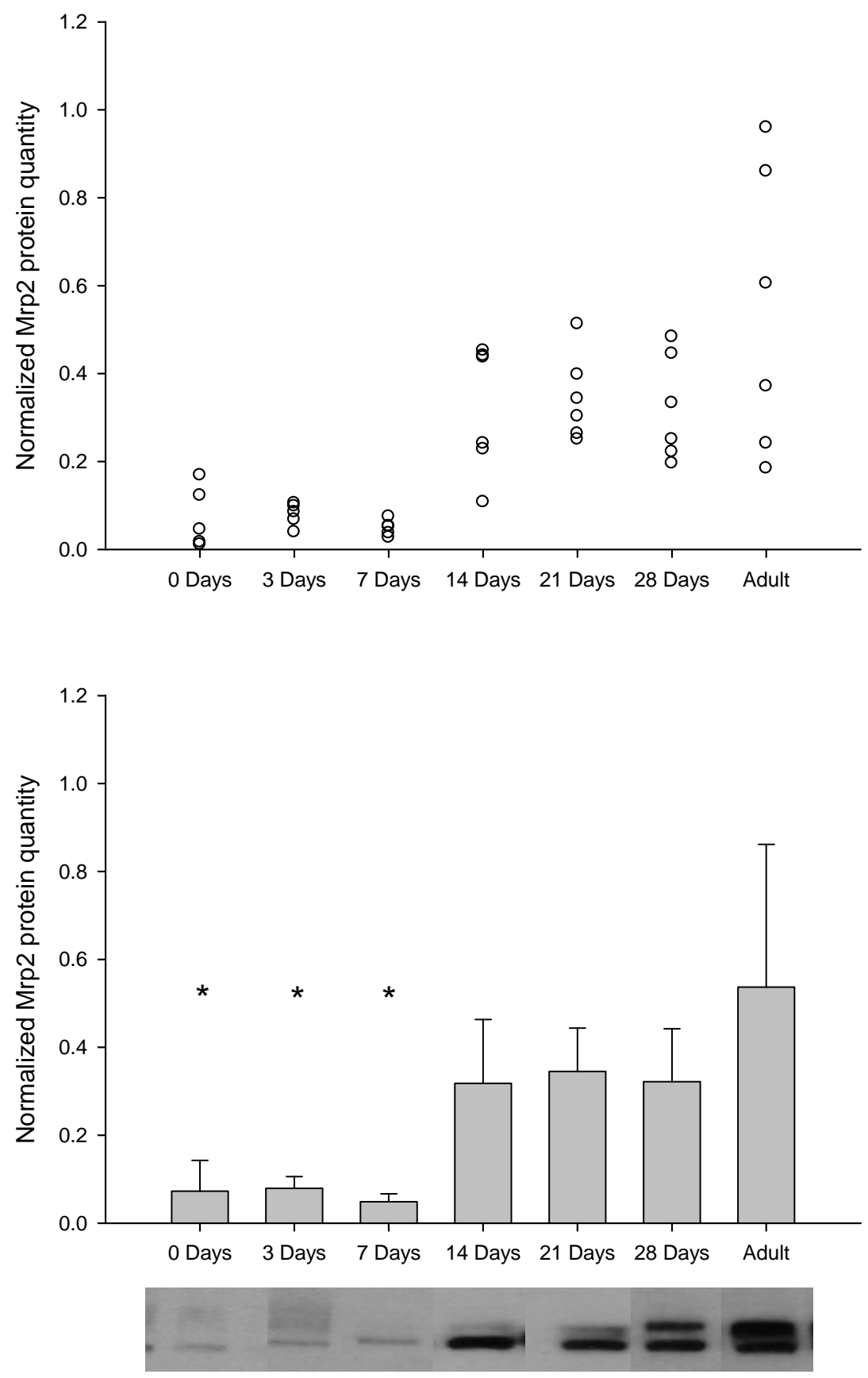

Figure 3-18. Ontogeny of Normalized Mrp2 Protein Expression in Rat Liver Samples. Upper panel. scatterplot of normalized Mrp2 protein expression of individual rats by each age group. Lower panel, bar graph presenting mean \pm standard deviation from six rat liver samples in each age group. Asterisks $(*)$ represents a significant difference $(\mathrm{p}<$ $0.05)$ compared to the adult group. Underneath the mean \pm standard deviation bar graph is a representative western immunoblot of two Mrp2 samples from each corresponding age group Mrp2, multidrug resistance-associated protein 2. 
days of age. This pattern was consistent with the results of Rosati [63], where adult rat liver Mrp2 expression was significantly greater than that of rats less than one week old. Similar findings were reported by Gao [61], where Mrp2 mRNA expression in rat livers from birth throughout 20 days of age fluctuated between $25-84 \%$ of adult values. Zinchuk [101] also reported less than 50\% of adult Mrp2 mRNA expression in those rat livers less than one week of age.

Protein expression for Mdr1/P-gp in general matched those detected for mRNA expression in our study. Mdr1/P-gp protein levels remained low throughout postnatal maturation but increased dramatically between 14 days of age and adulthood. This observation, however, was in contrast to a report by Mahmood [62], who stated that Mdr1/P-gp protein levels were greater than $100 \%$ in the newborn, 7 day-, and 21 day-old mouse liver as compared to adult mouse liver.

Similar to the Mdr1/P-gp results, Mrp2 protein expression in the rat livers also mimicked their mRNA expression pattern. Both Mrp2 mRNA and protein expression were less than $60 \%$ of adult values during the first 14 postnatal days, but increased to a maximal level by adulthood. The only divergence between protein and mRNA expression was that 14 day-old rat livers exhibited higher protein content then the mRNA levels. Again, the developmental pattern was in agreement with those reported for rat Mrp2 protein by Rosati [63], Gao [61], and Zinchuk [101]. Rosati [63] detected Mrp2 proteins in 15 day-old rats through immunoblotting while Gao [61], through immunostaining of rat livers, was able to demonstrate positive canalicular immunofluorescence comparable to those of adult rat livers in postnatal day 12 rats.

Regulators of Mdr1/P-gp and Mrp2 include nuclear receptors Pxr, Car, and Fxr [57, 58, 71, 72], while Hnf4 $\alpha$ functions as a master regulator of Pxr and Car [76]. Given our observation of the age dependency in Mdr1/P-gp and Mrp2 expression during rat liver maturation, we also investigated the ontogenic expression of nuclear receptors as a potential regulatory mechanism for the transporter expression. We were able to detect significant differences in nuclear receptor expression for Pxr, Car, and Fxr throughout the early postnatal period versus adulthood. Specifically, we described a developmental pattern for Pxr and Car whereby rat livers from 0 to 21 postnatal days initially exhibited a high transcript level at birth but gradually declined to $25 \%$ and $19 \%$ of adult levels by 21 days of age. However, by 28 days of age, both rat liver Pxr and Car expression dramatically increased to those near adult levels. Unlike Pxr and Car, Fxr expression in the rat livers followed a more gradual increase throughout maturation. Fxr mRNA expression started from approximately $30 \%$ of adult levels at birth and gradually rose to $65 \%$ of adult levels by postnatal week 4 . Our results were similar to previously published results from Balasubramaniyan [71] and Huang [102] and further support the regulatory role of nuclear receptors in age associated transporter expression. Balasubramaniyan [71] provided evidence of limited Pxr and Fxr expression in rats less than four week of age as compared to adult rats while Huang [102] reported that in mouse livers, expression of Car mRNA was significantly lower in the first week of life as compared to adult mice. 
Nuclear receptors are considered crucial regulatory elements for the coordinated expression of drug metabolizing enzymes and drug transporters, specifically those in the family of cytochrome $\mathrm{P} 450$ of enzymes and the ABC family of transporters. As such, we wished to determine whether the ontogeny observed in $\mathrm{ABC}$ transporters in our rat livers could be partially explained by its regulation through the nuclear receptors. As previously mentioned, $\mathrm{HNF} 4 \alpha$ forms a higher level of regulation for drug metabolism and transport by acting as a master regulator of nuclear receptors PXR and CAR [76]. We were able to describe a positive correlation between Hnf4 $\alpha$, Pxr, Car, and Fxr mRNA expression. Although our correlation cannot establish a direct causal relationship in Hnf $4 \alpha$ regulation of Pxr, Car, and Fxr, the data suggests a possible common pathway in the maturational regulation of these nuclear receptors. Aside from the nuclear receptors themselves, we also reported a positive correlation between Pxr, Car, and Fxr with the $\mathrm{ABC}$ transporters. In particular, Fxr was highly correlated with Mrp2 expression in the rat livers $\left(\mathrm{r}^{2}=0.83, \mathrm{p}<0.0001\right)$. This suggests that regulation of hepatic Mrp2 expression occurs mainly through Fxr with minimal co-regulation by other nuclear receptors.

The ontogeny of the $\mathrm{ABC}$ transporters and the nuclear receptors from our rat liver samples all indicated an increase in their expression to levels comparable to adult rats between 14 days and 28 days of age. This might be due to changes in environmental and xenobiotic exposures during this phase of development. Specifically, rat wean from breast milk at postnatal day 21 [99]. An increase in nuclear receptor expression and subsequent drug transporter expression might be due to changes in dietary exposures of these rats.

In conclusion, the findings in the current study further characterized the postnatal ontogeny of Mdr1/P-gp and Mrp2 during liver development in the rat. Specifically, Mdr1/P-gp and Mrp2 expression are incomplete early in the postnatal period but increase throughout maturation. As regulatory agents of $\mathrm{ABC}$ transporter expression, we also characterized the age-associated expression of nuclear receptors Pxr, Car, Fxr, and Hnf $4 \alpha$. Again, we observed low expression of nuclear receptors a birth that increased to adult values with maturation. Furthermore, we described positive correlations between the expressions of the nuclear receptors and the $\mathrm{ABC}$ transporters. An important extension of the current work will be to characterize whether changes in the expression Mdr1/P-gp and Mrp2 during normal pediatric development can translate into clinically significant difference in the elimination medications used in pediatric pharmacotherapy. 


\section{CHAPTER 4. THE EFFECT OF MRP2 DEFICIENCY ON THE IN VIVO PHARMACOKINETICS OF CEFTRIAXONE IN RATS}

\section{Introduction}

The human multi-drug resistance proteins (MRPs) consist of a family of ATPbinding cassette $(\mathrm{ABC})$ transporters that mediate the unidirectional transport of various organic anions as well as lipophilic substances conjugated to glutathiones, glucuronates, or sulfates. MRP2 (ABCC2) has been recognized as a major transporter of bilirubin and drug substrates as well as their conjugates into the bile. Thus, for drugs with considerable biliary excretion, changes in MRP2 expression may translate into profound differences in their pharmacokinetic profile and subsequent therapeutic efficacy. MRP2 has been associated with the biliary excretion of several therapeutic agents and its metabolites used in pediatric pharmacotherapy including various antibiotics, chemotherapeutic agents, and HIV protease inhibitors [103]. Specifically, MRP2 has been implicated in the biliary excretion of several therapeutic agents and its metabolites used in pediatric pharmacotherapy, including irinotecan, saquinavir, ritonavir, indinavir and ceftriaxone [104, 105]. In humans, a deficiency in MRP2 occurs in patients with Dubin-Johnson syndrome. Clinically, Dubin-Johnson syndrome manifests in chronic conjugated hyperbilirubinemia as well as impaired conjugated organic anion transport [106]. Mrp2 deficiency also occurs naturally in the TR-/Abcc2 strain of Wistar rats rendering them as a widely used animal model for the study of Mrp2 function in drug disposition [97].

As reported in the Chapters 2 and 3, MRP2 mRNA and protein expression in humans and rats are limited in the early periods of development and increase with maturation. Immaturity of MRP2-mediated drug transport throughout the body, including decreased MRP2-mediated hepatic biliary excretion, may be a source of deviation in drug pharmacokinetic properties between newborns and infants as compared to adults.

We chose the third-generation cephalosporin antibiotic ceftriaxone (Rocephin ${ }^{\circledR}$ ) as model drug to study the effect of ontogeny on MRP2-mediated elimination processes. Ceftriaxone is a broad spectrum cephalosporin antibiotic commonly used in the pediatric population for ear infections, respiratory tract infections, as well as meningitis. In contrast to the aforementioned MRP2 substrates, ceftriaxone is primarily eliminated by renal and biliary excretion (33-67\%) and does not appear to be metabolized to a relevant extent [50]. Additionally, ceftriaxone is excreted into the bile as an unconjugated drug $[49,104,107]$. Thus, studies on the effect of MRP2 ontogeny on ceftriaxone pharmacokinetics (PK) are not be obscured by concurrent developmental processes in Phase I or Phase II drug metabolizing enzymes, making ceftriaxone an ideal model drug to study the functional consequences of transporter maturation on in vivo pharmacokinetics. Additionally, there are implications that impaired MRP2 activity may play a role in adverse events associated with ceftriaxone used in neonates. While the product label advises against administering ceftriaxone to hyperbilirubinemic neonates, 
several clinical reports of ceftriaxone induced cholestasis and pseudolithiasis in neonates and children exist in the literature $[54,108]$. While little is known about the mechanism which leads to the biliary sludge, particularly for the high risk pediatric population, data implicates the reduced biliary excretion of ceftriaxone possibly due to an immature MRP2 in the pediatric patients [97, 109]. This suggests that newborns, particularly premature infants whose drug clearance mechanisms are still in development, may particularly be at a higher risk for ceftriaxone induced hyperbilirubinemia and cholestasis.

The aim of the present study was to evaluate possible variations in ceftriaxone disposition due to a deficiency in Mrp2 mediated biliary excretion. To do so, the pharmacokinetic parameters of ceftriaxone were determined in an animal model using wild-type and Mrp2-deficient (TR-) rats. The TR- rat was used as a model for decreased hepatic Mrp2 expression as observed in neonates and young infants. We quantified hepatic Mrp2 mRNA and protein levels in the WT and TR- rats in order to assess the contribution of Mrp2 to ceftriaxone kinetics. While the literature does not provide any evidence of Mdr1/P-gp in the biliary excretion of ceftriaxone, there is, in general, a certain shared degree of overlapping substrate specificity between Mdr1 and Mrp2 [103]. Therefore, we also needed to assess the potential role of P-gp in the biliary excretion of ceftriaxone through relative quantification of mRNA and protein expression of Mdr1/Pgp in the TR- and WT rats. The results of this study ultimately provide information for a better understanding of the potential for transporter mediated ceftriaxone toxicity in pediatric pharmacotherapy and the effect of transporter maturation in general.

\section{Materials and Methods}

\section{Pharmacokinetic Study}

Eight-week old male Wistar (Hsd:WI, $\mathrm{n}=7$ ) and Mrp2 deficient TR- (HsdAmc:TRAbcc2, $n=6$ ) rats were obtained from Harlan Inc. (Indianapolis, IN). All animals were catheterized in the external jugular vein by the vendor. Catheters were exteriorized between the shoulder blades to ensure the catheter remained in place over the sampling interval. Patency of the catheter was maintained by flushing the catheter daily with saline and heparinized glycerin solution $(500 \mathrm{U} / \mathrm{ml})$ as per vendor protocol. All animals were housed in individual standard laboratory cages on a 12 hour light-dark cycle and had access to food and water ad lilbitum. The experimental protocol was approved by the Animal Care and Use Committee (ACUC) of the University of Tennessee Health Science Center.

All animals were allowed to recover from surgery for at least two days before initiation of the PK study. On the first day of the PK study, the animals were given a single tail vein injection of ceftriaxone $100 \mathrm{mg} / \mathrm{kg}$ reconstituted in saline for injection. The rats were kept in plastic metabolic cages throughout the duration of the study. Blood samples were collected at predose, and 5, 15, 30, 60, 90, 120, 180, 240, and 360 min after 
the dose. Approximately $200 \mu \mathrm{L}$ of blood was drawn from the jugular vein catheter and replaced immediately with an equal volume of saline solution. Blood samples were stored in BD microvolume heparinized blood tubes and placed on ice. Plasma was separated by centrifuging the samples for 2 minutes at $15,000 \mathrm{~g}$ at $4^{\circ} \mathrm{C}$. Cumulative 24 hour urine and feces were also collected. Plasma fractions, urine, and fecal samples were stored at $-20^{\prime} \mathrm{C}$ until analysis.

At the end of the study, all rats were anesthetized with carbon dioxide gas $\left(\mathrm{CO}_{2}\right)$ and sacrificed by cervical dislocation. Rat liver biopsies were dissected out and immediately frozen in liquid nitrogen. All frozen liver samples were stored at $-70^{\circ} \mathrm{C}$ until further processing.

\section{Ceftriaxone Assay}

\section{Equipment}

Ceftriaxone plasma concentrations were determined by high pressure liquid chromatography (HPLC). The HPLC system consisted of a Shimadzu LC system (Columbia, MD) which included a system controller (model SLC 10AVP), pump (model LC-10AD), autosampler (Prominence SIL-20A), and UV detector (SPD-10AV) set at 270 $\mathrm{nm}$ and 0.01 absorbance unit. Data acquisition, processing, reporting, and system control were performed with the LCsolution version 1.21 (Shimadzu, Columbia, MD) software. Chromatographic peak separation was performed using the Gemini ${ }^{\mathrm{TM}} 5-\mu \mathrm{C}_{18}$ column $(150 \times 4.6 \mathrm{~mm})$ after passing through a Security Guard ${ }^{\mathrm{TM}} \mathrm{C}_{18} 4.0 \times 2.0 \mathrm{~mm}$ guard column (Phenomenex, Torrance, CA).

\section{Chemicals and Reagents}

Ceftriaxone sodium salt, cefuroxime sodium salt, and hexadecyltrimethylammonium bromide (HDTA) were all purchased from Sigma-Aldrich (St. Louis, MO). Potassium monophosphate $\left(\mathrm{KHPO}_{4}\right)$, HPLC grade water and HPLC grade acetonitrile were both obtained from Fisher Scientific (Fair Lawn, NJ).

The mobile phase consisted of 57-43\% acetonitrile (v/v) in $10 \mathrm{mM} \mathrm{K}_{2} \mathrm{HPO}_{4}$ buffer, $\mathrm{pH}$ 7.0, with $10 \mathrm{mM}$ HDTA. A stock solution of $1 \mathrm{M} \mathrm{K}_{2} \mathrm{HPO}_{4}$ was made in distilled, deionized water and later added to the mobile phase to make $10 \mathrm{mM} \mathrm{K}_{2} \mathrm{HPO}_{4} .10 \mathrm{~g}$ of HDTA was weighed out and added to $1 \mathrm{~L}$ of mobile phase. The mobile phase was degassed with a sonicator for 15 minutes. The flow rate was set at $1.0 \mathrm{~mL} / \mathrm{min}$.

\section{Quantification}

Quantification of ceftriaxone in rat plasma was modified from previously reported methods [110-113]. Plasma samples $(50 \mu \mathrm{l})$ were deproteinated with $450 \mu \mathrm{l}$ of ice-cold methanol (Fisher Scientific, Fair Lawn, NJ) along with $12.5 \mu \mathrm{l}$ of a stock $100 \mu \mathrm{g} / \mathrm{ml}$ cefuroxime solution as the internal standard. The sample was vortexed and placed on ice 
for 5 minutes followed by centrifugation at $2600 \mathrm{rpm}$ for 5 minutes at $4^{\circ} \mathrm{C} .50 \mu \mathrm{l}$ of the plasma supernatant was used for HPLC analysis.

Rat urine samples were diluted ten fold by adding to $100 \mu \mathrm{l}$ of urine $900 \mu \mathrm{l}$ of HPLC grade water along with $25 \mu \mathrm{l}$ of the stock solution of cefuroxime $100 \mu \mathrm{g} / \mathrm{ml}$. The samples were then vortexed and centrifuged at $2600 \mathrm{rpm}$ for 5 minutes at $4^{\circ} \mathrm{C} .25 \mu \mathrm{l}$ of the resulting supernatant was then used for HPLC analysis.

Rat fecal samples were first homogenized in $10 \mathrm{ml}$ of distilled water. The samples were then centrifuged at $2600 \mathrm{rpm}$ for 5 minutes at $4^{\circ} \mathrm{C} .100 \mu \mathrm{l}$ of the supernatant was then diluted with $900 \mu \mathrm{l}$ of HPLC grade water along with $25 \mu \mathrm{l}$ of the internal standard stock solution. The mixture was vortexed and $25 \mu \mathrm{l}$ was used for HPLC analysis.

A standard curve was constructed by calculating the peak area ratio of ceftriaxone and the internal standard cefuroxime for each of a series of calibration standards. The concentration of calibration standards of ceftriaxone ranged from 10 through $500 \mu \mathrm{g} / \mathrm{ml}$ for plasma, 10 through $800 \mu \mathrm{g} / \mathrm{ml}$ for urine, and 0.5 through $5 \mathrm{~g} / \mathrm{ml}$ for feces. The peak area ratio of the standards was plotted against their concentrations, and ceftriaxone concentration from the experimental samples was calculated by linear regression from the corresponding standard curves. All calibration curves were made prior to measurement of the experiment samples with correlation values of at least 0.995 . The lower limit of quantification (LLOQ) was $10 \mu \mathrm{g} / \mathrm{ml}$ for plasma and urine and $500 \mu \mathrm{g} / \mathrm{ml}$ for fecal samples. The accuracy of the assay was $13 \%$ and $17 \%$ at the LLOQ while the precision was $15 \%$.

\section{Pharmacokinetic Analysis}

The concentration-time data for ceftriaxone were analyzed by noncompartmental pharmacokinetics analysis using WinNonlin Professional version 4.1 (Pharsight Corporation; Mountain View, CA). Pharmacokinetic parameters calculated include clearance (CL), volume of distribution at steady state (Vss), area under the curve (AUC), elimination rate constant $(\mathrm{k})$, half life $\left(\mathrm{t}_{1 / 2}\right)$, percent dose of unchanged drug detected in urine ( $\%$ urine), and percent dose of unchanged drug detected in feces ( $\%$ fecal). Statistical analyses comparing each pharmacokinetic parameter between the TR- rats and wild-type Wistar rats was performed using a two-tailed unpaired Student's t-test through SPSS version 14.0 (Chicago, IL).

\section{mRNA and Protein Quantification for Mdr1a/1b and Mrp2}

Mdr1a/1b and Mrp2 mRNA and protein levels from the frozen rat liver tissues were analyzed using real time RT-PCR for mRNA quantification and Western immunoblotting for protein quantification. 
Briefly, approximately $0.3 \mathrm{~g}$ of frozen liver tissue was added to $600 \mu \mathrm{l}$ of denaturing solution and homogenized using a handheld homogenizer for approximately 15 seconds or until no fragments of tissue were visible. Total RNA from the rat livers was isolated using RNAgents ${ }^{\circledR}$ Total RNA Isolation Kit (Promega, Madison, WI) according to the manufacturer's protocol. First strand cDNA was synthesized from total liver RNA using the SuperScript ${ }^{\text {TM }}$ III First Strand cDNA Synthesis (Invitrogen, Carlsbad, $\mathrm{CA}$ ) according to the manufacturer's instructions. Real-time quantitative PCR was performed on an ABI Prism 7000 Sequence Detection System (Applied Biosystems, Foster City, CA) using primer pairs and TaqMan probes for rat Mdr1a, Mdr1b, and Mrp2 as well as the reference gene cyclophilin (see Chapter 3 for discussion on reference gene selection). Relative mRNA quantification was achieved using a relative standard curve methodology.

Protein levels of Mrp2 in the rat liver tissues were quantified through Western blot analysis. Approximately $0.5 \mathrm{~g}$ of rat liver tissue was used for membrane protein isolation through the use of Calbiochem ${ }^{\circledR}$ ProteoExtract ${ }^{\circledR}$ Native Membrane Protein Extraction Kit (M-PEK) according to the manufacturer's protocol. $20 \mu \mathrm{g}$ of rat liver membrane protein was fractionated using SDS-PAGE technique with NuPAGE ${ }^{\circledR} 4-12 \%$ Bis-Tris Gel. The separated proteins were then transferred overnight onto a Invitrolon ${ }^{\mathrm{TM}}$ PVDF $0.2 \mu \mathrm{m}$ membrane. Nonspecific binding sites on the PVDF membrane were blocked using 5\% nonfat dried milk in phosphate buffered saline ( $\mathrm{pH} 7.4)$ with $0.1 \%$ Tween (PBST) for one hour followed by primary monoclonal antibody incubation with P-gp (C219) (Alexis Biochemicals, San Diego, CA) diluted 1:100 fold, MRP2 ( $\left.\mathrm{M}_{2} \mathrm{III}-6\right)$ (Alexis Biochemical, San Diego, CA) diluted 1:200 fold, or GAPDH (Sigma-Aldrich, St. Louis, MO) diluted 1:10000 fold in 5\% nonfat dried milk in PBST for two hours. After discarding the primary antibody, the membrane was washed by three separate five minute washes with PBST. The membrane was then incubated for one hour with the secondary antibody, HRP-conjugated Anti-Mouse IgG (Cell Signaling Technology, Danvers, MA), diluted in 5\% nonfat dried milk in PBST either 1:5000 fold when probing P-gp and MRP2, or 1:10000 fold when probing for GAPDH. After another three separate five minute washings with PBST, the blots were then incubated with enhanced chemiluminescence ECL plus $^{\mathrm{TM}}$ (GE Healthcare, Piscataway, NJ) for 5 minutes, then developed on Kodak Biomax XAR autoradiography film after 1 minute and 3 minute exposure times. Protein band density was quantified using ImageJ (National Institutes of Health) after digitizing the image using a flatbed scanner.

\section{Results}

\section{Ceftriaxone Pharmacokinetics}

The mean plasma concentration versus time profile following a single intravenous injection of ceftriaxone $100 \mathrm{mg} / \mathrm{kg}$ in wild-type (WT) and Mrp2-deficient (TR-) Wistar rats is depicted in Figure 4-1. The concentration-time curve appears monoexponential for both groups. Mean pharmacokinetic parameters for ceftriaxone in wild-type and TR- rats 


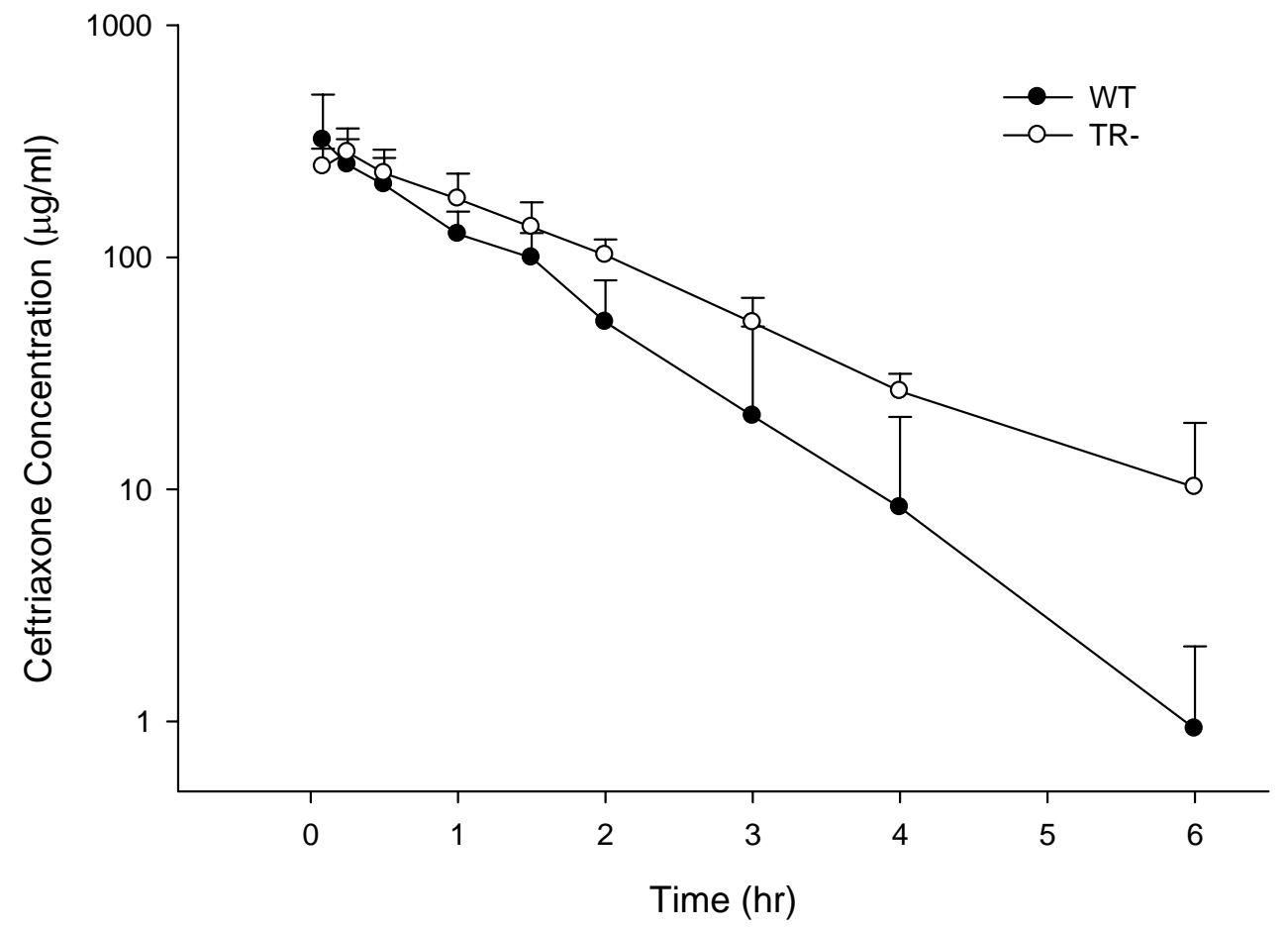

Figure 4-1. Plasma Ceftriaxone Concentration versus Time Profile in WT versus TRRats. 
are summarized in Table 4-1. The area under the curve (AUC) of ceftriaxone in TR-rats was approximately $30 \%$ higher than in WT rats. This may be attributed to the $30 \%$ decrease in clearance in the TR- rats. The elimination rate constant $(\mathrm{k})$ decreased by $37 \%$; consequently, terminal half-life $\left(\mathrm{t}_{1 / 2}\right)$ of ceftriaxone in plasma was significantly prolonged by approximately $34 \%$. The volume of distribution at steady state $\left(\mathrm{V}_{\mathrm{ss}}\right)$ was not significantly different between the two groups. The percent dose of ceftriaxone eliminated in the urine was significantly increased from $25.5 \%$ to $64.5 \%$ in TR-rats as compared to controls $(\mathrm{p}<0.001)$. Conversely, the percent dose of ceftriaxone recovered in feces was significantly higher in control rats than TR- rats $(18.5 \%$ vs. $0 \% ; p<0.05)$.

\section{Mdr1a, Mdr1b, and Mrp2 mRNA and Protein Quantification}

We were able to detect Mdr1a, Mdr1b, and Mrp2 mRNA using real-time PCR in all WT and TR- rat liver samples. Significant differences were detected for all three mean target gene expression between WT and TR- rats. TR- rats livers exhibited approximately three-fold higher expression of Mdr1a $(\mathrm{p}<0.001)$ and $\operatorname{Mdr} 1 \mathrm{~b}(\mathrm{p}<0.05)$ as compared to WT rat liver samples. As expected, TR- rat liver samples contained limited levels of Mrp2 mRNA, which was significantly lower than WT Mrp2 expression levels $(\mathrm{p}<0.05)$ (Figure 4-2). Western blot analysis of WT and TR- rats revealed a single band at $\sim 170 \mathrm{kDa}$ corresponding to Mdr1/P-gp as well as at $\sim 190 \mathrm{kDa}$ corresponding to Mrp2 in the rat liver tissues (Figure 4-3). Mean normalized protein expression levels were not significantly different for Mdr1/P-gp between WT and TRrats. However, mean Mrp2 protein expression level was significantly reduced for TR- rat liver as compared to WT rat liver $(\mathrm{p}<0.05)$ (Figure 4-4) Removal of outliers defined as samples with relative expression values 1.5 times outside the $25^{\text {th }}$ and $75^{\text {th }}$ percentiles had no influence on the statistical results.

\section{Discussion}

The present pharmacokinetic study on ceftriaxone disposition in WT vs. TR- rats clearly demonstrates the significance of Mrp2 mediated biliary excretion of ceftriaxone. Judging from the plasma concentration-time profile of a single intravenous administration of ceftriaxone in WT and TR- rats, we observed a significantly lower elimination rate constant $(\mathrm{k})$ for TR- rats as compared to the WT rats. We could attribute the change in elimination rate constant as an overall decrease in clearance in the TR- rats since there were no changes in volume of distribution between the two groups. This translated into a higher systemic exposure/AUC of ceftriaxone in the TR- rats. Since ceftriaxone is nearly completely eliminated as unchanged drug by excretion into the bile and urine, we were able to delineate the contribution of renal versus biliary elimination without any confounding effects of drug metabolizing enzymes.

No detectable amounts of ceftriaxone (LLOQ of $500 \mu \mathrm{g} / \mathrm{ml}$ in feces) were detected in the TR- fecal samples after 24 hours. However, approximately $19 \%$ of the original 
Table 4-1. Mean \pm SD Pharmacokinetic Parameters in WT versus TR- Rats.

\begin{tabular}{lcc}
\hline & Wild-type & TR- \\
& & \\
\hline & & \\
$\mathrm{k}\left(\mathrm{h}^{-1}\right)$ & $0.928 \pm 0.24$ & $0.588 \pm 0.06^{\mathrm{b}}$ \\
$\mathrm{t}_{1 / 2}(\mathrm{~h})$ & $0.788 \pm 0.19$ & $1.19 \pm 0.12^{\mathrm{c}}$ \\
$\mathrm{V}_{\mathrm{ss}}(\mathrm{L} / \mathrm{kg})$ & $0.321 \pm 0.11$ & $0.314 \pm 0.05$ \\
$\mathrm{CL}_{\mathrm{T}}(\mathrm{L} / \mathrm{h} / \mathrm{kg})$ & $0.279 \pm 0.09$ & $0.189 \pm 0.05^{\mathrm{a}}$ \\
$\mathrm{CL}_{\mathrm{r}}(\mathrm{L} / \mathrm{h} / \mathrm{kg})$ & $0.076 \pm 0.05$ & $0.123 \pm 0.05^{\mathrm{b}}$ \\
$\mathrm{AUC}$ & $396 \pm 148$ & $670 \pm 182$ \\
$\%$ urine $(24 \mathrm{mg} / \mathrm{h})$ & $25.5 \pm 12$ & $0.0 \pm 0.0^{\mathrm{a}}$ \\
$\%$ fecal $(24 \mathrm{~h})$ & $18.5 \pm 16$ & \\
\hline
\end{tabular}

${ }^{\mathrm{a}} \mathrm{p}<0.05 ;{ }^{\mathrm{b}} \mathrm{p}<0.01 ;{ }^{\mathrm{c}} \mathrm{p}<0.001$ 


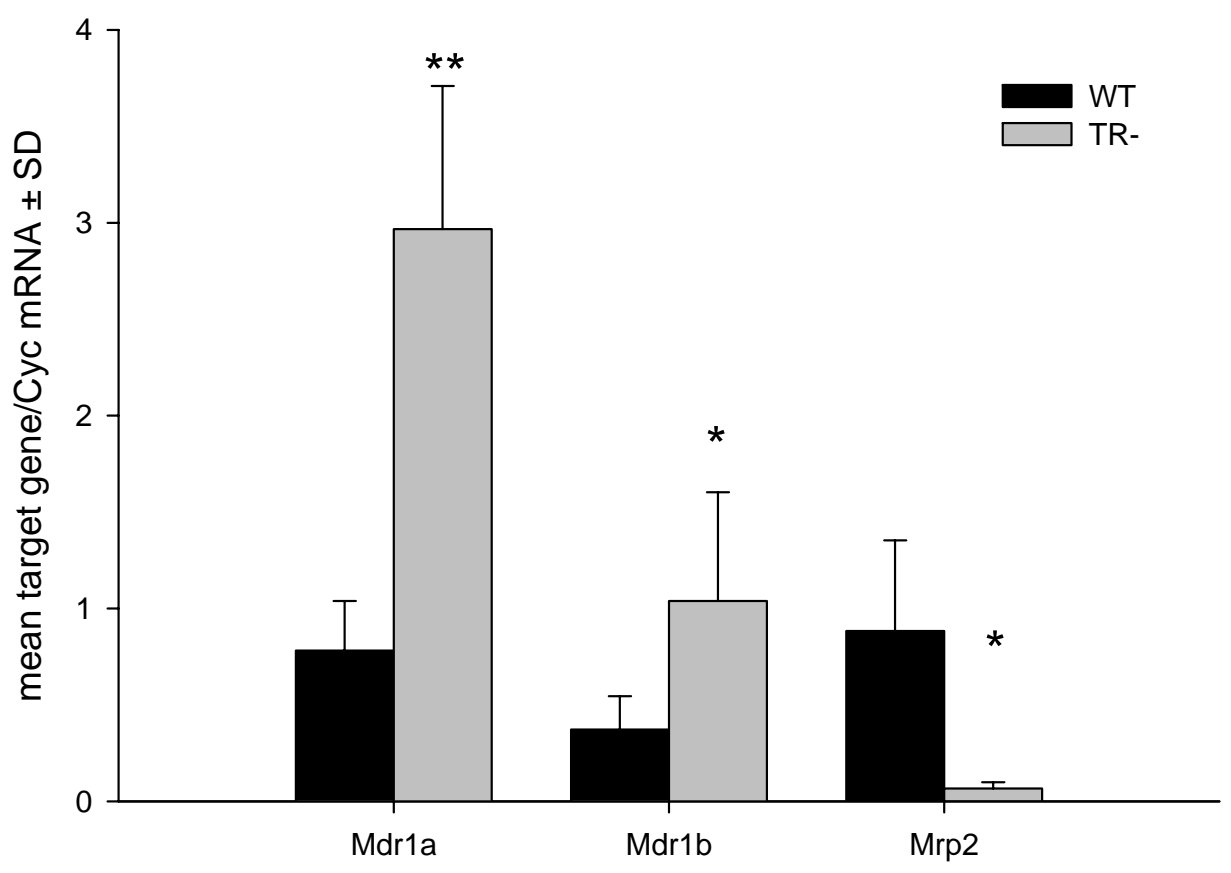

Figure 4-2 WT versus TR- Rat Liver Mdr1a, Mdr1b, and Mrp2 mRNA Expression. Bar graph presenting mean \pm standard deviation for hepatic mRNA gene expression of Mdr1a, Mdr1b and Mrp2 (normalized for cyclophilin (Cyc) expression) in WT vs. TRrats. Asterisks $(*)$ represent a significant difference $(* p<0.05 ; * * p<0.001)$.

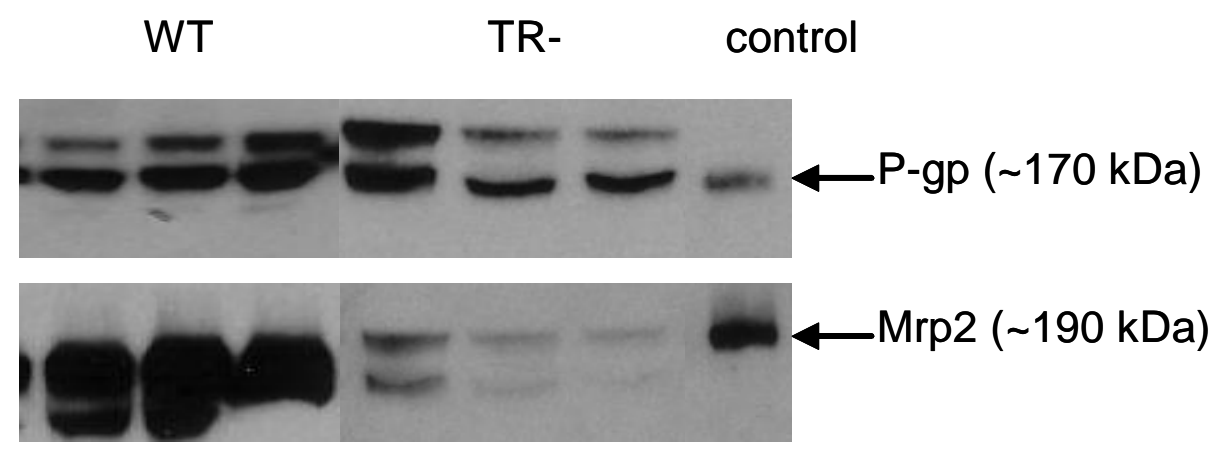

Figure 4-3. Immunoblot of WT and TR- Rat Liver P-gp and Mrp2 Protein Expression.

Representative Western blots of P-gp and Mrp2 in wild-type (WT) and Mrp2-deficient rats (TR-). P-gp and Mrp2 control membranes were included in each blot as a reference. 

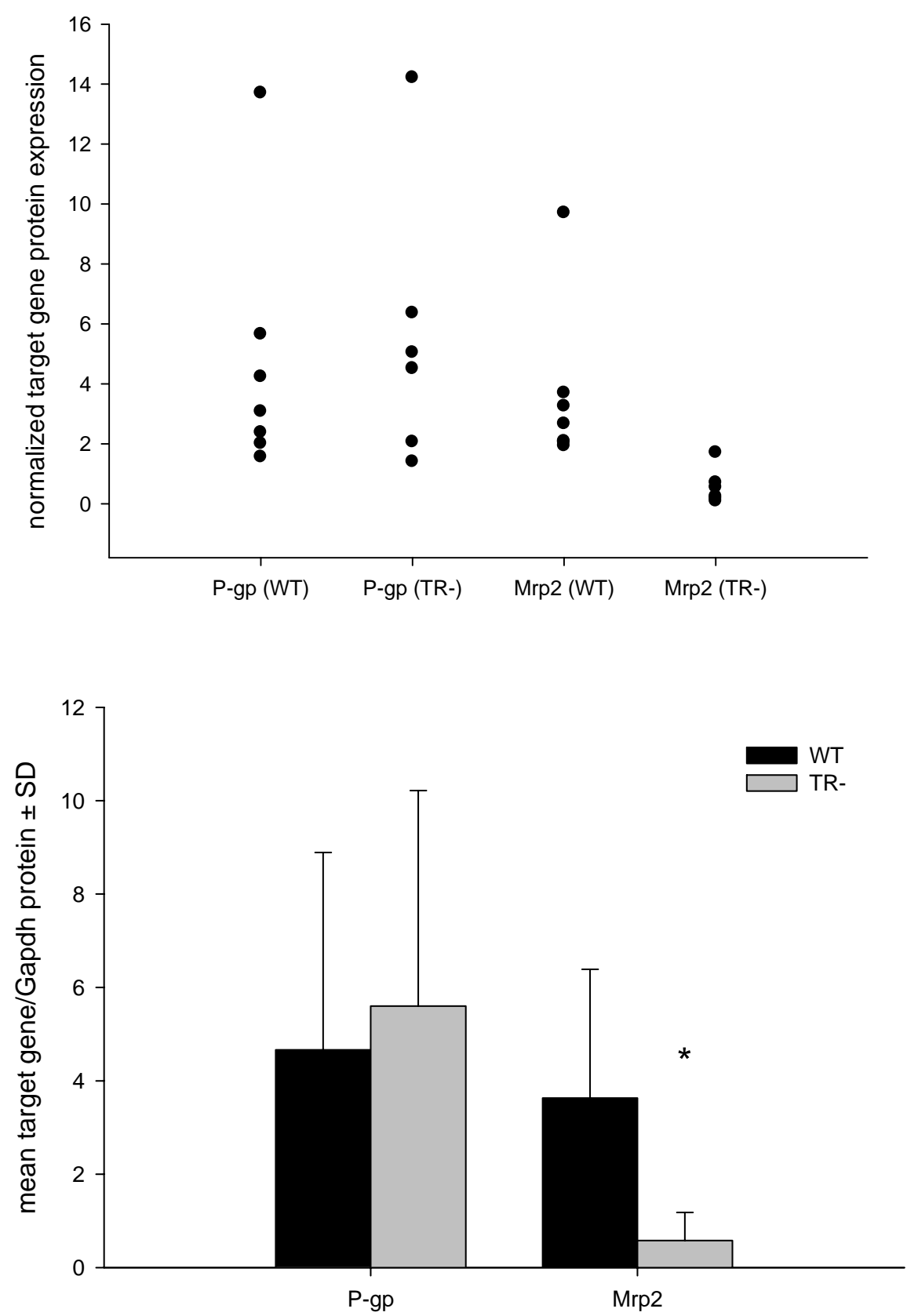

Figure 4-4. WT versus TR- Mdr1/P-gp and Mrp2 Protein Expression. Upper panel: Scatterplot of normalized P-gp and Mrp2 protein expression of individual WT and TR- rats. Lower panel: Bar graph presenting mean \pm standard deviation for normalized P-gp and Mrp2 mRNA gene expression in WT vs. TR- rats. 
dose of ceftriaxone was recovered in the 24 hour fecal samples of the WT rats. This supports our hypothesis that biliary excretion of ceftriaxone is mediated through liver Mrp2. This is further supported by the mRNA and protein quantification of Mdr1a/b and Mrp2 in both the WT and TR- rats. Biliary excretion of ceftriaxone through Mdr1/P-gp is improbable since expression of P-gp was detected in TR- rats yet no detectable amount of ceftriaxone was recovered from the feces.

Our results showed an apparent increase in renal clearance of ceftriaxone in the TRrats as compared to the WT rats. This may indicate a potential compensatory mechanism in the TR- rats for the overall clearance of ceftriaxone. Rat glomerular filtration rate has been estimated at $0.312 \mathrm{~L} / \mathrm{h} / \mathrm{kg}$ [114]. The predicted filtration rate of ceftriaxone in WT rats with a unbound fraction estimated at $5 \%$ would therefore be $0.0156 \mathrm{~L} / \mathrm{hr} / \mathrm{kg}$ [113]. Ceftriaxone renal elimination in both the WT and TR- rats appeared to undergo a net filtration and secretion process since the excretion ratio exceeded one in both instances. Previous reports have also demonstrated an increase in the urinary excretion of various organic anions with Mrp2-deficient rats $[115,116]$. This indicates a potential upregulation of other drug transporters in the kidney to compensate for the loss of Mrp2 function. Chen et al. [67] have recently provided evidence of increased Mrp4 expression in the kidneys of TR- rats. Given that Mrp2 and Mrp4 share overlapping substrate profiles as well as similar co-localization at the apical membrane of renal proximal tubules, the increase in renal clearance may be attributed to the upregulation of renal Mrp4 in the TR- rats. However, further experiments in TR- rats would be needed in order to confirm the underlying mechanisms which contribute to the renal elimination of ceftriaxone.

One other finding of interest was the significant elevation in mRNA expression level of Mdr1a and Mdr1b in the TR- rats as compared to the WT rats. However, the protein level of P-gp in the TR- rats was not significantly different from the WT rats. The discordance in Mdrla/b mRNA and P-gp protein expression suggests potential regulatory mechanisms at the post-transcriptional level.

Mrp2 mediated biliary excretion has potentially important clinical implications for pediatric pharmacotherapy. As concluded in the previous chapters, newborn and young infants have decreased or immature expression of hepatic Mrp2 as compared to older children and adults. For drugs with significant elimination through the bile, such as ceftriaxone, competition for biliary excretion via Mrp2 especially in the early stages of development may exacerbate or even cause clinical symptoms such as hyperbilirubinemia or even cholestasis. Reduced MRP2 mediated biliary excretion may also translate to a substantially decreased clearance and prolonged half-life of the affected medications in neonates and infants with immature biliary excretion function, thereby increasing the systemic exposure to these compounds. For drugs with a narrow therapeutic window, decreased Mrp2 mediated biliary excretion may lead to toxic drug concentrations in newborns and infants. Even for drugs which undergo Phase I and Phase II metabolism, the impact of the ontogeny of Phase III drug transporters must be considered when determining the pharmacokinetic profile of the drug or its metabolites. For example, for a compound that is biotransformed into a glucuronidated or sulfated metabolite which is a 
substrate for Mrp2, the potential competition for Mrp2 mediated biliary elimination may result in significant metabolite accumulation and subsequent reduced metabolic conversion of the parent drug and/or undesirable side effects related to the increased concentrations of parent drug or the metabolite.

The present study clearly defines the changes in pharmacokinetic parameters for ceftriaxone in wild-type versus Mrp2-deficient TR-rats. We use this animal model to illustrate the impact of low or deficient Mrp2 expression on drug elimination especially during the early stages of pediatric development as profiled in the human liver samples of newborns and infants investigated in Chapter 2. Pediatric clinical trials studying these effects are often unfeasible due to limitations in cost, recruitment, biological sampling, and ethical issues. The utility of mutant or knock-out animal models is invaluable in such cases where human studies are not feasible. While inter-species differences must be considered when extrapolating results from animal models to humans, an understanding of the basic effects of drug transporters and lack of their functional activity on in vivo drug pharmacokinetics nevertheless brings us a step closer to understanding and explaining some of the variability and toxicity observed in pediatric pharmacotherapy. 


\section{CHAPTER 5. SUMMARY}

Advances in technology and understanding of systems biology have provided tremendous strides towards improvements in modern human medicine. Unfortunately, the business of drug development often overlooks the needs of the pediatric population mainly due to cost issues as well as a lack of understanding of the dynamic changes which occur in children especially in the early stages of their development. Therefore, as more and more studies emerge on human organogenesis and physiology, it is the responsibility of clinical pharmacologists to translate such knowledge into safe and effective pharmacotherapy for all ages. In the current dissertation, we hypothesized that there are age associated changes in drug transporter expression which can lead to significant changes in pharmacokinetic parameters of drugs often used in pediatric pharmacotherapy. We aimed at unraveling a piece of the childhood development puzzle through characterization of the ontogeny of two major members in the ATP-binding cassette (ABC) family of drug transporters - MDR1/P-gp and MRP2 in human samples. In order to map out the ontogeny of these transporters in more detail, we also measured their expression in rats from seven specific ages ranging from newborn to adult. In addition, we sought to explain their potential developmental pattern by examining the expression of their regulators in the superfamily of nuclear receptors - including PXR, CAR, FXR, and HNF4 $\alpha$. Lastly, we demonstrated the potential clinical impact of maturational changes in drug transporters on the pharmacokinetic properties of ceftriaxone, a third generation cephalosporin antibiotic often used in the pediatric population.

Our study in human pediatric liver samples revealed significantly lower MDR1/Pgp mRNA expression between the early infant (before 8 months) and older childhood period. Our MDR1/P-gp protein expression in the pediatric liver samples, however, did not support the results for MDR1 mRNA expression. P-gp protein level was not significantly different across the various age groups in our subset of protein samples. The discordance in the relative expression of MDR1/P-gp mRNA and P-glycoprotein has been described in various cancer cell lines [81, 82]. This raises the possibility of posttranscriptional regulation of MDR1 as a potential source of variation for mRNA and protein expression in human pediatric liver samples.

MRP2 mRNA and protein quantification in the human pediatric liver samples revealed significant differences during ontogeny. Specifically, we demonstrated that MRP2 expression is limited in the early infant period but increases dramatically to levels comparable to childhood levels immediately prior to one year of age. Clinically, newborns are often jaundiced in the early postnatal period. This is thought to partly be due to the relatively immature hepatic metabolic pathways and hepatic transporter mediated elimination of unconjugated bilirubin. MRP2 is the primary hepatic canalicular transporter that mediates various organic anions as well as sulfated or glucuronidated bile salts and bilirubin. We provide evidence that hepatic expression of MRP2 is immature at birth, and therefore, drugs with high biliary excretion may exhibit altered pharmacokinetic properties and should be administered with caution in newborns. 
Nuclear receptors belong to a family of transcriptional factor which regulate the expression of their target genes, several of which include drug metabolizing enzymes and transporters. In particular, several nuclear receptors including PXR, CAR, FXR, and $\mathrm{HNF} 4 \alpha$ have been identified as regulatory agents for ABC transporters including MDR1/P-gp and MRP2. We quantified the expression of the nuclear receptors in order to establish their regulatory role in the development of MDR1/P-gp and MRP2. Our results revealed an interesting profile. PXR and FXR exhibited a lower expression level in the early phase of development. However, CAR and HNF4 $\alpha$ showed no differences throughout the early postnatal through childhood ages. Though both PXR and FXR expression was lower in the earlier age group, significant differences were only detected for FXR. Physiogically, this makes plausible sense since FXR is often referred to as a bile sensor capable of regulating the molecular processes which maintain bile acid homeostasis. Immaturity of FXR expression at birth is supported by evidence that bile acid synthesis and homeostasis appear to be postnatal ontogenic events as well.

Due to the limitations of conducting scientific research in humans, the use of animal models has historically provided great insight into our understanding of human development. As such, we wished to examine the ontogeny of Mdr1a/1b, Mrp2, Pxr, Car, Fxr, and Hnf4 $\alpha$ from rat liver samples in seven different postnatal ages in order to compliment our human results with more selected spacing of age and sample numbers in our rat samples. While the age at which maximal expression of these transporters and nuclear receptors differed; in general, we observed a developmental pattern in the expression of all the target genes. The protein levels for P-gp and Mrp2 also correlated well with the mRNA expression data. Expression of Mdr1/P-gp and Mrp2 were limited in the early periods of development, but gradually increased to maximal expression levels at approximately 28 days of age. Results for the nuclear receptors Pxr, Car, and Fxr were similar in that rat livers from 0 to 21 postnatal days initially exhibited less than $50 \%$ of adult rat liver content but increased dramatically from 28 days of age to adulthood. A similar pattern was observed for $\mathrm{Hnf} 4 \alpha$, though its mean relative expression appeared highly variable within each age group. From the rat model, we concluded that expression of Mdr1a/1b, Mrp2, Pxr, Car, and Fxr, in rat liver samples were significantly lower in the early postnatal period as compared to the older age groups.

The results from the human and rat liver transporter ontogeny studies led us to our next hypothesis that developmental changes in drug transporter expression could result in significant changes in the pharmacokinetic parameters of drug substrates for these transporters. We decided to test our hypothesis by comparing the pharmacokinetic parameters of ceftriaxone, a third generation cephalosporin antibiotic, in wild-type (WT) and a mutant strain of Mrp2-deficient (TR-) rats. We selected Mrp2-deficient rat as a surrogate model to represent the immaturity of Mrp2 early on in development as was evident from our rat and human liver samples. Ceftriaxone clearance was approximately $30 \%$ lower in the TR-group as compared to the WT group. Elimination half-life was approximately $30 \%$ longer for the TR-group since there was no significant change in volume at steady state between the two groups. There were no recoverable amounts of ceftriaxone in the feces of TR- rats as compared with the $19 \%$ unchanged drug recovered in the feces of the WT rats. Interestingly, there was almost a $40 \%$ increase in urinary 
excretion of ceftriaxone in the TR- indicating a potential compensatory mechanism for clearance of the drug. mRNA and protein expression of Mdr1a/1b and Mrp2 confirmed a deficiency of Mrp2 in the TR- rats as well as confirming the biliary excretion of ceftriaxone by Mrp2.

We have successfully determined the age associated expression of $\mathrm{ABC}$ transporters MDR1/Mdr1a/b and MRP2/Mrp2 in both human and rat liver samples. Furthermore, we also examined developmental expression of various nuclear receptors thought to be regulators of these drug transporters. Lastly, we demonstrated the changes in pharmacokinetic properties of ceftriaxone in a Mrp2-deficient rat model. The results of this study not only emphasize that children are not small adults, i.e. have distinctly different drug disposition mechanisms, but also that empiric dosing of drugs based on adult pharmacotherapy often used in the pediatric population may compromise the safety and efficacy of these medications. The challenge in pediatric pharmacotherapy will lie in the translation of our knowledge of the developmental pharmacology and biology during childhood into rational and practical drug design as well as age-appropriate dosing recommendations. 


\section{LIST OF REFERENCES}

1. Burns, L.E., J.E. Hodgman, and A.B. Cass, Fatal circulatory collapse in premature infants receiving chloramphenicol. N Engl J Med, 1959. 261: p. 131821.

2. Fox, E. and F.M. Balis, Drug Therapy in Neonates and Pediatric Patients, in Principles of Clinical Pharmacology, J. Arthur J. Atkinson, Editor. 2001, Academic Press. p. 460.

3. Leeder, J., Ontogeny of drug-metabolizing enzymes and its influence on the pathogenesis of adverse drug reactions in children. Current Therapeutic Research, 2001. 62(12): p. 900-912.

4. Morselli, P.L., R. Franco-Morselli, and L. Bossi, Clinical pharmacokinetics in newborns and infants. Age-related differences and therapeutic implications. Clin Pharmacokinet, 1980. 5(6): p. 485-527.

5. Shimada, T., et al., Interindividual variations in human liver cytochrome P-450 enzymes involved in the oxidation of drugs, carcinogens and toxic chemicals: studies with liver microsomes of 30 Japanese and 30 Caucasians. J Pharmacol Exp Ther, 1994. 270(1): p. 414-23.

6. Guengerich, F.P., Cytochrome P-450 3A4: regulation and role in drug metabolism. Annu Rev Pharmacol Toxicol, 1999. 39: p. 1-17.

7. Lacroix, D., et al., Expression of CYP3A in the human liver--evidence that the shift between CYP3A7 and CYP3A4 occurs immediately after birth. Eur J Biochem, 1997. 247(2): p. 625-34.

8. Schuetz, J.D., D.L. Beach, and P.S. Guzelian, Selective expression of cytochrome P450 CYP3A mRNAs in embryonic and adult human liver. Pharmacogenetics, 1994. 4(1): p. 11-20.

9. Jacqz-Aigrain, E. and T. Cresteil, Cytochrome P450-dependent metabolism of dextromethorphan: fetal and adult studies. Dev Pharmacol Ther, 1992. 18(3-4): p. 161-8.

10. Treluyer, J.M., et al., Expression of CYP2D6 in developing human liver. Eur J Biochem, 1991. 202(2): p. 583-8.

11. Goldstein, J.A., Clinical relevance of genetic polymorphisms in the human CYP2C subfamily. Br J Clin Pharmacol, 2001. 52(4): p. 349-55.

12. Koukouritaki, S.B., et al., Developmental expression of human hepatic CYP2C9 and CYP2C19. J Pharmacol Exp Ther, 2004. 308(3): p. 965-74.

13. Blake, M.J., et al., Ontogeny of drug metabolizing enzymes in the neonate. Semin Fetal Neonatal Med, 2005. 10(2): p. 123-38.

14. McCarver, D.G. and R.N. Hines, The ontogeny of human drug-metabolizing enzymes: phase II conjugation enzymes and regulatory mechanisms. J Pharmacol Exp Ther, 2002. 300(2): p. 361-6.

15. Kearns, G.L., et al., Developmental pharmacology--drug disposition, action, and therapy in infants and children. N Engl J Med, 2003. 349(12): p. 1157-67.

16. Alcorn, J. and P.J. McNamara, Ontogeny of hepatic and renal systemic clearance pathways in infants: part II. Clin Pharmacokinet, 2002. 41(13): p. 1077-94. 
17. Daniel, H. and G. Kottra, The proton oligopeptide cotransporter family SLC15 in physiology and pharmacology. Pflugers Arch, 2004. 447(5): p. 610-8.

18. CDER/FDA, General Considerations for Pediatric Pharmacokinetic Studies for Drugs and Biological Products - Draft Gauidance. 1998, Rockville: Food and Drug Administartion, Center for Drug Evaluation and Research.

19. Willis, C., C.E. Staatz, and S.E. Tett, Bayesian forecasting and prediction of tacrolimus concentrations in pediatric liver and adult renal transplant recipients. Ther Drug Monit, 2003. 25(2): p. 158-66.

20. Takahashi, H., et al., Developmental changes in pharmacokinetics and pharmacodynamics of warfarin enantiomers in Japanese children. Clin Pharmacol Ther, 2000. 68(5): p. 541-55.

21. Marshall, J.D. and G.L. Kearns, Developmental pharmacodynamics of cyclosporine. Clin Pharmacol Ther, 1999. 66(1): p. 66-75.

22. Laer, S., et al., Development of a safe and effective pediatric dosing regimen for sotalol based on population pharmacokinetics and pharmacodynamics in children with supraventricular tachycardia. J Am Coll Cardiol, 2005. 46(7): p. 1322-30.

23. de Wildt, S.N., et al., Pharmacodynamics of midazolam in pediatric intensive care patients. Ther Drug Monit, 2005. 27(1): p. 98-102.

24. Schuetz, E.G., W.T. Beck, and J.D. Schuetz, Modulators and substrates of Pglycoprotein and cytochrome P4503A coordinately up-regulate these proteins in human colon carcinoma cells. Mol Pharmacol, 1996. 49(2): p. 311-8.

25. Wacher, V.J., C.Y. Wu, and L.Z. Benet, Overlapping substrate specificities and tissue distribution of cytochrome P450 3A and P-glycoprotein: implications for drug delivery and activity in cancer chemotherapy. Mol Carcinog, 1995. 13(3): p. 129-34.

26. Watkins, P.B., The barrier function of CYP3A4 and P-glycoprotein in the small bowel. Adv Drug Deliv Rev, 1997. 27(2-3): p. 161-170.

27. Evans, W.E. and M.V. Relling, Pharmacogenomics: translating functional genomics into rational therapeutics. Science, 1999. 286(5439): p. 487-91.

28. Sereni, F. and N. Principi, Developmental pharmacology. Annu Rev Pharmacol, 1968. 8: p. 453-66.

29. Borst, P., et al., A family of drug transporters: the multidrug resistance-associated proteins. J Natl Cancer Inst, 2000. 92(16): p. 1295-302.

30. Konig, J., et al., Conjugate export pumps of the multidrug resistance protein (MRP) family: localization, substrate specificity, and MRP2-mediated drug resistance. Biochim Biophys Acta, 1999. 1461(2): p. 377-94.

31. Juliano, R.L. and V. Ling, A surface glycoprotein modulating drug permeability in Chinese hamster ovary cell mutants. Biochim Biophys Acta, 1976. 455(1): p. 152-62.

32. Gottesman, M.M., et al., Genetic analysis of the multidrug transporter. Annu Rev Genet, 1995. 29: p. 607-49.

33. Higgins, C.F., et al., A family of related ATP-binding subunits coupled to many distinct biological processes in bacteria. Nature, 1986. 323(6087): p. 448-50.

34. Hyde, S.C., et al., Structural model of ATP-binding proteins associated with cystic fibrosis, multidrug resistance and bacterial transport. Nature, 1990. 346(6282): p. 362-5. 
35. Dean, M., A. Rzhetsky, and R. Allikmets, The human ATP-binding cassette (ABC) transporter superfamily. Genome Res, 2001. 11(7): p. 1156-66.

36. Karpowich, N., et al., Crystal structures of the MJ1267 ATP binding cassette reveal an induced-fit effect at the ATPase active site of an ABC transporter. Structure, 2001. 9(7): p. 571-86.

37. Glavinas, H., et al., The role of ABC transporters in drug resistance, metabolism and toxicity. Curr Drug Deliv, 2004. 1(1): p. 27-42.

38. Thiebaut, F., et al., Cellular localization of the multidrug-resistance gene product P-glycoprotein in normal human tissues. Proc Natl Acad Sci U S A, 1987. 84(21): p. 7735-8.

39. Bakos, E., et al., Membrane topology and glycosylation of the human multidrug resistance-associated protein. J Biol Chem, 1996. 271(21): p. 12322-6.

40. Cole, S.P., et al., Overexpression of a transporter gene in a multidrug-resistant human lung cancer cell line. Science, 1992. 258(5088): p. 1650-4.

41. Leslie, E.M., R.G. Deeley, and S.P. Cole, Multidrug resistance proteins: role of P-glycoprotein, MRP1, MRP2, and BCRP (ABCG2) in tissue defense. Toxicol Appl Pharmacol, 2005. 204(3): p. 216-37.

42. $\quad$ Evers, R., et al., Vinblastine and sulfinpyrazone export by the multidrug resistance protein MRP2 is associated with glutathione export. Br J Cancer, 2000. 83(3): p. 375-83.

43. Lippert, C., et al., Mass balance and pharmacokinetics of MDL 16455A in healthy male volunteers. Pharm Res, 1995. 12: p. S390.

44. Sanofi-Aventis, Allegra(R) (fexofenadine). [product information]. 2007: Bridgewater, NJ.

45. Milne, R.W., et al., Hepatic disposition of fexofenadine: influence of the transport inhibitors erythromycin and dibromosulphothalein. Pharm Res, 2000. 17(12): p. 1511-5.

46. Angelin, B., et al., Quinidine reduces biliary clearance of digoxin in man. Eur J Clin Invest, 1987. 17(3): p. 262-5.

47. Minton, N.A. and P.G. Smith, Loperamide toxicity in a child after a single dose. Br Med J (Clin Res Ed), 1987. 294(6584): p. 1383.

48. Weaver, L.T., S.W. Richmond, and R. Nelson, Loperamide toxicity in severe protracted diarrhoea. Arch Dis Child, 1983. 58(7): p. 568-9.

49. Suzuki, H. and Y. Sugiyama, Transporters for bile acids and organic anions. Pharm Biotechnol, 1999. 12: p. 387-439.

50. Roche, Rocephin(R) (ceftriaxone) [product information]. 2004, Roche Laboratories: Nutley, New Jersey.

51. Bor, O., et al., Ceftriaxone-associated biliary sludge and pseudocholelithiasis during childhood: a prospective study. Pediatr Int, 2004. 46(3): p. 322-4.

52. de Moor, R.A., A.C. Egberts, and C.H. Schroder, Ceftriaxone-associated nephrolithiasis and biliary pseudolithiasis. Eur J Pediatr, 1999. 158(12): p. 975-7.

53. Xia, Y., et al., Concentrative biliary secretion of ceftriaxone. Inhibition of lipid secretion and precipitation of calcium ceftriaxone in bile. Gastroenterology, 1990. 99(2): p. 454-65.

54. Papadopoulou, F., et al., Incidence of ceftriaxone-associated gallbladder pseudolithiasis. Acta Paediatr, 1999. 88(12): p. 1352-5. 
55. Mangelsdorf, D.J., et al., The nuclear receptor superfamily: the second decade. Cell, 1995. 83(6): p. 835-9.

56. Wang, H. and E.L. LeCluyse, Role of orphan nuclear receptors in the regulation of drug-metabolising enzymes. Clin Pharmacokinet, 2003. 42(15): p. 1331-57.

57. Tirona, R.G. and R.B. Kim, Nuclear receptors and drug disposition gene regulation. J Pharm Sci, 2005. 94(6): p. 1169-86.

58. Kliewer, S.A., B. Goodwin, and T.M. Willson, The nuclear pregnane $X$ receptor: a key regulator of xenobiotic metabolism. Endocr Rev, 2002. 23(5): p. 687-702.

59. Zhang, Y., et al., Peroxisome proliferator-activated receptor-gamma coactivator 1alpha (PGC-1alpha) regulates triglyceride metabolism by activation of the nuclear receptor FXR. Genes Dev, 2004. 18(2): p. 157-69.

60. Ward, R.M. and R. Kauffman, Future of pediatric therapeutics: reauthorization of BPCA and PREA. Clin Pharmacol Ther, 2007. 81(4): p. 477-9.

61. Gao, B., et al., Differential expression of bile salt and organic anion transporters in developing rat liver. J Hepatol, 2004. 41(2): p. 201-8.

62. Mahmood, B., et al., Ontogeny of P-glycoprotein in mouse intestine, liver, and kidney. J Investig Med, 2001. 49(3): p. 250-7.

63. Rosati, A., et al., Physiological regulation of P-glycoprotein, MRP1, MRP2 and cytochrome P450 3A2 during rat ontogeny. Dev Growth Differ, 2003. 45(4): p. 377-87.

64. Schiengold, M., et al., Multidrug resistance gene expression during the murine ontogeny. Mech Ageing Dev, 2001. 122(3): p. 255-70.

65. van Kalken, C., et al., Multidrug resistance gene (P-glycoprotein) expression in the human fetus. Am J Pathol, 1992. 141(5): p. 1063-72.

66. Watchko, J.F., et al., P-glycoprotein and bilirubin disposition. J Perinatol, 2001. 21 Suppl 1: p. S43-7; discussion S59-62.

67. Chen, H.L., et al., Developmental expression of canalicular transporter genes in human liver. J Hepatol, 2005. 43(3): p. 472-7.

68. Johnson, M.A., et al., Clinical pharmacokinetics of lamivudine. Clin Pharmacokinet, 1999. 36(1): p. 41-66.

69. Tomer, G., et al., Differential developmental regulation of rat liver canalicular membrane transporters Bsep and Mrp2. Pediatr Res, 2003. 53(2): p. 288-94.

70. Olefsky, J.M., Nuclear receptor minireview series. J Biol Chem, 2001. 276(40): p. 36863-4.

71. Balasubramaniyan, N., et al., Multiple mechanisms of ontogenic regulation of nuclear receptors during rat liver development. Am J Physiol Gastrointest Liver Physiol, 2005. 288(2): p. G251-60.

72. $\quad$ Kast, H.R., et al., Regulation of multidrug resistance-associated protein 2 (ABCC2) by the nuclear receptors pregnane $X$ receptor, farnesoid $X$-activated receptor, and constitutive androstane receptor. J Biol Chem, 2002. 277(4): p. 2908-15.

73. Makishima, M., et al., Identification of a nuclear receptor for bile acids. Science, 1999. 284(5418): p. 1362-5.

74. Parks, D.J., et al., Bile acids: natural ligands for an orphan nuclear receptor. Science, 1999. 284(5418): p. 1365-8. 
75. Kamiya, A., Y. Inoue, and F.J. Gonzalez, Role of the hepatocyte nuclear factor 4alpha in control of the pregnane $X$ receptor during fetal liver development. Hepatology, 2003. 37(6): p. 1375-84.

76. Tirona, R.G., et al., The orphan nuclear receptor HNF4alpha determines PXRand CAR-mediated xenobiotic induction of CYP3A4. Nat Med, 2003. 9(2): p. 2204.

77. Vyhlidal, C.A., R. Gaedigk, and J.S. Leeder, Nuclear receptor expression in fetal and pediatric liver: correlation with CYP3A expression. Drug Metab Dispos, 2006. 34(1): p. 131-7.

78. Applied-Biosystems, User Bulletin \#2, in ABI Prism 7000 Sequence Detection System. 2000: Foster City, CA.

79. Bradford, M.M., A rapid and sensitive method for the quantitation of microgram quantities of protein utilizing the principle of protein-dye binding. Anal Biochem, 1976. 72: p. 248-54.

80. Rasband, W.S. ImageJ. 1997. http://rsb.info.nih.gov/ij/ [accessed April, 16, 2006].

81. Albertioni, F., et al., Multidrug resistance gene (mdr1) RNA levels in relation to P-glycoprotein content of leukemic cells from patients with acute leukemia. Med Oncol, 1995. 12(2): p. 79-86.

82. Gomez-Martinez, A., et al., Post-transcriptional regulation of P-glycoprotein expression in cancer cell lines. Mol Cancer Res, 2007. 5(6): p. 641-53.

83. Chiang, J.Y., Bile acid regulation of hepatic physiology: III. Bile acids and nuclear receptors. Am J Physiol Gastrointest Liver Physiol, 2003. 284(3): p. G349-56.

84. Kawamoto, T., et al., Phenobarbital-responsive nuclear translocation of the receptor CAR in induction of the CYP2B gene. Mol Cell Biol, 1999. 19(9): $\mathrm{p}$. 6318-22.

85. Chen, C.J., et al., Internal duplication and homology with bacterial transport proteins in the mdr1 (P-glycoprotein) gene from multidrug-resistant human cells. Cell, 1986. 47(3): p. 381-9.

86. Devault, A. and P. Gros, Two members of the mouse mdr gene family confer multidrug resistance with overlapping but distinct drug specificities. Mol Cell Biol, 1990. 10(4): p. 1652-63.

87. Gros, P., J. Croop, and D. Housman, Mammalian multidrug resistance gene: complete cDNA sequence indicates strong homology to bacterial transport proteins. Cell, 1986. 47(3): p. 371-80.

88. Schinkel, A.H., et al., Normal viability and altered pharmacokinetics in mice lacking mdr1-type (drug-transporting) P-glycoproteins. Proc Natl Acad Sci U S A, 1997. 94(8): p. 4028-33.

89. Croop, J.M., et al., The three mouse multidrug resistance ( $m d r)$ genes are expressed in a tissue-specific manner in normal mouse tissues. Mol Cell Biol, 1989. 9(3): p. 1346-50.

90. Schinkel, A.H., et al., Disruption of the mouse mdr1a P-glycoprotein gene leads to a deficiency in the blood-brain barrier and to increased sensitivity to drugs. Cell, 1994. 77(4): p. 491-502. 
91. Gottesman, M.M. and I. Pastan, Biochemistry of multidrug resistance mediated by the multidrug transporter. Annu Rev Biochem, 1993. 62: p. 385-427.

92. Gros, P., et al., Cloning and characterization of a second member of the mouse mdr gene family. Mol Cell Biol, 1988. 8(7): p. 2770-8.

93. Smit, J.W., et al., Contribution of the murine mdr1a P-glycoprotein to hepatobiliary and intestinal elimination of cationic drugs as measured in mice with an mdr1a gene disruption. Hepatology, 1998. 27(4): p. 1056-63.

94. Borst, P., et al., The multidrug resistance protein family. Biochim Biophys Acta, 1999. 1461(2): p. 347-57.

95. Jedlitschky, G., et al., ATP-dependent transport of bilirubin glucuronides by the multidrug resistance protein MRP1 and its hepatocyte canalicular isoform MRP2. Biochem J, 1997. 327 ( Pt 1): p. 305-10.

96. Kawabe, T., et al., Enhanced transport of anticancer agents and leukotriene C4 by the human canalicular multispecific organic anion transporter (cMOAT/MRP2). FEBS Lett, 1999. 456(2): p. 327-31.

97. Paulusma, C.C., et al., Congenital jaundice in rats with a mutation in a multidrug resistance-associated protein gene. Science, 1996. 271(5252): p. 1126-8.

98. Luo, G., et al., CYP3A4 induction by drugs: correlation between a pregnane $X$ receptor reporter gene assay and CYP3A4 expression in human hepatocytes. Drug Metab Dispos, 2002. 30(7): p. 795-804.

99. Kohn, D.a.C.C., Biology and diseases of rats. Laboratory animal medicine, ed. A.L. Fox JG, Loew FM, Quimby FW. 2002, New York: Academic Press.

100. Zhang, W., Ontogeny of Mechanisms in Drug Disposition: Age-Dependency of Pglycoprotein Expression and Renal Elimination Exemplified by the Sotalol Pharmacokinetics, in University of Tennessee. 2004: Memphis. p. 175.

101. Zinchuk, V.S., et al., Asynchronous expression and colocalization of Bsep and Mrp2 during development of rat liver. Am J Physiol Gastrointest Liver Physiol, 2002. 282(3): p. G540-8.

102. Huang, W., et al., Induction of bilirubin clearance by the constitutive androstane receptor (CAR). Proc Natl Acad Sci U S A, 2003. 100(7): p. 4156-61.

103. Chan, L.M., S. Lowes, and B.H. Hirst, The ABCs of drug transport in intestine and liver: efflux proteins limiting drug absorption and bioavailability. Eur J Pharm Sci, 2004. 21(1): p. 25-51.

104. Ho, R.H. and R.B. Kim, Transporters and drug therapy: implications for drug disposition and disease. Clin Pharmacol Ther, 2005. 78(3): p. 260-77.

105. Huisman, M.T., et al., Multidrug resistance protein 2 (MRP2) transports HIV protease inhibitors, and transport can be enhanced by other drugs. Aids, 2002. 16(17): p. 2295-301.

106. Paulusma, C.C., et al., A mutation in the human canalicular multispecific organic anion transporter gene causes the Dubin-Johnson syndrome. Hepatology, 1997. 25(6): p. 1539-42.

107. Gerk, P.M. and M. Vore, Regulation of expression of the multidrug resistanceassociated protein 2 (MRP2) and its role in drug disposition. J Pharmacol Exp Ther, 2002. 302(2): p. 407-15.

108. Ravisha, M.S. and S.V. Godambe, Ceftriaxone induced cholestasis in a neonate: a case report. Indian J Med Sci, 2004. 58(2): p. 73-4. 
109. Oude Elferink, R.P., et al., Hepatobiliary secretion of organic compounds; molecular mechanisms of membrane transport. Biochim Biophys Acta, 1995. 1241(2): p. 215-68.

110. Granich, G.G. and D.J. Krogstad, Ion pair high-performance liquid chromatographic assay for ceftriaxone. Antimicrob Agents Chemother, 1987. 31(3): p. 385-8.

111. Kohlhepp, S.J., D.N. Gilbert, and J.E. Leggett, Influence of assay methodology on the measurement of free serum ceftriaxone concentrations. Antimicrob Agents Chemother, 1998. 42(9): p. 2259-61.

112. Trautman, K.H.a.P.H., Determination of the cephalosporin Ro 13-9904 in plasma, urine, and bile by means of ion-pair reversed phase chromatography. J. High Resolut. Chromatogr. Chromatogr. Commun., 1981. 4: p. 54-59.

113. Kwon, K.I. and D.W. Bourne, Effect of caffeine on ceftriaxone disposition and plasma protein binding in the rat. J Pharmacokinet Biopharm, 1986. 14(4): $\mathrm{p}$. 397-408.

114. Davies, B. and T. Morris, Physiological parameters in laboratory animals and humans. Pharm Res, 1993. 10(7): p. 1093-5.

115. Chen, C., G.E. Hennig, and J.E. Manautou, Hepatobiliary excretion of acetaminophen glutathione conjugate and its derivatives in transport-deficient (TR-) hyperbilirubinemic rats. Drug Metab Dispos, 2003. 31(6): p. 798-804.

116. Huber, M., et al., Hereditary defect of hepatobiliary cysteinyl leukotriene elimination in mutant rats with defective hepatic anion excretion. Hepatology, 1987. 7(2): p. 224-8. 


\section{VITA}

Lisa Tang, daughter of Grant and Judy Tang, was born on January 31, 1976 in Taipei, Taiwan. After immigrating to the United States in 1985, she was shortly enrolled into the public school system in Atlanta, Georgia. Upon graduation from Parkview High School in 1994, she attended Emory University in Atlanta and graduated with a Bachelors of Science in Biology in 1998. In 1999, she enrolled in the joint Doctor of Pharmacy and Doctor of Philosophy (Pharm.D./Ph.D.) program at Mercer University in Atlanta. After completing one year at Mercer, she transferred to the same program at the University of Tennessee Health Science Center, Memphis. In 2003, she graduated with her Pharm.D. degree and has continued pursuing her Ph.D. under the direction of Dr. Bernd Meibohm. She anticipates completing her Ph.D. by December 2007. 